\title{
Development of Thermal Envelope Design Guidelines for Federal Office Buildings
}

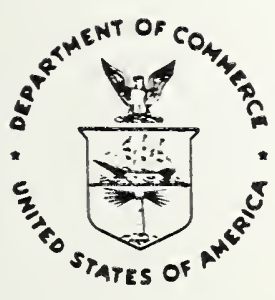

U. S. Department of Commerce

National Institute of Standards and Technology

Center for Building Technology

Gaithersburg, MD 20899

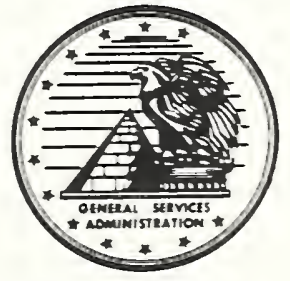

Prepared for:

General Services Administration

Public Buildings Service

Office of Real Property Development

Washington, DC 20405 



\section{Development of Thermal Envelope Design Guidelines for Federal Office Buildings}

Andrew K. Persily

October 1990

\section{U. S. Department of Commerce}

Robert A. Mosbacher, Secretary

National Institute of Standards and Technology

John W. Lyons, Director

Center for Building Technology

Gaithersburg, MD 20899
Prepared for:

General Services Administration Richard G. Austin, Administrator

Public Buildings Service

William C. Coleman, Commissioner Office of Real Property Development Washington, DC 20405 



\section{ABSTRACT}

Office building envelopes are generally successful in meeting a range of structural, aesthetic and thermal requirements. However, poor thermal enveiope performance will occur when there are discontinuities in the envelope insulation and air barrier systems, such as thermal bridges and air leakage sites. These discontinuities result from designs that do not adequately account for heat, air and moisture transmission, with many thermal defects being associated with inappropriate or inadequate detailing of the connections of envelope components. Despite the existence of these thermal envelope performance problems, information is available to design and construct envelopes that do perform well. In order to close the gap between available knowledge and current practice, the Public Buildings Service of the General Services Administration has entered into an interagency agreement with the Center for Building Technology of the National Institute of Standards and Technology to develop thermal envelope design guidelines for federal office buildings. The goal of this project is to transfer the knowledge on thermal envelope design and performance from the building research, design and construction communities into a form that will be used by building design professionals.

This report describes the NIST/GSA envelope design guidelines development at the end of the first year of effort on the project. The effort to this point has consisted of a literature review of research results and technical information on thermal envelope performance and design, an assessment of existing design guidelines as they relate to the thermal envelope, and the development of a format and outline for the design guidelines.

Key Words: airtightness, building envelopes, building performance, design, office building, thermal bridges, thermal envelope 

1. INTRODUCTION .

2. LITERATURE REVIEW

2.1 Revlew Strategy and Information Sources

2.2 Research Results

2.2.1 Wall Bridges and Thermal Defects

2.2.2 Air Leakage.

2.2.3 Wall System Performance Measurements

2.2.4 Roofing System Bridges and Defects

2.2.5 Roofing System Moisture

2.2.6 Envelope Diagnostics

2.2.7 Summary

2.3 Thermal Envelope Defects.

2.3.1 Thermal Bridges

2.3.2 Insulation System Defects

2.3.3 Roofing Systems

2.3.4 Wall Assemblies

2.3.5 Curtain Wall and Panel Systems .

2.3.6 Concrete Masonry Wall Systems.

2.3.7 Metal Building Systems .

2.3.8 Air Barriers and Sealants

2.3.9 Component Connections

2.3.10 Other Assemblies

2.3.11 Summary

2.4 Design Principles

2.4.1 Design and Construction Coordination . . . . . . . . . .19

2.4.2 Wall Systems

2.4.3 Roofing Systems

2.4.4 Windows

2.4.5 Air and Water Tightening . . . . . . . . . . . . . . . . . . . . . . . . .

2.4.6 Summary

2.5 Design Detalis . . . . . . . . . . . . . . . . .26

2.5.1 Glass and Metal Curtain Walls . . . . . . . . . . . .26

2.5.2 Masonry Walls . . . . . . . . . . . . . . . .27

2.5.3 Metal Stud Walls . . . . . . . . . . . . . . . 30

2.5.4 Precast Panel Seams . . . . . . . . . . . . . . . . . . . . . . . . .

2.5.5 Air Barrier Systems . . . . . . . . . . . . . . . . . . . . . . . . . . . . . .

2.5.6 Summary . . . . . . . . . . . . . . . . . . . . . . .

2.6 Summary of Literature Review. . . . . . . , . . . . .32

2.7 References. . . . . . . . . . . . . . . . . 33

3. EXISTING DESIGN GUIDELINES . . . . . . . . . . . . . . . . . . . . .

3.1 Construction Handbooks . . . . . . . . . . . . . .69

3.2 Energy Conservation Guides. . . . . . . . . . . . .70

3.3 Guidelines and Standards. . . . . . . . . . . . . .70

3.4 Summary. . . . . . . . . . . . . . . . . . . . . . . . . . . . . . . . . . .

3.5 References. . . . . . . . . . . . . . . . . . . . . . . . . . . . . .

4. THERMAL ENVELOPE DESIGN GUIDELINES . . . . . . . . . . . . . . .

4.1 Perspective of the Design Professional. . . . . . . . . . . 73

4.2 Description of the Guidelines. . . . . . . . . . . . . . 74

4.3 Guidelines Format . . . . . . . . . . . . . . . . . . . . . . . . . . . . .

4.4 Guidelines Organization . . . . . . . . . . . . . . . . . . . . . . . .

5. CONCLUSIONS... . . . . . . . . . . . . . . . . . . . . . . . . . . . . . . .

6. ACKNOWLEDGEMENTS . . . . . . . . . . . . . . . . . . . . . . . . . . 



\section{INTRODUCTION}

The exterior envelopes of office buildings perform a variety of roles including keeping the weather outdoors, facilitating the maintenance of comfortable interior conditions by limiting heat, moisture and air transmission, providing a visual and daylight connection to the outdoors, limiting noise transmission, supporting some structural loads, and providing an aesthetically pleasing appearance. Although building envelopes are generally successful in meeting these varied requirements, there are cases in which they do not provide an adequate level of performance in one or more of these areas. Shortcomings in building envelope thermal performance are manifested by excessive heat, air or moisture transmission that may lead to increased energy consumption, poor thermal comfort within the occupied space, and deterioration of envelope materials. Poor thermal envelope performance occurs because of discontinuities in the envelope insulation and air barrier systems, such as thermal bridges, compressed insulation and air leakage sites. Some of these discontinuities result from designs that do not adequately account for heat, air and moisture transmission, while others are caused by designs that are difficult to construct, do not have sufficient durability to perform adequately for a significant length of time, or can not withstand wind pressures or differential movements. Many of these thermal defects are associated with inappropriate or inadequate detailing of component connections.

Despite the existence of these thermal envelope performance problems, information is available to design and construct thermal envelopes that perform well. In order to bridge this gap between available knowledge and current practice, the Public Buildings Service of the General Services Administration has entered into an interagency agreement with the Center for Building Technology of the National Institute of Standards and Technology to develop thermal envelope design guidelines for federal buildings. The basic goal of this project is to take the knowledge on thermal envelope design and performance from the building research, design and construction communities and to organize it into a form that will be used by building design professionals. These guidelines will not direct the designer to choose a particular thermal envelope design, but rather will provide information on achieving good thermal envelope performance for the design that they have chosen. The intention is not to develop a comprehensive guide with specific recommendations on envelope systems or subsystems such as insulation levels, construction materials, and glazing areas. Rather the guidelines will provide the designer who has already made these decisions with specific information on how to make their building envelope perform as intended through an emphasis on design details that avoid thermal defects.

This report describes the NIST/GSA envelope design guidelines development at the end of the first year of effort on the project. This effort has consisted of a review of research results and technical information on thermal envelope performance and design to determine the nature and extent of the published information available for inclusion in the guidelines. Existing design guidelines were assessed as they relate to the thermal envelope to determine what design guidance is currently available. Following these assessments of available information, the proposed format of the guidelines and an outline of their content are presented. 



\section{LITERATURE REVIEW}

The NIST/GSA envelope design guidelines will be based on state-of-the-art knowledge concerning the design of building thermal envelopes for optimal performance in terms of heat, air and moisture transfer. To identify the extent and nature of published information on thermal envelope design, construction and performance, a literature review was conducted. This review concentrated on information concerning thermal performance problems in office building envelopes including descriptions of specific thermal defects, their significance in terms of heat, air and moisture transfer, and the effectiveness of alternative designs. The information obtained in the literature review is divided into four areas and is presented below in Sections 2.2 through 2.5. Section 2.2 summarizes research on thermal envelope performance, specifically how thermal envelope design and construction affect performance. The next section catalogs and describes the thermal envelope defects that were identified in the review. Section 2.4 contains a summary of general design principles for ensuring good thermal envelope performance and avoiding thermal defects. In section 2.5 a variety of thermal envelope design details are presented in which special attention has been given to the avoidance thermal defects.

\subsection{Review Strategy and Information Sources}

The literature review concentrated on the relationship between specific thermal envelope designs and the resultant heat, air and moisture transfer performance. The review was not directed towards procedures for making design decisions or for calculating thermal performance, but rather towards information that would be directly applicable in designing office building thermal envelopes that are free of thermal defects. Specifically, the required information is in the form of design defects that lead to thermal envelope performance problems and details that insure good thermal performance.

Information on thermal envelope design, construction and performance is available from primarily two sources, the building design and construction community and the building research community. There is more publication on the part of the research community, and therefore this review is more extensive in the area of research findings. A variety of sources were employed in this review. The Transactions of the American Society of Heating, Refrigerating and Air-Conditioning Engineers (ASHRAE) were examined dating back to the 1970 s for relevant materials. In addition, ASHRAE along with the U.S. Department of Energy has held a series of conferences entitled Thermal Performance of the Exterior Envelopes of Buildings. Four such conferences have been held in 1979, 1982, 1985 and 1989, and the proceedings of each were reviewed. The proceedings of the 1986 Symposium on Air Infiltration, Ventilation and Moisture Transfer sponsored by BTECC (Building Thermal Envelope Coordinating Council) were also useful sources of information. Several STPs (Special Technical Publications) published by the American Society of Testing and Materials (ASTM) were also reviewed. These STPs are the proceedings of conferences in a specific subject area of interest to an ASTM committee. STPS prepared by the following committees were considered: C-16 Thermal Insulation, C-24 Building Joint Sealants, D-8 Roofing, Waterproofing, and Bituminous Materials, and E- 
6 Performance of Building Constructions. In addition, the Institute of Research in Construction (IRC, formerly the Division of Building Research or DBR) at the National Research Council of Canada (NRCC) has published many informative documents containing research results and building design information. These include the Canadian Building Digests, Building Practice Notes, Seminar and Workshop Proceedings, Building Science Insight Proceedings and Building Science Forum Proceedings. A variety of other publications were examined including architectural handbooks, construction guides, and research reports from government and private organizations.

\subsection{Research Results}

This section discusses the results of the review of technical research relating building thermal envelope design and construction to thermal performance. The studies that were considered include research into the effects of thermal bridges on envelope heat loss, studies of envelope design features that are intended to eliminate such bridges, field and laboratory measurements of the performance of envelope systems, the identification of thermal bridges and other thermal defects in buildings, and the impact of envelope air leakage on building air exchange rates and moisture transfer. This review was not concerned with research into topics such as theoretical models of heat, air or moisture movement through envelope components, or techniques for determining optimum insulation levels. The significant research findings that were identified are organized into six areas: wall bridges and thermal defects, air leakage, wall system performance measurements, roofing system bridges and defects, roofing system moisture, and thermal envelope diagnostics.

\subsubsection{Wall Bridges and Thermal Defects}

This area includes research on changes in heat transmission rates due to thermal bridges and other thermal defects in wall systems, and in some cases the effectiveness of various fixes in correcting these defects. This research has included laboratory studies to determine the effects of thermal bridges on envelope heat transmission rates, field investigations to identify actual thermal bridges and to measure their impact on heat flow, and the development of calculation procedures to determine the impact of thermal bridges on heat transmission rates and condensation potential. Laboratory facilities have been used to study several thermal defects such as bridges associated with structural components in wall panels and insulation fastening systems, and gaps and spaces in wall insulation (Bankvall 1987, Brown 1986, McCaa 1987, Miller 1987, Strzepek 1987, Trethowen 1985 and 1988, Tye 1981, Van Geem 1989). Field tests have also been conducted to study the existence and effect of wall thermal defects such as thermal bridges due to structural members and panel supports in office buildings (Chang 1987, Fang 1985, Grot 1985) and panel ties and convective air movement within stud walls (Flanders 1982). Additional work has included the development and application of calculation techniques to determine the effects of selected thermal bridges on envelope heat transfer, as well as to identify and catalog thermal bridges in office building envelopes (Childs 1988, Grot 1985, Standaert 1986, Steven Winter Associates 1989, Tye 1986). The effectiveness of 
alternative designs at reducing the effects of thermal bridges has also been examined (Childs 1988, Steven Winter Associates 1989). The latter reference discusses alternative designs for twenty-one different bridges and presents the change in $U$ value associated with these alternatives. The $U$-values for the alternate designs range from 16 to $90 \%$ of the bridged $U$-values.

The research into thermal bridges and other thermal defects indicate that wall Rvalues can be reduced significantly by these defects. The effects of Z-girts in metal panel systems and convective airflow due to unfaced fibrous insulation have been shown to reduce the R-value of a wall system by as much as $50 \%$ (Brown 1986). The effects of metal studs in an insulated wall have been shown to reduce the R-value by $30 \%$ (Fang 1985). Insulation gaps and voids have also been shown to reduce the $R$ value of a wall system by as much as $50 \%$ (Brown 1986, McCaa 1987). In one study a $1 \%$ insulation void reduced the R-value by $5 \%$ (Tye 1981). An NIST field study of bridges and thermal defects in eight federal office buildings showed a 50 to 100\% increase in wall heat loss due to such defects as compared with the unbridged wall construction, with a net increase in the total wall heat loss rate from 10 to 20\% (Grot 1985). Thus, the effects of bridges and thermal defects on wall heat loss in office buildings are significant. In many cases the potential for improvement through the use of alternate design details has been demonstrated.

\subsubsection{Air Leakage}

Research on air leakage in office building envelope systems has included laboratory measurements of wall system air leakage, field measurements of envelope airtightness, and modeling of the effect of airtightness on building infiltration rates. Ganguli (1989) has conducted laboratory tests of three different wall systems in which pressure measurements were made across various components of the systems to determine if the systems were performing as intended. Field measurements of airtightness have been made on whole buildings and individual components using pressurization testing (Persily 1986a, Tamura 1966, 1967b, 1967b, 1976a, 1976b and 1967b). Tracer gas measurements of office building air infiltration rates have been conducted, revealing the effect of this air leakage when the building envelope is subjected to pressure differences caused by weather or building equipment operation (Grot 1986). Office building air exchange has been modeled to examine the effects of envelope airtightness, weather conditions, ventilation equipment operation and interior partitions on pressure differences across the building envelope and on air infiltration rates (Persily 1986b, Tamura 1967a).

The research into envelope air leakage can be summarized by several key findings. First, the exterior envelopes of modern office buildings are not particularly airtight. In fact, the measured airtightness levels have been shown to be similar to typical U.S. homes in terms of air leakage per square foot of envelope area. Also similar to homes, the fraction of leakage due to windows and doors constitutes only about 10 to $20 \%$ of the total envelope leakage (Persily 1986a). The majority of the leakage is associated with other features such as intersections between envelope components. Both measurements and modeling have shown that the airtightness of interior partitions has a significant impact on the strength of the stack effect in buildings. The existence of leakage between building floors and from these floors to vertical shafts lead to increased stack pressures across the building envelope and 
increased infiltration airflow rates through leaks in the envelope. Differences between mechanical ventilation system design aifflow rates and actual airflow rates can also contribute to the pressure differences across the building envelope. Based on this combination of envelope air leakage and pressure differences, office buildings can have significant air infiltration rates along with the associated heating and cooling loads. Measurements of infiltration rates in eight modern office buildings ranged from 0.1 to 0.7 air changes per hour, constituting from 20 to $60 \%$ of the design heating loads of these buildings (Grot 1986). Such infiltration and exfiltration can also lead to moisture damage of envelope materials, building occupant discomfort, and indoor air quality problems.

\subsubsection{Wall System Performance Measurements}

There has been much research involving measurements of the heat transmission rates of wall systems, often for the assessment of calculation procedures and the generation of information for handbooks. These measurements have generally been made on walls that do not deviate significantly from design, rather than as examinations of the effects of thermal defects on the performance of these walls. Most of these measurements have been made in laboratory test facilities, either guarded or calibrated hot boxes (Burch 1989, Shu 1986, Van Geem 1985, 1986, 1987 and 1989). Heat transmission rates of wall systems have also been made in the field (Flanders 1985, Fang 1987).

This body of research has been useful in verifying that measured R-values are close to their calculated values when thermal conductivity information is available for the building materials and the wall is built to design. This work has been particularly useful in studying calculation techniques that account for two and three dimensional heat transfer effects, such as those associated with heat flow through structural members.

\subsubsection{Roofing System Bridges and Defects}

Research on roofing system thermal bridges and defects has been concerned primarily with changes in the heat transmission rate of a roofing system due to the existence of such defects. These tests have included a variety of constructions and settings, i.e., laboratory hot boxes, outdoor test facilities and field sites. The defects that have been evaluated include poorly fitting insulation in between roof rafters (Clausen 1988), insulation gaps in roofing systems (Hedlin 1985, Broderick 1986, Snyder 1986), insulation compression by structural components in metal panel systems (Waite 1981, Miller 1982), and thermal bridging effects of metal fasteners in low-slope roofing systems (Burch 1987). Some work has also been done on the effects of seams and penetrations on the water vapor permeance of insulation facing materials (Kelso 1982).

This research has shown that even small gaps in roof insulation, $5 \%$ or less in area, can reduce the R-value of the system by $50 \%$ (Hedlin 1985, Broderick 1986). Similar reductions in R-value have been shown to exist in metal building systems due to insulation compression by structural members and fastener connections (Snyder 1986). There has been some work on alternative purlin designs for these systems that increase the R-value by about $30 \%$ (Waite 1981). 


\subsubsection{Roofing System Moisture}

Research on roofing system moisture has involved the determination of the change in heat transmission rates of roofing systems or insulations as a function of moisture content. These tests have been done in outdoor test facilities (Hedlin 1982 and 1988, Tobiasson 1987) and in laboratory facilities (Knab 1981). Additional research has been conducted into the effectiveness of systems to prevent moisture accumulation in roof insulation (Hedlin 1976, Musgrave 1982) and systems to remove such moisture, e.g., breather vents (Tobiasson 1982).

This research has shown that moisture accumulation can increase the heat transmission rate of a roofing system by two or three times its dry value. The use of breather vents to keep roofing insulation dry has been studied by Tobiasson (1982). This work showed that these vents require decades to dry out wet roof insulation and their installation may lead to additional leakage of water and air.

\subsubsection{Envelope Diagnostics}

There has been much research on diagnostic techniques to evaluate the thermal performance of building envelopes in the field. This research has concentrated on the development and demonstration of various techniques for evaluating conductive heat transfer and airtightness. Two techniques have been used to make in-situ measurements of thermal resistance or $U$-value, heat flux transducers and portable calorimeters. Heat flux transducers measure the heat flux over small envelope areas (up to several square inches) and several are generally used in assessing the thermal performance of an envelope system (Anderson 1985, ASTM 1985, Flanders 1985). Portable calorimeters are used to measure U-values over several square feet of envelope area (Brown 1981 and 1982, Fang 1987). Infrared thermography is used to qualitatively evaluate heat transfer through the envelope (ASHRAE 1981, ASTM 1986, CGSB 1986, ISO 1983). Additional devices are under development for evaluating the thermal performance of envelopes using dynamic approaches, but have not been as widely used as the three techniques mentioned above (Modera 1987). Several field evaluations of office building envelopes have been conducted using combinations of heat flux transducers, portable calorimeters and infrared thermography (Chang 1987, Fang 1987, Flanders 1985). These field studies have demonstrated the practicality of these measurement techniques and have provided information on actual thermal envelope performance values and the existence of specific thermal defects. The use of these diagnostic procedures points out that any effort to assure thermal envelope performance must be supported by a diagnostic evaluation effort.

Diagnostic procedures also exist for assessing air leakage characteristics of building envelopes, including pressurization testing and tracer gas measurement of air exchange rates. Pressurization testing is used to evaluate the airtightness of envelope components such as windows and doors (ASTM 1984a and 1984b) and the airtightness of whole buildings (ASTM 1987). The pressurization technique involves imposing a series of pressure differences across the building envelope or component in question using a fan or blower and measuring the airflow rate required to maintain each pressure difference. Whole building pressurization has been applied to several office building, revealing that their envelopes are not as airtight as is commonly assumed and that windows and doors constitute only a small fraction of the total 
leakage in these buildings (Persily 1986a, Shaw 1973). Tracer gas testing is used to measure actual air exchange rates in buildings by measuring the indoor tracer gas concentration response to a controlled injection of tracer gas into the building interior (ASTM 1983, Lagus 1985). The application of the tracer gas decay technique in several modern office buildings has revealed the existence of significant air infiltration rates in these buildings, relative to design expectations, constituting a large fraction of the space conditioning load (Grot 1983, Persily 1985). Infrared thermographic inspection has been shown to be useful in identifying the location of air leakage sites in building envelopes (Chang 1987).

\subsubsection{Summary}

Research on the relationship between envelope design and thermal performance has concentrated on two areas that are relevant to the development of the NIST/GSA design guidelines, the effects of thermal defects on the heat transmission rates of envelope systems and the phenomena of envelope air infiltration. There has been much research on the changes in heat transmission rates of wall and roofs due to thermal bridges and other thermal defects such as insulation gaps and voids, air movement within insulation and moist insulation. This work has included laboratory and field tests, as well as mathematical modeling, and has shown that such thermal defects can severely degrade performance. There is only limited information in the research literature on specific envelope design details that lead to thermal defects and alternate details that provide good thermal performance. The information that does exist is not generally comprehensive, i.e., does not provide information on thermal bridges and defects in a wide variety of thermal envelope systems. Research on air infiltration has contributed to an understanding of how envelope airtightness, leakage in interior partitions, weather conditions, and ventilation system operation interact to cause envelope infiltration. Field measurements have shown unexpectedly high levels of office building envelope leakage and significant air infiltration rates resulting from this leakage.

\subsection{Thermal Envelope Defects}

The literature contains discussions of thermal and air leakage defects in the envelopes of office buildings, either from case studies from specific building envelope designs or discussions of generic building construction types. As part of the literature review, these defects were classified into general categories, and this section discusses the thermal defects that were identified. Table 2.1 is an outline of the thermal defects containing ten classes, the first two being the general categories of thermal bridges and insulation defects. The remaining eight categories are based on envelope subsystems, i.e., roofing, wall assemblies, curtain wall and panel systems, concrete masonry wall systems, metal building systems, air barriers and sealants, component interfaces, and other assemblies. All thermal defects are basically discontinuities in the envelope insulation layer or the plane of airtightness within the building envelope. Some are designed into the thermal envelope. Others are the result of poor construction or occur over time due to the effects of wind pressures, aging and/or differential movements of building components. 
Table 2.1 SUMMARY OF THERMAL DEFECTS

\begin{tabular}{|c|c|}
\hline Thermal Bridges & $\begin{array}{l}\text { Structural elements } \\
\text { Component connections } \\
\text { Envelope penetrations } \\
\text { Comer effects }\end{array}$ \\
\hline Insulation Defects & $\begin{array}{l}\text { Discontinuity in insulation system design } \\
\text { Voids and gaps } \\
\text { Unsupported insulation } \\
\text { Compression by fasteners and other elements } \\
\text { Fibrous insulation exposed to air spaces } \\
\text { Poor fitting batt insulation }\end{array}$ \\
\hline Rooflng & $\begin{array}{l}\text { Insulation defects: gaps } \\
\text { Thermal bridges: penetrations, structural elements } \\
\text { Air leakage: penetrations, structural elements, flutes in comugated } \\
\text { steel decking, incomplete attachment of loose-laid membranes }\end{array}$ \\
\hline Wall Assemblies & $\begin{array}{l}\text { Airilow passages within the envelope } \\
\text { Poor material selection or attachment }\end{array}$ \\
\hline Curtain Wall / Panel Systems & $\begin{array}{l}\text { Tnermal bridges in factory-made panels } \\
\text { Panel seams } \\
\text { Panel supports penetrating insulation and/or air bartier }\end{array}$ \\
\hline Concrete Masonry & $\begin{array}{l}\text { Air leakage through blocks and mortar joints } \\
\text { Air seal to spandrel beams and columns } \\
\text { Upward air movement through concrete blocks }\end{array}$ \\
\hline Metal Buildings & $\begin{array}{l}\text { Purlins: thermal bridges, insulation compression } \\
\text { Air channels due to corrugated claddings }\end{array}$ \\
\hline Alr Barriers and Sealants & $\begin{array}{l}\text { Discontinuity of air barriers } \\
\text { Use of insulation or insulation adhesives as air barriers } \\
\text { Punctured or displaced air bamiers } \\
\text { Polyethylene: inadequate support, lack of continuity } \\
\text { Inappropriate selection of sealant materials } \\
\text { Sealant fallure due to differential movement } \\
\text { Lack of interior finishing }\end{array}$ \\
\hline Component Interfaces & $\begin{array}{l}\text { Floor wall } \\
\text { Window wall } \\
\text { Walvroof } \\
\text { Columnwall } \\
\text { Wallwall } \\
\text { Walveriling }\end{array}$ \\
\hline Other Assemblles & $\begin{array}{l}\text { Overhangs } \\
\text { Soffits } \\
\text { Stairwells } \\
\text { Interior Partitions }\end{array}$ \\
\hline
\end{tabular}

\subsubsection{Thermal Bridges}

Thermal bridges are noninsulating building elements that penetrate the envelope insulation system, thereby leading to increased heat flow rates. Tye (1986) has divided thermal bridges into four categories, structural elements, component connections, envelope penetrations and corner effects. Structural elements are 
generally high strength and relatively highly conductive elements used to connect building elements to the building structure that become thermal bridges when they penetrate the envelope insulation system. Bridges of this type include large elements such as beams, floor slabs, and foundations, as well as smaller elements such as studs, purlins, exterior panel supports, and insulation fasteners. Component connections are high strength, highly conductive element assemblies that serve to hold or connect building components within the envelope, such as window and door frames and window and curtain wall mullions. Envelope penetrations include elements that pass from the inside to the outside, interrupting the continuity of the envelope insulation. These include stacks, vents, utility conduits, pipes, and rooftop equipment supports. Finally, corner effects refer to constructions at corners that accentuate two-dimensional heat flow. Some corner constructions also lead to discontinuities in the envelope insulation layer and the air barrier. A recent report by Steven Winter Associates (1989) identified twenty-one thermal bridges found in commercial building envelopes, calculated the effect of each on heat transmission rates and condensation potential, and proposed alternative constructions. Several specific examples of thermal bridges associated with specific envelope constructions are presented and discussed in the following sections.

\subsubsection{Insulation Defects}

Defects in the envelope insulation system include discontinuities in the insulation layer and arrangements of the insulation that decrease its effectiveness. Envelope performance is degraded by the resultant increase in heat transfer rates and the increased potential for condensation when components in contact with moist air attain colder temperatures than anticipated. Insulation defects include voids or gaps in insulation systems that exist due to poor installation of the insulation material, movement of the insulation due to a lack of adequate physical support, and compression of insulation caused by fasteners or other building elements.

The thermal effectiveness of vertically-installed fibrous insulation is severely degraded when this insulation is exposed to an air space on one or both sides. Poor thermal performance results convective airflows through and perhaps around the insulation. This defect can be avoided by designs in which the insulation completely fills the cavity or which employ a continuous air barrier on the exposed side of the insulation. Batt insulation is associated with similar performance problems when the batts are poorly installed or do not fit well within the available space. These include arching or air channels caused by oversized batts, gaps due to undersized batts, and gaps and air channels caused by poor installation of batts. The existence of gaps or air channels within the insulation system and air movement through these spaces severely degrades the effectiveness of the insulation.

\subsubsection{Roofing Systems}

The thermal performance of roofing systems is reduced by thermal defects including insulation defects, thermal bridges, air leakage and moisture transfer. The insulation defects include those discussed above, with gaps between insulation boards and batts being a particular problem. Thermal bridges in roofing systems are associated with penetrations and structural elements. Childs (1988) has studied three specific thermal bridges caused by high conductivity components penetrating the 
insulation of a roofing system consisting of lightweight concrete on a metal deck. These penetrations include a pipe used to support rooftop mechanical equipment, a steel I-beam also used as an equipment support, and a concrete pillar used to support a window washing system. The increase in the heat transmission rate due to these bridges, as compared with the unbridged roof area, are calculated by Childs. In the case of the concrete pillar an alternative design employing rigid insulation on the sides of the pillar is suggested. Steven Winter Associates (1989) also discusses bridging by roof equipment supports, as well as roof railings, and calculates the effect on heat transmission rates of these bridges and alternate, nonbridging designs.

One of the most serious thermal performance problems in roofing systems is air leakage. Air leakage through or around insulation decreases the thermal effectiveness of the system. In cold climates the leakage of moist air from inside the building into the roofing system will cause condensation within the roofing system, leading to increased heat flow through moist insulation and possibly the degradation of roofing materials. While vapor retarders are effective in controlling the diffusion of moisture into the roofing system, it has been repeatedly pointed out that convection due to air leakage is the predominant mechanism for moisture transport into roofing systems (Tobiasson 1985, 1989). Such air leakage is due to improper sealing of the same penetrations of the roofing system that lead to thermal bridges, i.e., pipes, plumbing vent stacks and structural supports for rooftop equipment. Other air leakage sites are associated with structural features such as expansion joints, incomplete attachment of loose-laid membranes, and unsealed penetrations through flutes in corrugated steel decking. Many important air leakage sites are associated with the connection of the roofing system to the exterior walls. Several specific thermal defects associated with this connection are discussed below.

\subsubsection{Wall Assemblies}

Good thermal performance of a wall assembly requires the secure attachment of the elements which make up the wall and the avoidance of airflow passages within the system. A failure to achieve secure attachment of wall elements causes air movement within the wall, which severely degrades thermal performance and increases the potential for condensation. While envelope air leakage from inside to out is an obvious problem, other modes of air movement also cause problems. Air exchange between the building interior and the envelope system, air exchange between the envelope system and the outdoors, and air movement within the envelope system itself can result in significant degradation of thermal envelope performance. Air movement within the envelope system degrades thermal performance due to aifflow around and through thermal insulation and due to self-contained convective loops within the envelope system. Avoiding such air movement within the envelope requires a well-designed wall assembly that does not contain extensive vertical airflow passages and that insures that the elements remain in position over time. Vertical air spaces are sometimes designed into wall systems, for example between the interior wallboard and the inner face of the backup wall. Such air spaces can extend over several stories of a building, and these situations can be particularly problematic. As discussed earlier, the existence of an air space next to a layer of fibrous insulation will severely decrease its thermal effectiveness. Almost any kind of wall system can 
develop significant airflow paths within the envelope because of designs or materials that can not resist wind pressures or structural movement or that otherwise lack adequate durability. The inadequate support or attachment of envelope components can result in the repositioning of envelope elements due to wind forces or the movement of structural components.

An example of a wall assembly defect due to poor attachment of components is depicted in Figure 2.1 for a wall consisting of a solid concrete panel facade, an air space, rigid insulation and a hollow block backup wall (Burn 1983). In this wall the rigid insulation was prevented from achieving complete contact with the backup wall by the vertical leg of the shelf angle holding up the exterior concrete panel. As a result, very little of the asphalt adhesive on the back of the rigid insulation actually contacted the block. Air moving though the block wall was then free to move through the spaces on both sides of the insulation. In this case, cold air movement resulted in condensation on the outer surface of the inner block. Burn suggests that this problem could have been avoided by reducing the permeability of the block by parging or the application of a membrane, and by employing an alternative means of attaching the insulation to the block wall.

An example of the inadequate support of envelope elements leading to their repositioning is shown in Figure 2.2 for a parapet wall and a concrete deck roofing system (Quirouette 1989). The wall construction consists of a brick facade, an insulated steel stud wall, an air/vapor retarder, and an interior drywall finish. The parapet consists of a brick facade, rigid insulation, an air/vapor retarder, and a block wall. The rigid insulation of the parapet was spot adhered to the polyethylene retarder, which was attached at the top of the wall studs and the top of the parapet top plate. Because the polyethylene was not adequately supported, it moved back and forth with wind pressures and eventually tore. The movement of the polyethylene also pulled the rigid insulation from its original location, which in turn pulled the polyethylene further out of place. The parapet air seal was rendered total ineffective, and the effectiveness of the rigid insulation was severely degraded.

\subsubsection{Curtain Wall and Panel Systems}

Curtain wall systems or systems employing premade panels as the exterior facade are associated with particular thermal defects (Quirouette 1983, Rousseau 1983). Factory-made panels have certain advantages in terms of quality control, but sometimes contain thermal bridges around the frames or where structural elements connect the two sides of the panel. Once these panels are installed, the seams of these panels are sometimes associated with air leakage or thermal bridging. A source of thermal defects in curtain wall and panel systems are the supports used to attach exterior panels to the structure of the building. These supports act as thermal bridges where they penetrate the wall insulation and can result in further insulation system defects and air leakage when inadequate attention is given to these penetrations.

Figure 2.3 shows an example of a thermal bridge associated with an outrigger 1 beam supporting a precast concrete exterior panel (Childs 1988). The I-beam, located above a suspended ceiling, penetrates the exterior wall insulation. The increase in the heat transmission rate due to this bridge, as compared with the unbridged wall area, is calculated by Childs. Figure 2.4 shows another example of a panel support problem associated with the spandrel beam above a window head where a diagonal 
kicker for the spandrel hangers penetrates the interior drywall and the insulation above a suspended ceiling (Kudder 1988). The diagonal kicker constitutes an obvious thermal bridge, but it also led to air leakage because the kicker penetration of the drywall was not sealed, providing an air path from the interior to the cavity behind the facade. Additional examples of thermal defects due to panel supports have been identified by Richtmyer (1981) and Grot (1985). In the first case, the steel struts supporting a granite facade penetrated the wall insulation layer. Insulation was ineffectively pieced around the struts, and there was no precaution taken to control air leakage where the supports penetrated the wall. The second example occurred in the case of an insulated precast concrete panel which was supported by two diagonal steel beams. The supports bypassed the panel insulation and these thermal bridges were clearly revealed by infrared thermographic inspection of the walls.

\subsubsection{Concrete Masonry Wall Systems}

Concrete masonry wall systems are associated with air leakage defects because concrete block backup walls are quite leaky when they are not properly treated (Burn 1980 and 1983, Quirouette 1989). This air leakage occurs through the block itself if it is not parged or otherwise treated and through cracks in the mortar due to mortar shrinkage, incomplete filling of mortar joints, or differential movement due to thermal or structural effects. The connections of concrete block backup walls to spandrel beams and structural columns can also be significant sources of air leakage. Vertical air movement through the interiors of concrete blocks can seriously compromise the thermal effectiveness of a wall system and contribute to the stack effect in a building (Handegord 1982).

The importance of air leakage through concrete blocks is demonstrated by the example of a precast concrete panel wall with U-shaped column covers and C-shaped spandrel panels on a cast-in-place concrete frame with a concrete block infill wall (Quirouette 1989). A two-dimensional schematic showing the spandrel panel is shown in Figure 2.5. The blocks behind the convector cabinets were exposed and untreated. Air passed through the blocks, into the space between the infill wall and the spandrel panel, and up behind the column covers. Serious condensation, freezing and melting problems occurred in this wall due to the moist air that was able to reach the back of the concrete panels.

Several examples of defects associated with leakage at the connection of concrete block walls and structural beams or columns have also been identified. Kudder (1988) documented one such case concerning the connections of a concrete block interior backup wall to the spandrel beam above and to the structural columns on the side. Air leakage paths were created because the air seals at these connections were insufficient to compensate for construction tolerances, differential movement of the block wall and the structural elements, and block shrinkage. Another case occurred in a wall consisting of metal siding, hollow block, rigid insulation and an inner block wall incorporating structural steel columns (Bum 1983). As shown in Figure 2.6, air leakage from the building interior occurred at the joints between the columns and the inner block wall, and then continued through the joints in the insulation and the outer block wall. The moisture condensed and froze on the cold metal siding, eventually leading to severe crumbling of the block at the outer wythe joints. 


\subsubsection{Metal Building Systems}

Purlins in metal building systems are associated with two types of thermal defects, thermal bridges where these purlins pass through the insulation layer and insulation compression by the purlins. The compression of insulation reduces its $R$ value and creates air channels in the wall system that can further degrade the thermal effectiveness. Corrugated claddings also create air channels in these wall systems, with the resultant convective currents degrading the insulation effectiveness.

\subsubsection{Air Barriers and Sealants}

The successful performance of air barriers and sealants depends entirely on the maintenance of a continuous plane of airtightness over the entire building envelope and the selection of appropriate materials and means of attachment (Ashton 1986, Handegord 1981, Perreault 1986, Quirouette 1989). Defects associated with air barriers and sealants include designs that fail to maintain the continuity of the air barrier system, the inappropriate use of insulation or insulation adhesives as air barriers, and the puncture or displacement of air barrier materials either during construction or as a result of the movement of building components. While polyethylene is a relatively airtight material, it will not perform as an effective air barrier when it is not adequately supported or when used in situations where it is difficult to maintain continuity. Additional sources of failure in air barrier systems include the inappropriate choice of sealant materials given the conditions (e.g., temperature, humidity, solar exposure) to which they will be exposed and joint designs and sealant selections that can not accommodate differential movements within the envelope system.

Discontinuities occur in the envelope air barrier when there is a failure to finish the entire interior facade of a wall system when this facade is serving as an air barrier, whether or not this function is realized. Air leakage occurs when only the visible portions of the interior facade are finished, allowing air leakage though the unfinished areas. One example of this situation was discussed earlier where the interior block walls behind convector cabinets were left unfinished, allowing air to leak into and thorough the blocks (see Figure 2.5). Two other cases where incomplete finishing of the interior caused air leakage problems are described by Kudder (1988). The first leakage site, shown in Figure 2.7, was caused by a lack of finishing of the interior drywall behind a spandrel beam. Because of the obstruction caused by the beam, it was impossible to install drywall screws or to tape the drywall joints all the way up the height of the wall. An air path therefore existed from the building interior to the cavity behind the exterior facade. Kudder described another air leakage site in a wall with an interior plaster finish over lath attached to metal furring. The interior plaster finish over the lath was extended only slightly above the suspended ceiling, leaving the lath and furring exposed to the return air plenum. Interior air was free to flow into the wall assembly and around the concrete spandrel beam to the exterior facade.

\subsubsection{Component Connections}

The connections between building components are associated with many thermal defects including air leakage, thermal bridging and insulation defects. Most 
occur because inadequate attention is given to maintaining the continuity of the insulation layers and air barrier systems of the components meeting at these connections. Particular concern has been directed towards the intersection of the floor slab and the exterior wall (Chang 1987, Childs 1988, Fang 1984), the installation of the window in the wall (Rousseau 1988, Patenaude 1988), and the wall/roof junction (Riedel 1982, Turenne 1980). The floor-wall connection is often the site of significant thermal bridging when the floor slab penetrates the wall insulation. This location is also often associated with air leakage. Window-wall connections are associated with air leakage and air barrier discontinuities, insulation voids and compression around window frames, positioning of the thermal break of the window system such that air is able to infiltrate around it, and designs in which the area of the window frame exposed to the outdoors is larger than the area exposed to the indoors. This last defect causes the inner frame to be cold, increasing the potential for condensation. The wall-roof junction is a common location for air leakage due to discontinuities between the wall air barrier and the roof membrane or air barrier. The wall air barrier may or may not extend to the roof deck, and the roof membrane seldom extends to the end of the roof where it could be sealed to the wall air barrier. Rather, the roof membrane is often turned up at the roof edge, leaving a discontinuity in the envelope air barrier at this junction. The connections between walls and structural columns and between different wall systems can be associated with thermal bridges and insulation defects. These connections are also associated with air leakage due to the use of air sealing systems that can not accommodate differential movements between the two different components. This situation was discussed above with reference to concrete block masonry walls and structural columns and spandrel beams. As discussed above, the intersection of the wall and a suspended ceiling is sometimes associated with inadequate airtightness and missing insulation when materials and finishes are not carried up above the suspended ceiling level (Handegord 1982, Kudder 1988).

Several examples of thermal defects occurring at component connections have been described in the literature, particularly at the connections of floors and exterior walls. Childs (1988) described two thermal bridges at wall-floor connections, in one case the floor being the ground floor slab. Figure 2.3 depicts the second bridge described by Childs, occurring where an intermediate floor slab and I-beam penetrate the exterior wall insulation. Childs recommends redesigning this connection such that the floor slab does not extend through the plane of the wall insulation and rigid insulation is used at the end of the floor slab, under the wall insulation. The increase in the heat transmission rate due to both of these bridges, as compared with the unbridged connections, is calculated by Childs. Grot (1985) describes four wall-floor thermal bridges, the first in a wall consisting of a brick veneer, concrete block, glass fiber board insulation and an interior gypsum finish. A schematic of this bridge is shown in Figure 2.8. As in the case of the bridge shown in Figure 2.3, the concrete floor slab penetrates the wall insulation. The steel beam supporting the floor slab is insulated on the outside, but still interrupts the insulation layer. Heat flux transducer measurements on these beams revealed that this insulation was not effective, if it was even installed. This detail also suffered from significant air leakage at the intersection of the floor and wall. The second wall-floor thermal bridge described by Grot is almost identical to the situation in Figure 2.8 except that the wall had a tile facade and blanket insulation. The concrete floor slab penetrated the insulation to the tile, and the steel 
beam supporting the floor slab was uninsulated. The third bridge occurred in a precast concrete panel wall with batt insulation above the concrete floor behind the fin radiators and semi-rigid insulation on the inside of the precast panel from the radiator to the suspended ceiling. This system was discussed earlier in the section on Curtain Wall and Panel Systems in which the thermal bridging caused by the panel supports was described. In this wall-floor connection, a bridge was created where the concrete floor penetrated the semi-rigid insulation. In addition, there was no batt insulation from the ceiling to the floor above. The last wall-floor thermal bridge described by Grot is in a precast concrete panel wall with glass fiber batt insulation and an interior finish of gypsum on metal studs. The construction is shown in Figure 2.9. In this system, a thermal bridge exists where the floor penetrates the wall insulation. There is also a large gap in the gypsum, insulation and the panel at the overhang of the precast panel. This gap allows airflow between the return air plenum and the interior of the overhang, causing the overhang to act as a fin. Poor thermal performance is also caused by air movement within the air space between the panel and the insulation.

Quirouette (1983) has described some difficulties with the connection between grade and an curtain exterior wall. Figure 2.10 shows a common design detail for this connection, consisting of insulation at the bottom of the wall, an air seal on the inside, and flashing over the outside of the opening. Part of the problem is due to the fact that the insulation under the mullion is out of line with the thermal break of the mullion. In addition, cold air infiltration past the flashing and into the insulation creates the potential for condensation on the interior of the wall mullion tube surface. Rain water accumulation in the cavity between the wall section and the floor deteriorates the floorto-mullion seal. An alternative construction that avoids these problems is to seal the connection at the outside of the mullion and place insulation outside of this seal in a vented cavity covered with flashing. There should be no insulation under the wall mullion.

The connections between windows and exterior walls are also associated with thermal defects, and Figure 2.11 depicts a poor design detail for the connection between a masonry wall and a window in a curtain wall system (Quirouette 1983). This detail has been found to result in condensation on the inside mullion surface and efflorescence on the outside surface of the brick veneer. This thermal defect exists because the thermal break of the wall mullion is out of the line with the wall insulation, causing the interior of the mullion to get cold and increasing the potential for interior condensation. In addition, there is a discontinuity between the wall air barrier and the window air seal at this same junction. An alternative design of this detail must involve aligning the wall insulation and the mullion thermal break.

The connections between exterior walls and roofing systems are often associated with air leakage and other thermal defects. Four cases of air leakage at wall-roof connections have been described by Riedel (1982). Alternative designs for these connections are presented in section 2.5. The first case involves an insulated steel deck roof and a masonry wall, shown in Figure 2.12. The wall-roof connection consists of metal edging extending from the outside of the masonry wall over the wood plates and then attached to the roof membrane. Air is able to leak from outside under the metal edging and between the wood plates. It then flows under the roof membrane, into the roof insulation and the building interior. Riedel proposes a fix for this leak employing a vinyl membrane on the inside of the metal edging that is sealed to the roof membrane and to the outside of the masonry wall. The second case 
identified by Riedel, shown in Figure 2.13, involves a steel roof deck with an overhang in which air leaks in through the bottom and outer edge of the overhang. The air then passes over the top of the outside wall and into the roof insulation. Air is also able to move past the building wall above the deck since the deck flutes may be only loosely stuffed with glass fiber insulation. The suggested fix is to provide seals where the roof deck passes over the top of the outside wall. The top of the deck ribs should be filled in order to provide a flush surface for cementing the roof insulation, and the bottom of the deck should be filled with foam insulation at the top of the wall. A felt cutoff should be employed within the roof insulation in the plane of the building wall. The third leakage defect identified by Riedel, depicted in Figure 2.14, occurs in a parapet wall in which interior air leaks through the deck-wall joint, into the insulation and into the block wall. Moisture can then collect in these walls, the parapet, the roof insulation and the base flashings. To fix this leak an air/vapor retarder is needed under the roof insulation. The retarder should be sealed to the inside of the parapet wall, and a loop should be provided in the retarder to accommodate deck-wall movement. The last air leakage site identified by Riedel is at the expansion joint of a wall-deck junction where the metal expansion joint cover meets the roof membrane. This leakage site can be fixed by employing a flexible flashing under the expansion joint cover running from the roof membrane to the inside of the parapet wall. Batt insulation should be installed under this flashing with a vapor retarder on the underside of the insulation.

Another thermal defect at a wall-roof connection is shown schematically in Figure 2.15 (Burn 1983). The wall consists of a metal panel facade, rigid insulation, concrete block and acoustical insulating interior tile. The roof has a metal panel interior and batt insulation between the interior and the deck. In this building, air moved through the acoustical insulation and into cracks in the blockwork joints caused by block shrinkage and movement. The air then flowed up through the block cores, around the horizontal structural members supporting the roof and into the roof system. The fix suggested by Burn is to reduce the permeability of the blocks by parging or applying a membrane.

A severe air leakage and moisture problem associated with a roof overhang, depicted in Figure 2.16, is described by Perreault (1980). The wall consists of a brick veneer, rigid insulation and a block backup wall, and the roof has an insulated metal deck. The overhang construction consists of a soffit enclosed on the top by an extension of the roof deck and on the back by the building's block wall. Precast concrete panels make up the sides of the soffit. The bottom consists of stucco applied to a mesh that is suspended by wires passing through holes in the deck. Due to the leakage of moist interior air into this overhang, there was severe frost on the soffit panels, the steel truss members, and the suspension wires. This leakage occurred through the roof deck flutes between the top of the block wall and the underside of the deck. These joints were filled with glass wool but were not sealed. Air leakage also occurred through the upper flutes of the deck and then through holes in the deck associated with the suspension wires. Perreault states that this air leakage problem could have been avoided by sealing the top and bottom of the roof deck at the wall junction with foam and caulking.

Turenne (1980) described another air leakage defect at a wall-roof connection involving a wall consisting of a brick veneer, rigid insulation and a block backup wall. As shown in Figure 2.17, an I-beam over the block wall supports the roof deck and the 
wall insulation is carried up to the outside of the I-beam. Due to movement at the beam-block interface, the masonry can not be effectively sealed to the underside of the spandrel beam. Also, the l-beam insulation is not supported and would not be expected to remain in place, breaking the continuity of both the envelope air barrier and insulation systems. To avoid these problems, a gap should be left between the bottom of the beam and the top of the wall so that the beam can deflect freely and not transfer its load to the wall. The exterior of the beam should be faced with drywall, and a flexible membrane should be installed along the edge of the steel deck connecting this drywall to the roof vapor retarder. Another flexible membrane should be used to seal the gap between the drywall and the air barrier in the block wall.

\subsubsection{Other Assemblies}

There are variety of other assemblies in buildings that are associated with thermal envelope defects. Overhangs, where a heated space extends out over an exterior wall, is one such assembly where air leakage, insulation defects and thermal bridging occur due to a lack of proper design. Soffits, for example those located over an entrance, can be associated with air leakage and heat loss from the building interior into the soffit and then to the outdoors (Perreault 1980, Quirouette 1983, Turenne 1980). Stairwells located at building perimeters can also be associated with thermal defects (Kudder 1988). They are often enclosed in concrete block with a single coat of paint and insulation board adhered to the exterior face of the block. A single coat of paint results in substantial permeability from the stairwell to the cavity beyond the backup wall, and the insulation board on the exterior of the block will not provide a functional air barrier. The airtightness of interior partitions, such as stairwells, elevator shafts and shafts associated with building services, is often neglected despite its importance to building thermal performance. Airflow communication between the building interior and these vertical shafts serve to connect the floors of a building in terms of airflow, thereby increasing the stack pressures across the exterior envelope and increasing infiltration rates. These stack pressures can also interfere with the effective operation of ventilation and smoke control systems.

\subsubsection{Summary}

This section has presented a discussion of thermal defects in building envelope systems. Some of these defects are the result of design details that do not maintain the continuity of the insulation layer and the air barrier system. Examples of thermal defects caused by poor designs include thermal bridges, insulation compression by building elements, and the existence of vertical air channels within wall systems. Other thermal defects arise due to poor construction practice or careless installation of materials or components. The interfaces between envelope components and systems can be sites of thermal defects due to both design and construction defects. Many thermal defects are associated with designs that do not provide adequate support to materials and elements given the wind pressures and structural movements to which they are exposed. These forces and differential movements always exist in envelope systems, and they must be accounted for in the attachment of insulation materials and air barriers and the selection and application of sealants. 


\subsection{Design Principles}

Although some office buildings have been designed and built with the thermal envelope defects described above, design and construction techniques are available to avoid these problems. This section summarizes design principles idenified during the literature search that are directed towards achieving good thermal envelope performance. These design principles are organized into sections on design and construction coordination, wall systems, roofing systems, windows, and air and water tightening.

\subsubsection{Design and Construction Coordination}

Some thermal envelope performance problems arise due to a lack of coordination among the various disciplines (architectural, structural, mechanical, electrical) during the design and construction of the total envelope system. In these cases the activities of the separate disciplines are not considered in relation to one another, and the design and activities of one discipline conflict with those of another, preventing the construction of an effective thermal envelope. Poor communication and a segregated approach to developing design details can result in envelope systems that can not be effectively insulated or air sealed (Kudder 1988). Kudder presents a good example of such a problem that occurred at the edge of a floor slab, discussed in section 2.3.8 and shown in Figure 2.7. The structural drawing showed only the spandrel beam supporting the floor slab, but did not show the wall. The architectural drawing included the wall, but did not show the beam located just inside the wall. The structural drawing implied that there was free access for the installation of fireproofing on both sides of the beam, and the architectural drawing implied that there was free access to the wall for the installation and finishing of the drywall all the way up to the floor slab. In fact, due to location of the beam, the drywall screws could not be installed and the drywall joints could not be taped.

Improved coordination among the disciplines has been repeatedly pointed out as a means of preventing many thermal envelope problems. This coordination includes providing the general contractor with an understanding of the function of the air/vapor retarder and the draftsman with an understanding of the level of detailing required during construction in order to provide an effective system (Wallace 1986). Wallace also suggests that a complete thermal envelope evaluation be written into the architectural/mechanical specifications. Such an inspection can include whole building and component pressurization testing for airtightness, in-situ R-value measurements, and infrared thermographic inspections. An inspection should be conducted as early as possible in the construction process in order to take advantage of the opportunity to repair the thermal defects that are identified before the construction is completed and the building is occupied. A pre-construction thermal evaluation of a mocked-up section of the thermal envelope has also been suggested.

\subsubsection{Wall Systems}

The basic design goals for ensuring good thermal performance of wall systems are the provision of air barrier and insulation systems that are continuous over the entire exterior envelope, the use of an insulation system that is protected from air movement through or around the insulation material, and the control of water vapor 
migration and condensation as well as effective rainproofing and drainage. These general goals need to be addressed differently in different wall systems.

Glass and metal curtain wall systems require attention in several specific areas to achieve a system with good thermal performance (Quirouette 1983). Maintaining the continuity of the air barrier over the entire wall system requires particular attention to the interfaces between the various elements of the wall. Such interfaces include the connections of glass panels to the shoulder flanges of mullions and of metal spandrel panels to mullion flanges. A design that works well in these situations is the use of a pressure-equalized cavity in exterior mullion caps and an air seal connecting the inner mullion flanges to the inside face of the window glass or infill panel. The interface of a curtain wall system to another wall type or to a building element such as a parapet or soffit requires a structurally adequate air barrier that is securely connected to the material in the curtain wall that performs the air barrier function. The air barrier at this interface should be rigid so that insulation can be brought into intimate contact with its surface. The insulation generally requires a protective cover that serves as an exterior finish, and the cavity between the cladding and the inside air barrier should be pressure-equalized and drained to the outside.

In metal panel walls, thermal performance can be severely degraded by air movement in vertical columns created by V-ribbed or corrugated steel panels. The detrimental effects of this air movement next to the wall insulation can be avoided by the use of an air barrier that isolates the insulation from these air columns (Brown 1986). Metal wall systems are also plagued by thermal bridging due to structural elements such as purlins and insulation attachment systems. Alternative designs of these elements exist that are more thermally efficient.

Masonry wall systems are generally associated with significant air leakage due to the permeability of the blocks, and shrinkage and cracks in the mortar. The airtightness of these walls can be improved by the application of a layer of plaster or some other material in order to seal the blocks and the joints (Burn 1980). In addition, the connections between masonry walls and other building components, particularly structural members, must be air sealed using systems that can accommodate the differential movement of these components. Masonry wall systems must also be designed to inhibit vertical air movement through the interiors of the blocks.

Cavity walls, which contain an air space between the interior finish wall and the exterior facade, must be designed to prevent interior air from reaching the cavity (Kudder 1988). Otherwise the moisture in this air will condense on the back of the exterior facade, increasing the potential for damage to the facade and the backup wall materials. If a fibrous insulation system is used and it is exposed to the cavity, a structurally sound air barrier system should be installed on the cavity side of the insulation.

\subsubsection{Roofing Systems}

The primary design issue in roofing systems is rainproofing and drainage. Since this issue is given so much attention elsewhere, it is not directly addressed in this report. The control of condensation associated with water vapor migration from the building interior into the roofing system is the main issue of concern here. The primary mechanism by which this moisture gets into the roofing system is convection due to air 
leakage and not diffusion, and therefore the best defense against condensation is airtight construction of the roofing system. Regardless of the best intentions and efforts, there will always be some water vapor migration and condensation, and the issue then becomes whether the moisture accumulates in the roofing system over the long term. In cold climates, moisture condenses over the winter and is absorbed by building materials. It then reevaporates and migrates out of the roof during the warmer weather. As long as the winter accumulation of moisture can be removed during the summer, there will be no buildup of moisture over time and the roofing system will generally not be affected significantly either in terms of thermal or material performance. Therefore, roofing system design guidelines are based on the prevention of the accumulation of moisture over a condensation/evaporation cycle (Condren 1982, Tobiasson 1988).

While air leakage control is of primary importance in the control of roofing system condensation, much attention is still given to the question of when vapor retarders are needed for the control of diffusion. The National Roofing Contractors Association (NRCA 1988) recommends the use of a vapor retarder when the indoor relative humidity is greater or equal to $45 \%$ and the average January outdoor temperature is less than $40 \mathrm{~F}$. Tobiasson (1989) points out that these guidelines are oversimplified, recommending vapor retarders when they are not needed and not specifying them when they may be. He instead recommends that one consider the winter condensation potential and the drying potential during the warm weather when deciding when a vapor retarder is necessary. He has developed a map of the United States that gives the indoor relative humidity above which a vapor retarder should be specified, allowing for corrections based on indoor temperature.

Condren (1982) describes the design requirements for the installation of an effective vapor retarder. As in the case of an air barrier he states that extreme care must be taken to insure that a vapor retarder is fully continuous throughout the roofing system, including all seams, penetrations and the roof edges. The vapor retarder and its associated seals and terminations must be as airtight as the roofing membrane is water tight. In order to achieve such an installation, Condren stresses attention to detail during the design phase and rigorous inspection during construction. Another issue with regards to vapor retarders is their location within the roofing system. Tobiasson (1989) states that if the vapor retarder is barely needed, it can be placed relatively close to the cold side of the roof. If the vapor drive is high and a vapor retarder is clearly necessary, then it must be placed closer to the warm side of the roof. The proper location within the roofing system depends on the materials within the roof and their relative $R$-values. Tobiasson presents a graph defining the relative percentages of the roof R-value that can be on the warm side of the vapor retarder as a function of indoor relative humidity.

Regardless of how much care is taken in the design and construction of a roofing system, it is inevitable that some moisture will migrate into the roofing system from precipitation and/or the condensation of water vapor from indoor air. Some people recommend the use of breather vents and air channels within the roofing system in order to remove such moisture (Condren 1982). Others state that it is extremely difficult to ventilate a compact roof and that breather vents are apt to do more harm than good. Tobiasson (1989) has done experimental studies showing that it takes decades to dry out a compact roof with breather vents, and he states further that he sees no evidence that unvented roofs perform any worse than vented roofs. A related 
construction issue is the removal of moisture when a roofing system is installed over a wet substrate such a lightweight insulating concrete. While it is generally recognized that the wet material should be allowed to dry as much as possible before the roofing system is installed, Tobiasson (1989) recommends the use of a perforated steel deck to allow moisture to escape below and a vapor retarder over the wet material to prevent moisture from reaching materials installed above. He also restates his case against breather vents, stating that they will not dry out this wet material. Funk (1988) agrees with the recommendations of Tobiasson about a perforated deck below and the ineffectiveness of topside venting, and points out the potential for damage in cold climates if the material is not dry by the first winter. He therefore suggests that such decks be placed in late spring or early summer. On the other hand, Condren (1982) does not agree that perforated decks are effective in drying the wet materials and recommends the use of vents to dry the material.

Other roofing system design issues are specific to particular systems. Tobiasson $(1985,1989)$ makes design recommendations for different roofing systems appropriate to their individual characteristics. He states that framed roofing systems generally will have air leakage problems and recommends the installation of an air barrier even when a vapor retarder is not needed. Also, since it is difficult to seal all of the air leakage paths into the roofing system from the building interior, he recommends the provision of venting on the cold side of the insulation. Tobiasson states that protected or inverted membrane roofing systems have the advantage of creating a "perfect" air and vapor retarder, eliminating any chance of introducing vapor traps and using a single component for both the membrane and the retarder. Because the insulation is above the membrane and is in contact with exterior moisture, he recommends the use of only extruded polystyrene insulation but points out that it still requires protection from ultraviolet radiation and physical abuse. Tobiasson points out the advantages of the so-called "nail one-mop one" roofing system in which there are two layers of insulation, and the vapor retarder is installed between the two layers. The lower layer of insulation is mechanically fastened to the deck, and the upper layer of insulation board is installed with bitumen. The joints of the two layers of insulation are staggered to reduce air leakage. Tobiasson recommends this system as the best way to achieve airtightness, increase wind uplift resistance, and reinforce the roof against stresses and strains.

\subsubsection{Windows}

Apart from the selection of the window system itself, the most important envelope thermal performance issue with regards to windows is the interface between the window and the wall. To achieve good thermal performance at this interface, the continuity of the insulation and air barrier layers must be maintained at all points along this interface (Rousseau 1988). Therefore, both the wall and the window must have well-defined planes of airtightness so that they can be joined (Patenaude 1988). Airtightness at this intersection also requires the selection of air seals that are compatible with the sealing materials of the glazing unit and based on estimations of the joint movement at the interface. The control of condensation is another important thermal performance issue and involves keeping the inside surface of the glazing and framing elements warm. This is achieved by maintaining the continuity of the thermal 
barrier of the envelope at the interface and by eliminating infiltration of cold air past the thermal break. In addition, the area of the window frame exposed to the exterior should be smaller than the area exposed to the interior. The window reveal should also be designed to keep the window nearer to the interior finish (Patenaude 1988). Rousseau (1988) describes the advantages of using the pressure-equalized rain screen principle at window frame connections.

\subsubsection{Air and Water Tightening}

Air and water tightening are of primary importance in achieving good thermal envelope performance. Water tightening refers to the prevention of water vapor migration into the envelope, but also involves rainproofing of the exterior and proper drainage of exterior facades and roofing systems. Airtightness is of particular importance in high-rise buildings because they experience substantial pressure differences due to stack and wind effects, and therefore they must be built to high standards of envelope airtightness (Handegord 1982). It is preferable to have the building's structural frame inward and separate from the exterior wall system, since the elimination of structural penetrations of the wall makes it easier to incorporate a continuous air barrier system that is protected by the wall insulation from the fluctuating conditions of weather. The building structural members are also isolated from thermal fluctuations, thereby reducing differential movement of building components and stresses on the thermal envelope systems. Handegord also points out the importance of the airtightness of internal floors and partitions. Achieving airtightness in these components redistributes the total stack pressure difference of the building, reducing the pressure difference across exterior walls on each floor. The reduction of these pressure differences decreases the building infiltration rate and allows for better control of ventilation air distribution and smoke movement in the event of a fire. At a more fundamental level Handegord (1980) states the need to eliminate the idea that envelope leakage is an appropriate method of ventilating a building. Such leakage is undesirable, unnecessary and uneconomical because this air can not be treated or conditioned, nor can its rate or distribution be controlled. Furthermore, outward air leakage can result in condensation within the envelope and the deterioration of materials and systems.

Envelope airtightness is achieved through the design and installation of an air barrier system as part of the thermal envelope. The requirements of an air barrier system include continuity, structural integrity, air impermeability, and durability (Lischkoff 1988, Quirouette 1989). Continuity means more than there not being holes in the air barrier. It also means that the continuity of the air barrier is maintained at the connections between various building components and systems. Whenever components intersect, a design detail of the air barrier system should be developed separately for this connection. The requirement for structural integrity refers to the need for the air barrier to be able to resist imposed wind loads, or to be supported by something that can resist these loads, without rupturing or pulling away from its supports. This requirement limits the situations in which plastic sheets can be used as an air barrier because they themselves are not structurally sound. As long as the sheet is securely fastened to a rigid substrate, preferably between two rigid layers, it will perform well. The problems with plastic sheets arise when they are not adequately supported and when they are used to seal around penetrations. Air impermeability is 
a basic material requirement of the air barrier. Many materials meet this requirement including glass, sheet steel, gypsum board, cast-in-place concrete and properly supported polystyrene. Other materials are not impermeable to air, e.g., concrete blocks, fiber board sheathing, and expanded polystyrene, and these must not ie used as air barriers. Durability is not an intrinsic property of the air barrier system, but is dependent on the environment (temperature, moisture, ultraviolet radiation, proximity to other materials), including the environment during construction. It is important to realize that one may need to protect the air barrier during construction. The durability of the air barrier system should either be proven by experience or the air barrier should be positioned in a way that it is accessible for inspection and maintenance.

The position of the air barrier within the thermal envelope is not important from a dust, noise or energy perspective. But from a durability point of view, it is better to locate the air barrier towards the inside of the insulation and the exterior facade where it is protected from environmental extremes and solar radiation (Lischkoff 1988). Keeping it inside the walls also facilitates a design which allows interstitial water or condensation to be vented or drained to the outdoors.

Perreault (1989) has described a variety of air barrier systems available for use in buildings. In the Accessible Drywall Approach, the interior drywall is the main component of the air barrier system. High performance sealants are used to seal the drywall and other materials because of the greater tolerances needed in commercial constructions and the larger differential movements associated with the longer spans. Easy access to the air barrier from the interior provides for inspection and repair. This approach works well in concrete structures. In the Nonaccessible Drywall Approach a layer of drywall sheathing located within the envelope is the main component of the air barrier system. Joints between the boards and other components are sealed with strips of elastomeric membrane. There are fewer perforations of the air barrier in this approach as compared to accessible drywall. It is particularly advantageous in steel structures because the air barrier can be extended past the steel columns and floors. Since the air seal materials are nearly inaccessible, they must be durable and attached so that long term performance is ensured. Metal air barrier systems are used in curtain walls and in sheet metal walls. In curtain walls the air barrier is made of glass, metal pans and extrusions, gaskets, tapes and sealants. In preengineered sheet metal walls, the interior sheet steel liner acts as both an interior finish and as an air/vapor barrier. In masonry walls a factory-made elastomeric membrane can be used as an air barrier. This membrane is applied to the entire surface of the masonry backup wall and is used to make airtight connections between building components. These membrane air barriers can be thermofusible or peel-and-stick.

The control of water vapor migration through the thermal envelope is a separate issue from achieving airtightness, though obviously related to it. Water vapor moves from inside buildings in winter by diffusion and air leakage into exterior walls, ceilings, and roofs and can condense as water or frost on colder outer components. Melting, collection or absorption, and refreezing can deteriorate or displace components of the exterior facade. If this condensate is not removed by drainage or evaporation, it can contribute to paint failure on the exterior cladding, corrosion of metal connections or cladding, and decay and deterioration of organic materials. The diffusion of moist interior air into the envelope can be reduced by a vapor retarder. A vapor retarder is a membrane or interior coating, which need not be completely continuous over the 
envelope, that can limit the rate of diffusion to acceptable levels. Because cracks, fissures and holes in the vapor retarder will allow much greater rates of moisture transfer and accumulation, it is crucial to also have a continuous air barrier system in the envelope to control moisture transier. Some moisture transfer and condensation within the envelope is inevitable. In walls, drainage by gravity is most effective in removing this moisture and all walls should have cavities that are drained and flashed to the outside. One should consider carrying the flashing all the way to the vapor retarder because during warm weather vapor will be driven inward to the outer face of the vapor retarder where it may then condense, and the flashing will serve to remove the water. Removing moisture by ventilating the wall is not particularly effective, especially as the air gets colder and is able to carry less moisture. In addition, attempts to ventilate walls can result in the circulation of outdoor air through porous insulation, joints in insulation, and spaces between insulation and other envelope elements, thereby significantly reducing the thermal performance of the insulation system and possibly even cooling interior surfaces below the interior dewpoint temperature (Handegord 1982).

While rainproofing of the building envelope is not generally considered a thermal performance issue, rainproofing systems impact the envelope design and interact with airightening and insulation systems. There are four basic mechanisms for rain penetration into the envelope: capillary, gravity, kinetic energy and air transport (Rousseau 1983). To control capillary flow, one should introduce a large gap in joints in the exterior facade to prevent wetted materials from touching other materials in the cavity behind the facade. Gravity is controlled by sloping all horizontal joints and interfaces to the outside so water that accumulates in the cavity will drain to the outside. Water transport by kinetic energy is controlled by designing a deflector on the outside of a joint, inserting strips in the grooves of a joint to create a baffle, or creating a labyrinth intrinsic to the shape of panel edges. To control air transport of water, one can apply the pressure-equalized rain sceeen principle (discussed below), which reduces the air pressure differences across the exterior cladding that drive this transport.

Several design approaches have been ussd to control rain penetration in office building envelopes, the first being the Face Seal irethod (Quirouette 1983, Rousseau 1983). In this approach, all exterior joints are caulked to make the facade airtight and rainproof. This system can perform well for short periods of time relative to the building life, but caulking compounds will deteriorate rapidly due to exposure to sun, water, and freeze/thaw cycles. The caulking is also subject to thermally induced differential movements. Therefore, the face seal approach is based on the expectation of sealing the facade perfectly and requires continuous attention and maintenance. In the TwoStage Seal approach (Handegord 1982, Rousseau 1983), there is a deflector on the exterior of the facade to control rain penetration and an air pressure seal on the inner face of the cladding for airtightness. Since the air seal is located behind the rain seal, it is not exposed to water and ultraviolet radiation. It is still exposed to stresses due to the differential movement of the facade and structure. When using either the face seal or two-stage seal approach in walls with concrete cladding, there is generally a backup wall behind the facade. This backup wall is generally not built to be airtight because the facade is supposed to be airtight. There may be no air space behind the cladding so there are no drainage paths to remove the rain that does penetrate. The panel facade, being located on the cold side of the insulation, may act as a vapor 
retarder on the cold side of the envelope. Moisture from inside may then condense on the back of the facade and at the joints.

The Pressure-Equalized Rain Screen approach to envelope design has clear advantages over the other approaches (Ganguli 1989, Quirouette 1983, Rousseau 1983). A vented cavity is located behind the exterior cladding, and an airtight inner wall is constructed behind the cladding. Because the cavity is well vented to the outside, it is essentially at the same pressure as the exterior cladding, preventing pressure-driven rain transport into the cavity. The cavity must be compartmentalized over the facade, both horizontally and vertically, to prevent pressure-driven airflow and water movement through the cavity. With the airtight layer located behind the cladding, the air barrier can be located on the warm side of the wall insulation, providing thermal stability to the seal joints and reducing stresses caused by temperature changes.

\subsubsection{Summary}

This section contains general principles for the design and construction of office building envelopes with good thermal performance through the control of heat, air and moisture transfer and by minimizing the occurrence of thermal defects. The basic design requirements are insulation and air barrier systems that are continuous and effective, the use of materials that are appropriate to the environment (including that encountered during construction), joint details that account for differential movement of components, and a means of dealing effectively with rain penetration and the removal of condensation. The implementation of these design principles will vary according the envelope system being employed.

\subsection{Design Details}

The literature contains many design details in which special attention has been given to thermal and air leakage performance. This section contains forty design details that were identified in the literature review, organized by envelope construction.

\subsubsection{Glass and Metal Curtain Walls}

Eight design details for glass and metal curtain wall construction are described by Quirouette (1983). This reference includes a sketch of each detail and an accompanying discussion of thermal bridging and air/vapor barriers. The details include the following:

Window mullion/insulated spandrel panel connection (Figure 2.18): This detail employs a pressure-equalized cavity in the mullion that communicates with the cavity between the spandrel glass and the panel insulation. Air barrier continuity is maintained by connecting the metal pan behind the spandrel panel insulation to the air seal at the inner surface of the mullion shoulder.

Parapet wall (Figure 2.19): This detail employs a rigid air/vapor barrier that runs from the mullion shoulder, over the top of the mullion and over the top of the parapet wall where it is connected to the roof membrane. There is insulation 
outside of this rigid barrier over the mullion and over the parapet wall.

Outside corner (Figure 2.20): This detail deals with the case in which the mullion shoulders are on the outside of the exterior wall. A rigid air/vapor barrier connects the two mullion shoulders on each wall and is structurally adequate to carry the wind pressure loads at the corner. Insulation is placed on the outside of this barrier, and a decorative cap is placed outside of the corner insulation.

Inside corner (Figure 2.21): In this detail, the mullion shoulders are on the inside of the exterior wall. A rigid air/vapor barrier connects the two mullion shoulders, and there is insulation installed behind the barrier. A decorative metal panel is on the outer surface of the corner; the space between the outer panel and the rigid barrier need not be insulated.

Grade connection (Figure 2.22): This detail specifies a rigid air/vapor barrier running from the lower shoulder of the mullion to the floor or curb. Insulation is placed outside this barrier and flashing is installed such that there is a vented cavity behind this flashing. No insulation is placed under the mullion. This design solves the problems discussed with reference to Figure 2.10.

Precast panel interface (Figure 2.23): In this detail the precast panel is in the plane of the mullion, and the space between the panel and mullion is insulated. An air barrier runs from the mullion shoulder, between the mullion and this insulation, and is connected to the air barrier in the insulation system behind the panel.

Connection to heated soffit (Figure 2.24): In this detail there is a mullion at the base of the curtain wall that is connected to the floor of the heated soffit. A rigid metal air/vapor barrier runs from the lower shoulder flange of the mullion face to the air barrier on the inside surface of the soffit floor. Insulation is placed outside this air barrier under the mullion, extending past the edge of the soffit floor insulation.

Sloped walls (glass roofs) (Figure 2.25): Mullion sections are used to provide an interconnected rain gutter system with drainage to the outside. The gutters are well below the primary air seal of the interface of the glass and the mullion.

\subsubsection{Masonry Walls}

Twenty design details for masonry walls were identified in the literature review. Unless otherwise stated, the masonry wall construction consists of a brick facade, an air space, rigid insulation, an air/vapor barrier, and a masonry backup wall. The masonry wall details that were identified include the following:

Foundation wall/ground floor connection (Burn 1980) (Figure 2.26): In this detail, the outer face of the concrete block wall and the outer face of the concrete foundation wall are in the same plane and support the wall air barrier consisting of textured mastic. The masonry wall insulation and the foundation wall insulation are in the same plane.

Wall/window sill connection (Burn 1980) (Figure 2.27): In this detail the wall air 
barrier is turned back over a wood plate built over the top course of concrete block and is sealed to the window frame.

Wall/window sill connection (Patenaude 1988) (Figure 2.28): In this detai! the wood plate over the top course of block extends over the top of the wall insulation. The air barrier runs from the outer face of the concrete block, under the wood plate towards the inside of the building, and up over the wood plate. It is then sealed to the window frame.

Wall/window jamb connection (Burn 1980) (Figure 2.29): The wall air barrier is turned in at the edge of the concrete block and sealed to the interior of the window frame.

Wall/floor connection (Burn 1980) (Figure 2.30): The outer edge of the slab is in the same plane as the outer face of the block wall. The wall insulation continues past the edge of the floor slab, avoiding the thermal bridging that occurs when the floor slab penetrates this insulation layer. The joint between the edge of the slab and the top of the concrete block wall is sealed with a flexible membrane to accommodate movement at this joint.

Wall/floor connection and window head in a steel frame building (Burn 1980) (Figure 2.31): In this detail a steel spandrel beam is located behind the concrete block wall and the floor slab is extended to the outer surface of the block wall. The wall insulation is continuous from the upper floor, over the end of the floor slab, and to the lower floor. A flexible membrane seals the edge of the slab to the top of the block wall.

Wall/column connection and window jamb (Burn 1980) (Figure 2.32): In this detail the outer surface of the concrete block wall is in the same plane as the column face, simplifying the effective installation of the air barrier and wall insulation.

Wall/steel column connection and window jamb (Burn 1980) (Figure 2.33): In this detail the column is located inside of the block wall.

Wall/steel column connection and window jamb (Burn 1980) (Figure 2.34): In this detail the column is recessed into the block wall. The outer flanges of the steel column are bridged by a piece of sheet steel.

Flat roof edge (Burn 1980) (Figure 2.35): In this detail the concrete roof deck extends over the block wall, and the wall insulation extends past the roof edge. The roof membrane is connected to the wall air/vapor barrier on the outside of the roof edge. A flexible membrane is used to seal between the block wall and the concrete roof deck to meet the needs for flexibility, durability and airtightness.

Flat roof edge (Riedel 1982) (Figure 2.36): This detail describes a steel deck terminating at the inside edge of the masonry wall. A metal cap covers the top of the wall and a flexible membrane is installed under this cap. This membrane is sealed to the outside of the masonry wall and to the roof membrane, which is brought up on top of the masonry wall. 
Flat roof edge in a steel frame building (Burn 1980) (Figure 2.37): In this detail the steel roof deck extends to the outer edge of the masonry wall, and the steel spandrel beam is in the plane of this wall. Gypsum or plywood bridges the outside flanges of the beam, flush with the outer face of the block wall. There is a gap between the beam and the top of the block wall, and this gap is sealed with a flexible membrane to accommodate movement at this joint. The roof membrane is sealed to the wall barrier.

Flat roof edge in a steel frame building (Turenne 1980) (Figure 2.38): In this detail the steel spandrel beam is located inside of the wall, allowing the beam to deflect freely. The roof membrane is joined to the wall barrier by a flexible membrane that is supported by a sheet metal closure.

Overhang roof (Riedel 1982) (Figure 2.39): This detail describes a steel deck that extends over a masonry wall. The deck ribs are filled with foam both above and below the deck where it passes over the wall. A felt cutoff is installed in the roof insulation in this same plane.

Parapet wall/roof connection (Riedel 1982) (Figure 2.40): In this detail the roof membrane is extended to the inner surface of the parapet wall and sealed to the wall under the flashing. A loop of excess material is left in the membrane to accommodate deck/wall movement.

Parapet wall/roof connection at expansion joint (Riedel 1982) (Figure 2.41): In this detail the roof membrane is sealed to a flexible flashing installed under the metal expansion joint cover. This flashing is sealed to the inner surface of the parapet wall under the flashing. Thermal insulation is installed beneath this flashing in the space between the roof deck and the wall. A vapor retarder is installed beneath this insulation.

Setback wall/roof connection (Turenne 1980) (Figure 2.42): In this detail, a masonry wall rises above a concrete deck roof. The roof membrane, located between the deck and the roof insulation, is sealed to the wall barrier.

Setback wall/roof connection (Turenne 1980) (Figure 2.43): In this detail, the masonry wall consists of metal siding, an air space, batt insulation, an air/vapor barrier and a masonry backup wall and rises above a steel deck roof. The roof membrane, located under the roof insulation, is sealed to the wall barrier. A loop in the membrane is provided at the roof wall gap to accommodate differential movement between the roof and the wall.

Setback wall/roof connection (Turenne 1980) (Figure 2.44): In this detail, a masonry wall rises a short distance above a steel deck roof. The masonry wall then supports a wall of metal siding, an air space, and batt insulation. The roof membrane, located between the deck and the roof insulation, is sealed to the masonry wall barrier, which in turn is sealed to the upper wall barrier. 


\subsubsection{Metal Stud Walls}

In these details the wall construction consists of a brick facade, an air space, rigid insulation, an air/vapor barrier, and a metal stud wall with gypsum on both sides. Using this construction, services can be installed within the metal stud wall without disturbing the air/vapor barrier. The wall details that were identified include the following:

Wall/foundation connection (Quirouette 1980) (Figure 2.45): In this detail, the foundation insulation and the wall insulation are in the same plane. The wall barrier is extended down from the outside of the metal stud wall and connected to the foundation barrier with a flexible connection.

Wall/floor connection (Quirouette 1980) (Figure 2.46): In this detail, the outer gypsum board of the stud wall is extended down over the edge of the floor slab. The metal studs are shortened to accommodate the floor deflection.

Wall/floor connection (Quirouette 1980) (Figure 2.47): In this detail, the wall does not contain an air/vapor barrier between the insulation and the metal stud wall. Instead the interior gypsum finish serves as the barrier, and a mastic is used to provide a flexible seal between the interior gypsum board and the floor. The outer gypsum need not be extended over the floor slab.

Wall/floor connection and window head and sill (Quirouette 1980) (Figure 2.48): In this detail, the floor slab extends to the outer gypsum board and is supported by a steel beam. The outer gypsum board is carried down over the outside of the beam and is sealed to the outer gypsum of the floor below by a flexible membrane.

Wall/steel column connection and window jamb (Quirouette 1980) (Figure 2.49): In this detail, the column is setback from the outer gypsum board. The air seal is brought to the inner face of the window.

Flat roof edge (Quirouette 1980) (Figure 2.50): In this detail, the steel beam supporting the roof is setback from the outer gypsum board. The outside of the beam is covered by a gypsum board that is sealed to the outer gypsum of the wall with a flexible membrane. The studs are shortened under the beam in order to accommodate deflection of the beam.

\subsubsection{Precast Panel Seams}

In the earlier section on Design Principles three different approaches to achieving air and water tight seals were described, face seal, two-stage seal and pressure equalized rain screen. The application of these three approaches to precast concrete panel seams are shown by Rousseau (1983). In all three cases the insulation is located directly behind the precast panel.

Face seal (Figure 2.51): In this system all exterior joints are caulked to make the facade airtight and rainproof. Both a vertical joint and a horizontal joint are shown. There are no airspaces between the panel and the insulation, and the 
insulation and the backup wall.

Two-stage seal (Figure 2.52): Details are shown for a vertical and a horizontal joint, in which there are separate seals for controlling air leakage and rain penetration. The rain seal is on the outer surface of the facade and the air seal is on the inside of the panel joint.

Pressure equalized rain screen (Figure 2.53): A floor/wall connection is shown in which the wall consists of a precast concrete panel, an air space or pressureequalized cavity, insulation, an air/vapor barrier, and an interior stud wall. The cavity is connected to the outside by openings in the precast cladding, eliminating the rain sealing of the outer facade. The wall air barrier acts as the air seal.

\subsubsection{Air Barrier Systems}

Four different air barrier systems were described in the section on Design Principles. The following details corresponding to each of these approaches are given in Perreault (1989).

Wall/floor connection, accessible drywall approach (Figure 2.54): In this detail the wall consists of a brick facade, an air space, rigid insulation, batt insulation and interior gypsum. The interior gypsum serves as the air/vapor barrier and high performance sealants are used to seal the drywall to other materials. An elastomeric membrane is used to seal the top of the gypsum to the bottom of the floor slab.

Wall/floor connection, nonaccessible drywall approach (Figure 2.55): Two details of this connection are shown in the reference, one in which there is a concrete floor slab and the other with a concrete slab on a steel deck with a steel spandrel beam. In both cases the wall consists of a panel facade, an air space, batt insulation, and a stud wall with gypsum on both sides. The exterior gypsum serves as the air/vapor barrier. The joints between the exterior gypsum and other components are sealed with elastomeric membranes. In the steel frame case, the spandrel beam is well within the interior stud wall and the membrane air seal is carried over the floor slab and steel deck from the upper gypsum board to the lower gypsum board.

Wall/floor connection, metal air barrier (Figure 2.56): This detail is for curtain wall construction in which the air barrier is made of glass, metal extrusions, a metal pan behind the insulation, and various gaskets, tapes and sealants.

Wall/floor connection, elastomeric membrane system (Figure 2.57): This detail shows the wall/floor connection for a wall consisting of a brick facade, an air space, rigid insulation, and a concrete block backup wall. A concrete floor slab extends to the outer face of the block wall. An elastomeric membrane serves as the air/vapor barrier and is located on the outer face of the concrete block. This membrane is carried down over the edge of the floor slab. 


\subsubsection{Summary}

This section presents several design details in which a special effort has been given to the control of heat, air and moisture transfer. The existence and application of these design details demonstrates that good thermal envelope performance arid the design of envelope connections can be achieved without extraordinary efforts using available technology and materials.

\subsection{Summary of Literature Review}

The literature review on thermal envelope design and performance has revealed the existence of much useful information for the development of the NIST/GSA design guidelines. This information includes the characterization of thermal envelope defects such as thermal bridges, insulation defects and air leakage. The existence, impact, and in some cases the extent of these defects has been established through both laboratory and field work. Research in the area of calculation and modeling has enabled the quantification of the effects of thermal defects on envelope heat transfer rates and the effects of air leakage on building infiltration rates. The review has identified design principles for the design and construction of building envelopes that avoid the occurrence of such thermal defects, resulting in good thermal performance. Many design details have been presented in published reports that provide effective alternatives to the details which result in these defects. The main conclusions of the literature review are that thermal defects exist and have significant detrimental effects on energy consumption, thermal comfort and material performance. The identification of these defects, their classification and the presentation of alternative designs has been limited to specific buildings, specific envelope components and component connections associated with specific building constructions. There are no thorough presentations of thermal envelope defects, poor design details or alternative designs for the great variety of building envelope constructions. This is the information that will be presented in the thermal envelope guidelines, and this review has shown that the research literature is an incomplete source of this information. This information does exist in the practical experience of building envelope design and construction professionals, and their knowledge must be a major source of input to the guidelines as they are developed. 


\subsection{References}

ANSI-ASHRAE, "Application of Infrared Sensing Devices to the Assessment of Building Heat Loss Characteristics," Standard 101, American Society if Heating, Refrigerating and Air-Conditioning Engineers," 1981.

ASTM, "Standard Test Method for Determining Air Leakage Rate by Tracer Dilution," E 741, American Society for Testing and Materials, 1983.

ASTM, "Standard Test Method for Rate of Air Leakage Through Exterior Windows, Curtain Walls, and Doors," E 283, American Society for Testing and Materials, 1984.

ASTM, "Standard Method for Field Measurement of Air Leakage Through Installed Exterior Windows and Doors," E 783, American Society for Testing and Materials, 1984.

ASTM, "Standard Test Method for Steady-State Heat Flux Measurements and Thermal Transmission Properties by Means of the Heat Flow Meter Apparatus," C 518, American Society for Testing and Materials, 1985.

ASTM, "Standard Practice for Thermographic Inspection of Insulation Installations in Envelope Cavities of Wood Frame Buildings," C 1060, American Society for Testing and Materials, 1986.

ASTM, "Standard Test Method for Determining Air Leakage Rate by Fan Pressurization," E 779, American Society for Testing and Materials, 1987.

Anderson, B.R., "The Measurement of U-Values on Site," ASHRAE/DOE/BTECC Thermal Penformance of the Exterior Envelopes of Buildings III, American Society of Heating, Refrigerating and Air-Conditioning Engineers, Inc., ASHRAE SP 49, p.3, 1986.

Ashton, H.E., R.L. Quirouette, "Coatings, Adhesives and Sealants," Performance of Materials in Use, NRCC 24968, National Research Council of Canada, p.29, 1986.

Bankvall, C.G., "Air Movements and the Thermal Performance of the Building Envelope," Thermal Insulation: Materials and Systems, ASTM STP 922, F.J. Powell and S.L. Matthews, Eds., American Society for Testing and Materials, p.124, 1987.

Bankvall, C.G., "Thermal Performance of the Building Envelope as Influenced by Workmanship," Thermal Insulation: Materials and Systems, ASTM STP 922, F.J. Powell and S.L. Matthews, Eds., American Society for Testing and Materials, p.679, 1987.

Broderick, T.B., "Measurements of Energy Flows Through Commercial Roof/Ceiling Insulation Systems," ASHRAE Transactions, 92(2B), p.541, 1986.

Brown, W.C., G.D. Schuyler, "A Calorimeter for Measuring Heat Flow Through Walls," ASHRAE/DOEORNL Conference Thermal Performance of the Exterior Envelopes of Buildings, American Society of Heating, Refrigerating and Air-Conditioning Engineers, Inc., ASHRAE SP 28, p.262, 1981.

Brown, W.C., G.D. Schuyler, "In Situ Measurements of Frame Wall Thermal Resistance," ASHRAE Iransactions, 88(1), p.667, 1982.

Brown, W.C., "Heat Transmission Tests on Sheet Steel Walls," ASHRAE Transactions, 92(2B), p.554, 1986.

Burch, D.M., B.A. Licitra, D.F. Ebberts, R.R. Zarr, "Thermal Resistance Measurements and Calculations of an Insulated Concrete Block Wall," ASHRAE Transactions, 95(1), p.398, 1989.

Burch, D.M., P.J. Shoback, K. Cavanaugh, "A Heat Transfer Analysis of Metal Fasteners in Low-Slope Roofs," Boofing Research and Standards Development, ASTM STP 959, R.A. Critchell, Ed., American Society for Testing and Materials, p.10, 1987. 
Bum, K.N., "Masonry Walls," Censtnuction Details for Air Tiahtness, Record of the DBR

Seminar/Workshop, Proceedings No.3, NRCC 18291, National Research Council of Canada, p.13, 1980.

Bum, K.N., "Masonry Wall Systems," Exterior Walls: Understanding the Problems, NRCC 21203, National Research Council of Canada, p.15, 1983.

CGSB, "Manual for Thermographic Analysis of Building Enclosures," CAN/CGSB-149.2-M86, Canadian General Standards Board, 1986.

Carlsson, B., A. Elmroth, P. Engvall, Airtiahtness and Thermal Insulation Building Design Solutions, D37, Swedish Council for Building Research, Stockholm, 1980.

Chang, Y.M., R.A. Grot, L.S. Galowin, "Infrared Inspection Techniques for Assessing the Exterior Envelopes of Office Buildings," Thermal Insulation: Materials and Systems, ASTM STP 922, F.J. Powell and S.L. Matthews, Eds., American Society for Testing and Materials, p.175, 1987.

Childs, K.W., "Analysis of Seven Thermal Bridges Identified in a Commercial Building," ASHBAE Iransactions, 94(2), p.1776, 1988.

Clausen, I., H. Hoyer, "The Effect of Installation Defects on the Thermal Performance of Mineral Fiber Insulation," Sympesium on Air Infiltration. Ventilation and Moisture Transfer, Building Thermal Envelope Coordinating Council, p.292, 1988.

Fang, J.B., Grot, R.A., K.W. Childs, G.E. Courville, "Heat Loss from Thermal Bridges," Building Besearch and Practice. The Journal of CIB, Vol. 12, No. 6, p.346, 1984.

Fang, J.B., R.A. Grot, "In Situ Measurement of the Thermal Resistance of Building Envelopes of Office Buildings," ASHRAE Transactions, 91(1B), p.543, 1985.

Fang, J.B., R.A. Grot, "Field Measurements of the Thermal Resistance of Office Buildings," Thermal Insulation: Materials and Systems, ASTM STP 922, F.J. Powell and S.L. Matthews, Eds., American Society for Testing and Materials, p.107, 1987.

Flanders, S.N., S.J. Marshall, "In Situ Measurement of Masonry Wall Thermal Resistance," ASHBAE Iransactions, 88(1), p.677, 1982.

Flanders, S.N., "Measured and Expected R-Values of 19 Building Envelopes," ASHBAE Iransactions, 91(2B), p.49, 1985.

Flanders, S.N., "In-Situ Assessment of Two Retrofit Insulations," ASHRAE/DOE/BTECC Thermal Performance of the Exterior Envelopes of Buildings III, American Society of Heating, Refrigerating and AirConditioning Engineers, Inc., ASHRAE SP 49, p.32, 1986.

Ganguli, U.,"Wind and Air Pressure on the Building Envelope," An Air Barrier for the Building Envelope, Proceedings of Building Science Insight '86, National Research Council of Canada, NRCC 29943, p.7, 1989.

Grot, R.A., "The Air Infiltration and Ventilation Rates in Two Large Commercial Buildings," ASHBAE/DOE Thermal Performance of the Exterior Envelopes of Buildings Il, American Society of Heating, Refrigerating and Air-Conditioning Engineers, Inc., ASHRAE SP 38, p.391, 1983.

Grot, R.A., K.W. Childs,J.B. Fang, G.E. Courville, "The Measurement and Quantification of Thermal Bridges in Four Office Buildings," ASHBAE Iransactions, 91(1B), p.558, 1985a.

Grot, R., M. Modera, J.B. Fang, H. Park, "Instrumentation for the In-Situ Measurement of Building Envelopes," ASHRAE Transactions, 91(2B), p.1088, $1985 \mathrm{~b}$.

Grot, R.A., A.K. Persily, "Measured Air Infiltration and Ventilation Rates in Eight Large Office Buildings," Measured Air Leakage of Buildinas, ASTM STP 904, H.R. Trechsel and P.L. Lagus, Eds., American Society for Testing and Materials, p.151, 1986. 
Handegord, G.O., "Design Principles," Constnuction Details for Air Tiahtness, Record of the DBR

Seminar/Workshop, Proceedings No.3, National Research Council of Canada, NRCC 18291, p.1, 1980.

Handegord, G.O., "Air Leakage, Ventilation, and Moisture Control in Buildings," Moisture Miaration in Buildings, ASTM STP 779, M. Lieff and H.R. Trechsel, Eds., American Society for Testing anıd Materials, p.223, 1982.

Hedlin, C.P., "Moisture Contents in Protected Membrane Roof Insulations - Effect of Design Features," Boofing Systems, ASTM STP 603, American Society for Testing and Materials, p.36, 1976.

Hedlin, C.P., "Effect of Moisture on Thermal Resistance of Some Insulations in a Flat Roof under FieldType Conditions," Thermal Insulation. Materials, and Systems for Enerov Conservation in the "80s, ASTM STP 789, F.A. Govan, D.M. Greason, and J.D. McAllister, Eds., American Society for Testing and Materials, p.602, 1982.

Hedlin, C.P., "Effect of Insulation Joints on Heat Loss through Flat Roofs," ASHRAE Transactions, 91(2B), p.608, 1985.

Hedlin, C.P., "Heat Flow through a Roof Insulation Having Moisture Contents between 0 and $1 \%$ by Volume, in Summer," ASHBAE Transactions, 94(2), p.1579, 1988.

ISO, "Thermal Insulation - Qualitative Detection of Thermal Irregularities in Building Envelopes - Infrared Method," 6781, International Standards Organization, 1983.

Kelso, R.M., "Water Vapor Flow and High Thermal Resistance Insulation Systems for Metal Buildings," Thermal Insulation. Materials, and Systems for Energy Conservation in the '80s, ASTM STP 789, F.A.

Govan, D.M. Greason, and J.D. McAllister, Eds., American Society for Testing and Materials, p.651, 1982.

Knab, L.I., D.R. Jenkins, R.G. Mathey, "The Effect of Moisture on the Thermal Conductance of Roofing. Systems," ASHRAE/DOE-ORNL Conference Thermal Performance of the Exterior Envelopes of Buildings, American Society of Heating, Refrigerating and Air-Conditioning Engineers, Inc., ASHRAE SP 28, p.816, 1981.

Kudder, R.J., K.M. Lies, K.R. Holgard, "Construction Details Affecting Wall Condensation," Symposium on Air Infiltration. Ventilation and Moisture Transfer, Building Thermal Envelope Coordinating Council, p.131, 1988.

Lagus, P., A.K. Persily, "A Review of Tracer-Gas Techniques for Measuring Airflows in Buildings," ASHRAE Transactions, 91(2B), p.1075, 1985.

Lischkoff, J., R. Quirouette, V. Stritesky, "Design, Construction and Performance Evaluation on Air Barrier Systems," Symposium on Air Infiltration. Ventilation and Moisture Transfer, Building Thermal Envelope Coordinating Council, p.281, 1988.

Lux, M.E., W.C. Brown,"Air Leakage Control," An Air Barrier for the Building Envelope, Proceedings of Building Science Insight '86, National Research Council of Canada, NRCC 29943, p.13, 1989.

McCaa, D.J., E.D. Pentz, J. Carre, L.J. Infante, "Experiences in Identification of Thermal Bridging and Elimination of the Thermal Short," Thermal Insulation: Materials and Systems, ASTM STP 922, F.J. Powell and S.L. Matthews, Eds., American Society for Testing and Materials, p.310, 1987.

Miller, R.G., M. Sherman, "Thermal Performance of Insulated Metal Building Roof Deck Constructions," Thermal Insulation. Materials, and Systems for Eneray Conservation in the '80s, ASTM STP 789, F.A. Govan, D.M. Greason, and J.D. McAllister, Eds., American Society for Testing and Materials, p.384, 1982.

Miller, R.G., J.A. Berry, M. Sherman, "Thermal Performance of Metal Furred/Foam Board Insulated Wall Systems," Thermal Insulation: Materials and Systems, ASTM STP 922, F.J. Powell and S.L. MatthewS, Eds., American Society for Testing and Materials, p.720, 1987. 
Misselhorn, D.J., "Some Problems with Insulation Over Suspended Ceilings," ASHRAE Joumal, p.46, March 1979.

Modera, M.P., M.H. Sherman, "In Situ Measurement of Wall Thermal Performance: Data Interpretation and Apparatus Design Recommendations," Thermal Insulation: Materials and Systems, ASTM STP \$22, F.J. Powell and S.L. Matthews, Eds., American Society for Testing and Materials, p.91, 1987.

Musgrave, D.S., "Moisture Transfer in a Metal Building Roof Insulation System," Moisture Miaration in Buildings, ASTM STP 779, M. Lieff and H.R. Trechsel, Eds., American Society for Testing and Materials, p.54, 1982.

NRCA, The NRCA Boofing and Waterproofing Manual, 3rd Edition, National Roofing Contractors Association, Rosemont, Illinois, 1989.

Patenaude, A., D. Scott, M. Lux, "Integrating the Window with the Building Envelope," Windew Performance and New Technolegy, NRCC 29348, National Research Council of Canada, p. 47, 1988.

Perreault, J.C., "Application of Design Principles in Practice," Censtruction Details for Air Tiahtness, Record of the DBR Seminar/Workshop, Proceedings No.3, National Research Council of Canada, NRCC 18291, p.7, 1980.

Perreault, J.C., "Service Life of the Building Envelope," Performance of Materials in Use, NRCC 24968 , National Research Council of Canada, p.5, 1986.

Perreault, J.C.,"Air Barrier Systems: Construction Applications," An Air Barrier for the Building Envelope, Proceedings of Building Science Insight '86, National Research Council of Canada, NRCC 29943, p.20, 1989.

Persily, A.K., R.A. Grot, "Ventilation Measurements in Large Office Buildings," ASHRAE Transactions, 91(2A), p.488, 1985.

Persily, A.K., R.A. Grot, "Pressurization Testing of Federal Buildings," Measured Air Leakage of Buildings, ASTM STP 904, H.R. Trechsel and P.L. Lagus, Eds., American Society for Testing and Materials, p.184, 1986a.

Persily, A.K., R.A. Grot, "The Airtightness of Office-Building Envelopes," ASHRAE/DOE/BTECC Thermal Performance of the Exterior Envelopes of Buildings III, American Society of Heating, Refrigerating and AirConditioning Engineers, Inc., ASHRAE SP 49, p.125, $1986 \mathrm{~b}$.

Persily, A.K., L.N. Norford, "Simultaneous Measurements of Infiltration and Intake in an Office Building," ASHRAE Transactions, 93(2), p.42, 1987.

Quirouette, R.L., "Metal Stud Walls," Construction Details for Air Tiahtness, Record of the DBR Seminar/Workshop, Proceedings No.3, National Research Council of Canada, NRCC 18291, p.21, 1980.

Quirouette, R.L., "Glass and Metal Curtain Wall Systems," Exterior Walls: Understandina the Problems, NRCC 21203, National Research Council of Canada, p.27, 1983.

Quirouette, R.L.,"The Air Barrier Defined," An Air Barrier for the Building Envelope, Proceedings of Building Science Insight '86, National Research Council of Canada, NRCC 29943, p.1, 1989.

Richtmyer, T.E., W.B. May, C.M. Hunt, J.E. Hill, "Thermal Performance of the Norris Cotton Federal Building in Manchester, New Hampshire," ASHRAE/DOE-ORNL Conference Thermal Pentermance of the Exterior Envelopes of Buildings, American Society of Heating, Refrigerating and Air-Conditioning Engineers, Inc., ASHRAE SP 28, p.781, 1981.

Riedel, R.G., "Roof/Wall Seals in Buildings," Moisture Migration in Buildings, ASTM STP 779, M. Lieff and H.R. Trechsel, Eds., American Society for Testing and Materials, p.83, 1982. 
Rousseau, M.Z., R.L. Quirouette, "Precast Panel Wall Assemblies," Exterior Walls: Understanding the Problems, NRCC 21203, National Research Council of Canada, p.43, 1983.

Rousseau, M.Z., "Windows: Overview of Issues," Window Penformance and New Technolooy, NRCC 29348, National Research Council of Canada, p. 1, 1988.

Schuyler, G.D., K.R. Solvason, "Effectiveness of Wall Insulation," Thermal Insulation. Materials, and Systems for Energy Conservation in the '80s, ASTM STP 789, F.A. Govan, D.M. Greason, and J.D. McAllister, Eds., American Society for Testing and Materials, p.542, 1982.

Shaw, C.Y., D.M. Sander, G.T. Tamura, "Air Leakage Measurements of the Exterior Walls of Tall Buildings," ASHRAE Transactions, 79(2), p.173, 1973.

Shu, L.S., R.D. Orlandi, "Laboratory Measurements of Thermal Transmittance of Several Masonry Wall Systems," ASHRAE Transactions, 92(2B), p.567, 1986.

Snyder, M.K., "Heat-Transmission Coefficients for Metal Building Systems," ASHRAE Transactions, 92(2B), p.577, 1986.

Steven Winter Associates, "Catalog of Thermal Bridges in Commercial and Multi-Family Residential Construction," ORNL/Sub/88-SA407/1, Oak Ridge National Laboratory, 1989.

Strzepek, W.R., "Thermal Resistances of Various Concrete Masonry Wall Constructions Incorporating Rigid Plastic Foam Insulation," Thermal insulation: Materials and Systems, ASTM STP 922, F.J. Powell and S.L. Matthews, Eds., American Society for Testing and Materials, p.582, 1987.

Tamura, G.T., C.Y. Shaw, "Air Leakage Data for the Design of Elevator and Stair Shaft Pressurization Systems," ASHRAE Transactions, 82(2), p.179, 1976a.

Tamura, G.T., C.Y. Shaw, "Studies on Exterior Wall Air Tightness and Air Infiltration of Tall Buildings," ASHRAE Transactions, 82(1), p.122, 1976b.

Tamura, G.T., A.G. Wilson, "Pressure Differences Caused by Wind on Two Tall Buildings," ASHRAE Transactions, 74.(2), p.170, 1968.

Tamura, G.T., A.G. Wilson, "Building Pressure Caused by Chimney Action and Mechanical Ventilation," ASHRAE Transactions, 73(2), p.2.1, 1967 a.

Tamura, G.T., A.G. Wilson, "Pressure Differences Caused by Chimney Effect in Three High Buildings," ASHRAE Transactions, 73(2), p.1.1, 1967b.

Tamura, G.T., A.G. Wilson, "Pressure Differences for a Nine-Story Building as a Result of Chimney Effect and Ventilation System Operation," ASHRAE Transactions, 72(1), p.180, 1966.

Tobiasson, W., C. Korhonen, B. Coutermarsh, A. Greatorex, "Can Wet Roof Insulation Be Dried Out?," Thermal Insulation. Materials and Systems for Enerov Conservation in the ' 80 s, ASTM STP 789, F.A. Govan, D.M. Greason, and J.D. McAllister, Eds., American Society for Testing and Materials, p.626, 1982.

Tobiasson, W., "Condensation Control in Low-Slope Roofs," Moisture Control in Buildinas Conference Proceedings, Building Thermal Envelope Coordinating Council, p.47, 1985.

Tobiasson, W., A. Greatorex, D. VanPelt, "Wetting of Polystyrene and Urethane Roof Insulations in the Laboratory and on a Protected Membrane Roof," Thermal Insulation: Materials and Systems, ASTM STP 922, F.J. Powell and S.L. Matthews, Eds., American Society for Testing and Materials, p.421, 1987.

Tobiasson, W., "Vents and Vapor Retarders for Roofs," Symposium on Air Infiltration. Ventilation and Moisture Transfer, Building Thermal Envelope Coordinating Council, p.187, 1988.

Tobiasson, W., "Vapor Retarders for Membrane Roofing Systems," Proceedings of the 9th Conference on Roofing Technology, Gaithersburg, MD, p.31, 1989. 
Trethowen, H.A., "Thermal Insulation and Contact Resistance in Metal-Framed Panels," ASHRAE Iransactions, 94(2), p.1802, 1988.

Trehowen, H.A., "R-Values That Are Made-to-Measure," ASHBAE Transactions, 91(2B), p.36, 1985.

Trethowen, H.A., "Thermal Insulation and Contact Resistance in Metal-Framed Panels," ASHRAE Iransactions, 94(2), p.1802, 1988.

Turenne, R.G., "WallRoof Junctions and Soffits," Constnuction Details for Air Tiahtness, Record of the DBR Seminar/Workshop, Proceedings No.3, National Research Council of Canada, NRCC 18291, p.25, 1980.

Tye, R.P., A.O. Desjarlis, J.G. Bourne, S.C. Spinney, "The Effective Thermal Performance of an Insulated Standard Stud Wall Containing Air Gaps," ASHBAE/DOE-OBNL Conference Thermal Penformance of the Exterior Envelopes of Buildings, American Society of Heating, Refrigerating and Air-Conditioning Engineers, Inc., ASHRAE SP 28, p.965, 1981.

Tye, R.P., J.P. Silvers, D.L. Brownell, S.E. Smith, "New Materials and Concepts to Reduce Energy Losses Through Structural Thermal Bridges," ASHBAE/DOE/BTECC Thermal Performance of the Exterior Envelopes of Buildings 111 , American Society of Heating, Refrigerating and Air-Conditioning Engineers, Inc., ASHRAE SP 49, p.739, 1986.

Van Geem, M.G., "Thermal Transmittance of Concrete Block Walls with Core Insulation," ASHBAE Iransactions, 91(2B), p.17, 1985.

Van Geem, M.G., "Summary of Calibrated Hot Box Test Results for Twenty-One Wall Assemblies," ASHRAE Transactions, 92(2B), p.584, 1986.

Van Geem, M.G., "Heat Transfer Characteristics of a Masonry Cavity Wall," Ihermal Insulation: Materials and Systems, ASTM STP 922, F.J. Powell and S.L. Matthews, Eds., American Society for Testing and Materials, p.318, 1987.

Van Geem, M.G., "Effects of Ties on Heat Transfer through Insulated Concrete Sandwich Panel Walls," ASHRAE/DOE/BTECC/CIBSE Conference Thermal Performance of the Exterior Envelopes of Buildinos IV. American Society of Heating, Refrigerating and Air-Conditioning Engineers, Inc., p.206, 1989.

Waite, H.J., M.K. Snyder, "Thermal Spacers Improve Roof Insulation Performance of Metal Buildings," ASHRAE/DOE-ORNL Conference Thermal Pentormance of the Exterior Envelopes of Buildings,

American Society of Heating, Refrigerating and Air-Conditioning Engineers, Inc., ASHRAE SP 28, p.631, 1981.

Wallace, J.R., "Case Studies of Air-Leakage Effects in the Operations of High-Rise Buildings," ASHRAE/DOE/BTECC Thermal Performance of the Exterior Envelopes of Buildinas III, American Society of Heating, Refrigerating and Air-Conditioning Engineers, Inc., ASHRAE SP 49, p.229, 1986. 


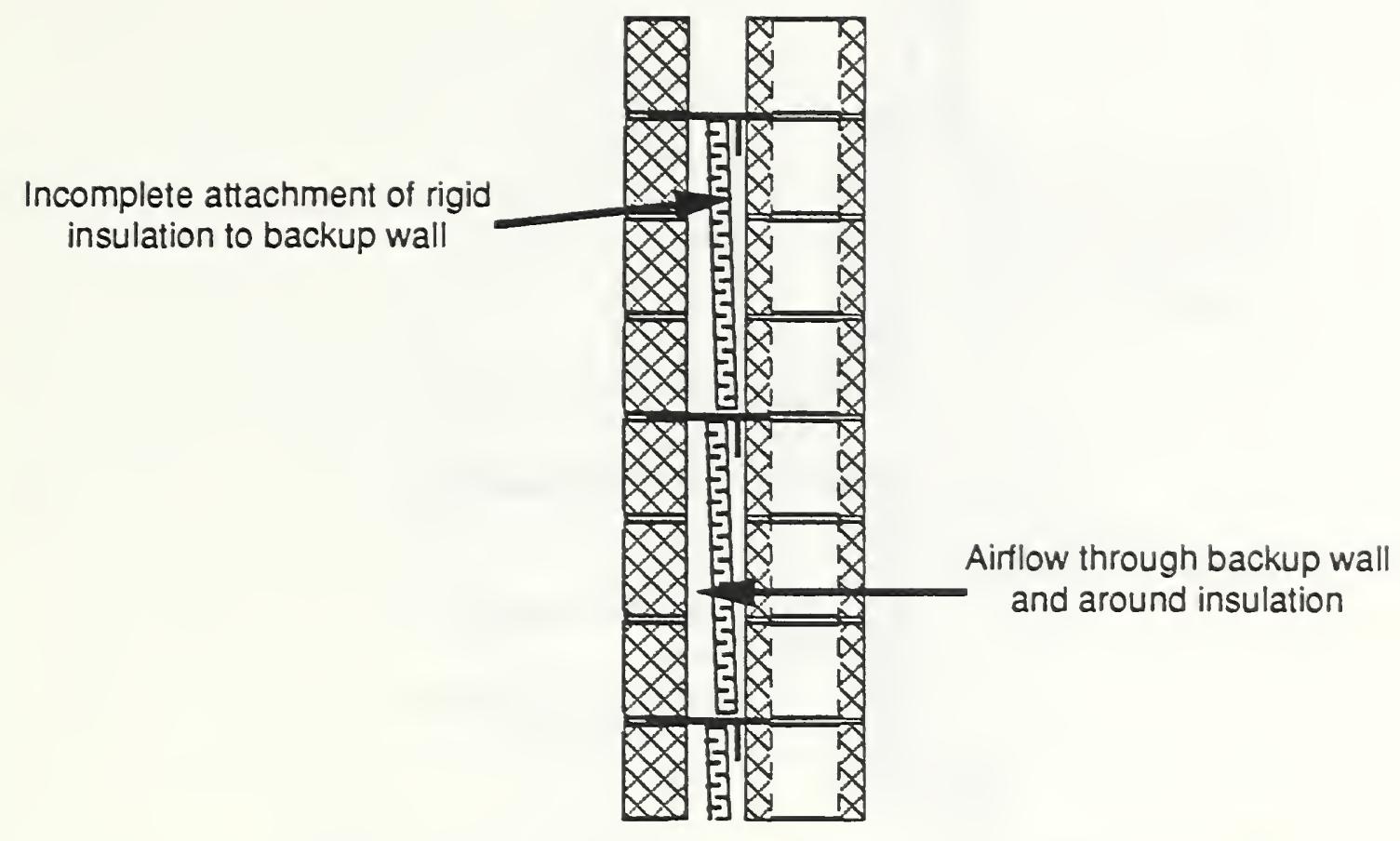

Figure 2.1 Example of Poor Material Attachment (Burn 1983)

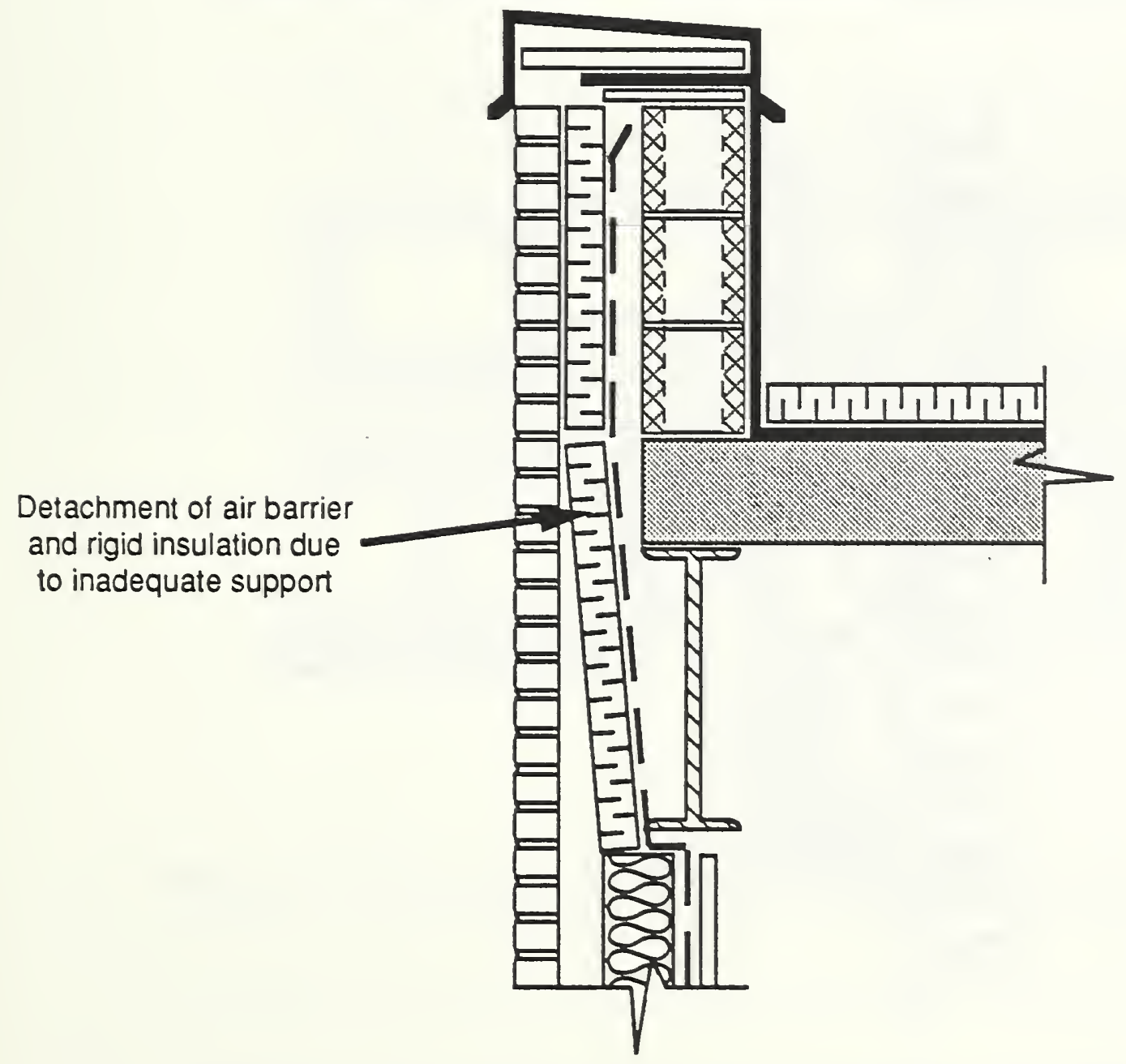

Figure 2.2 Example of Inadequate Material Support (Quirouette 1989) 


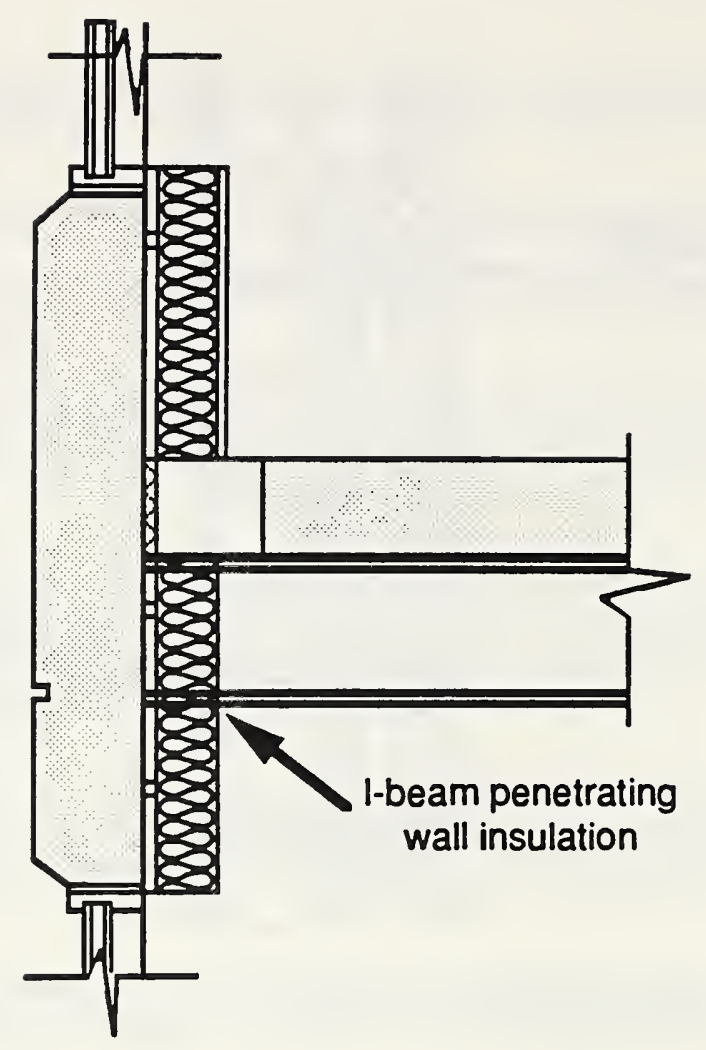

Figure 2.3 I-Beam Supporting Precast Panel (Childs 1988)

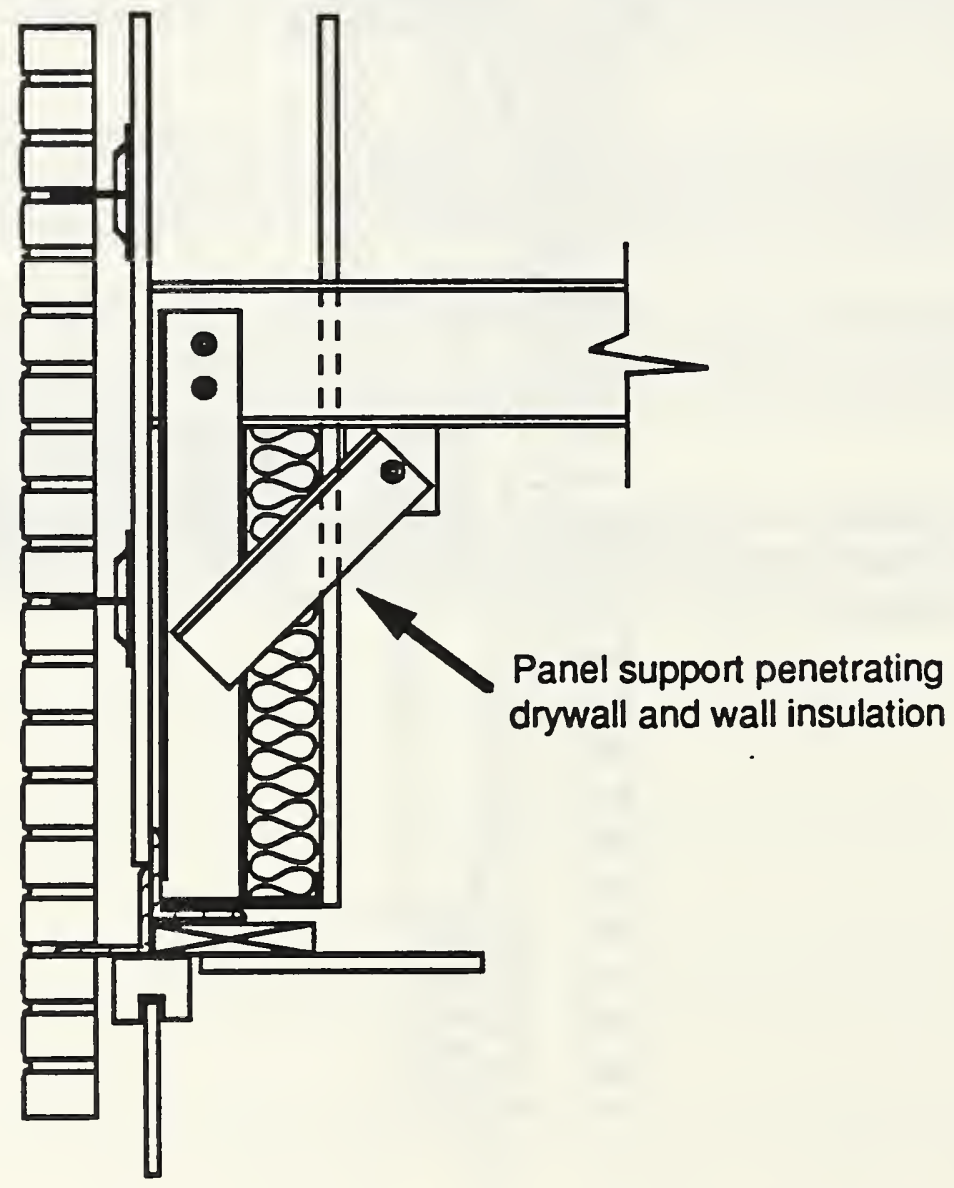

Figure 2.4 Diagonal Kicker Suporting Spandrel (Kudder 1988) 


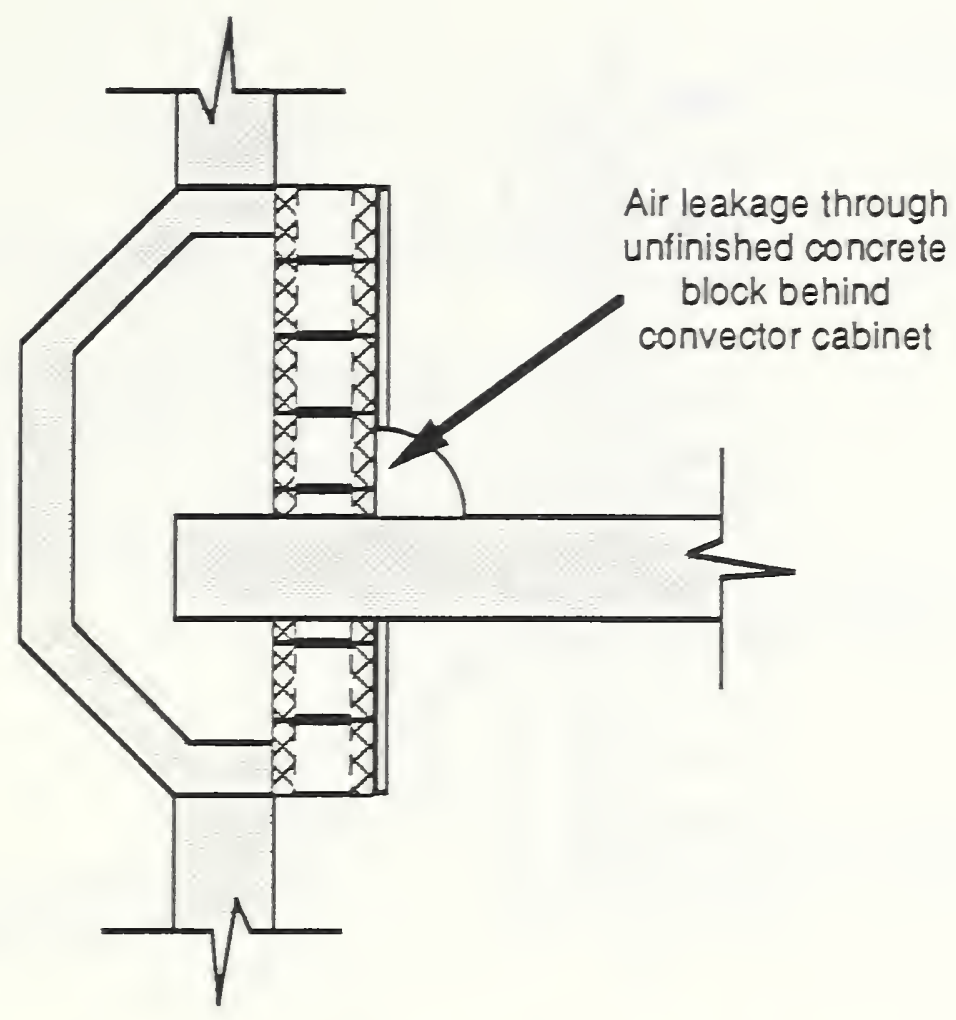

Figure 2.5 Air Leakage through Concrete Blocks (Quirouette 1989)

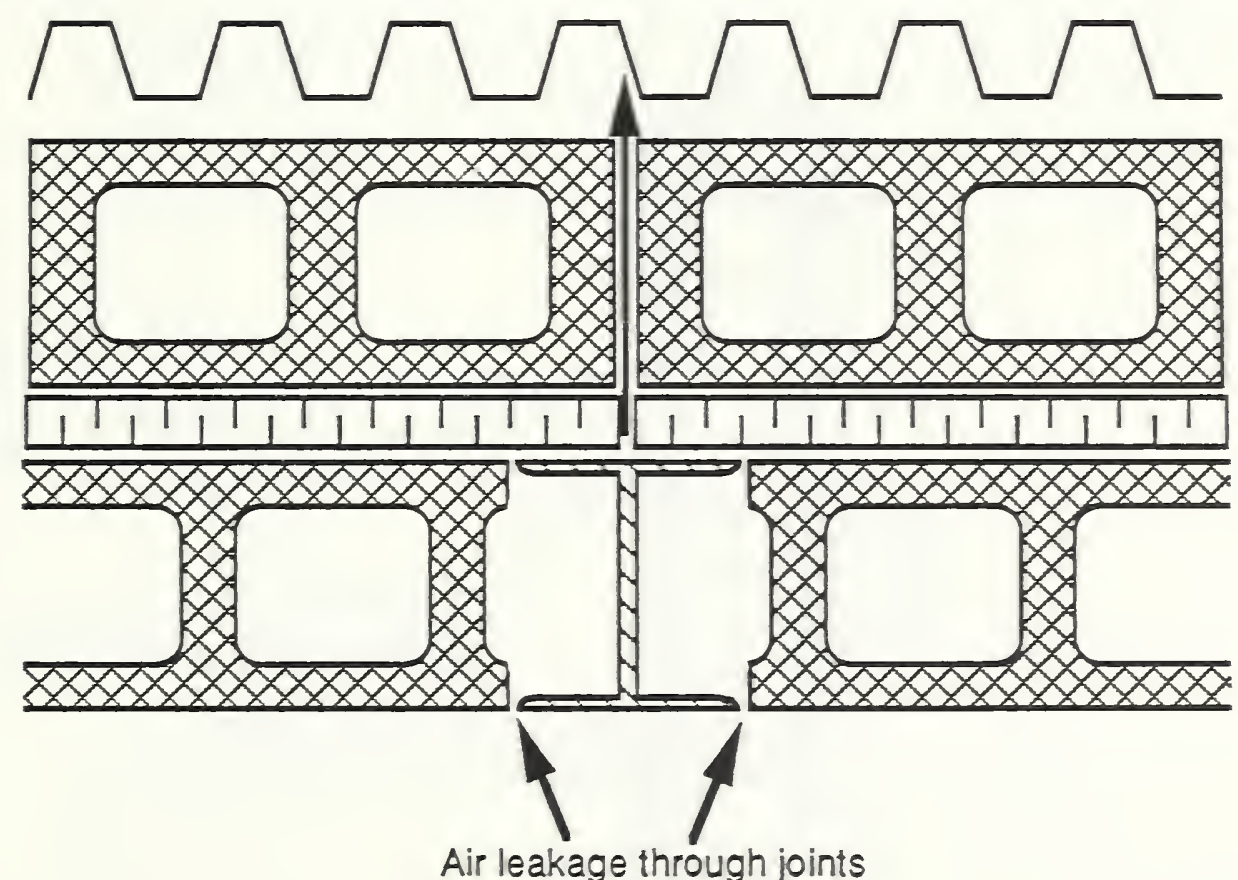

Figure 2.6 Air Leakage at Concrete Block/Column Connection (Burn 1983) 


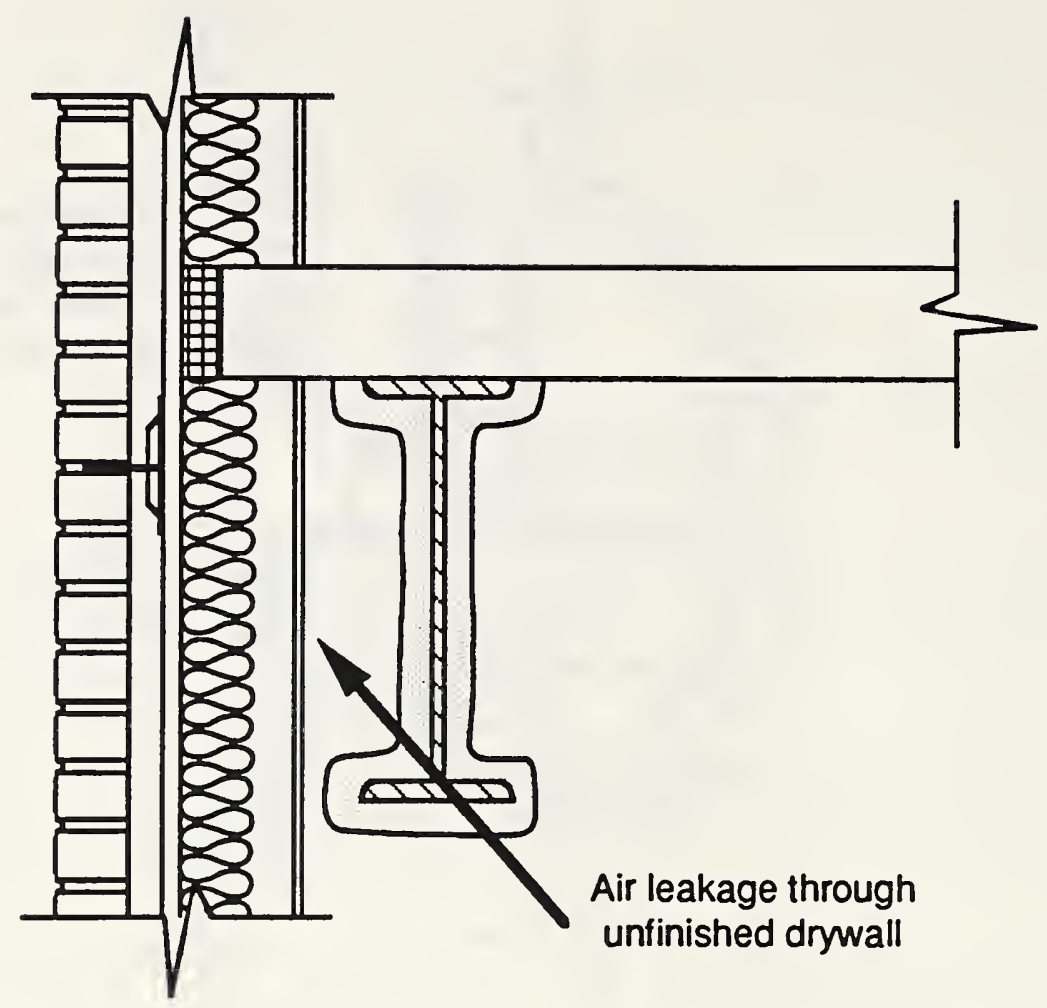

Figure 2.7 Unsealed Drywall due to Inaccessibility (Kudder 1988)

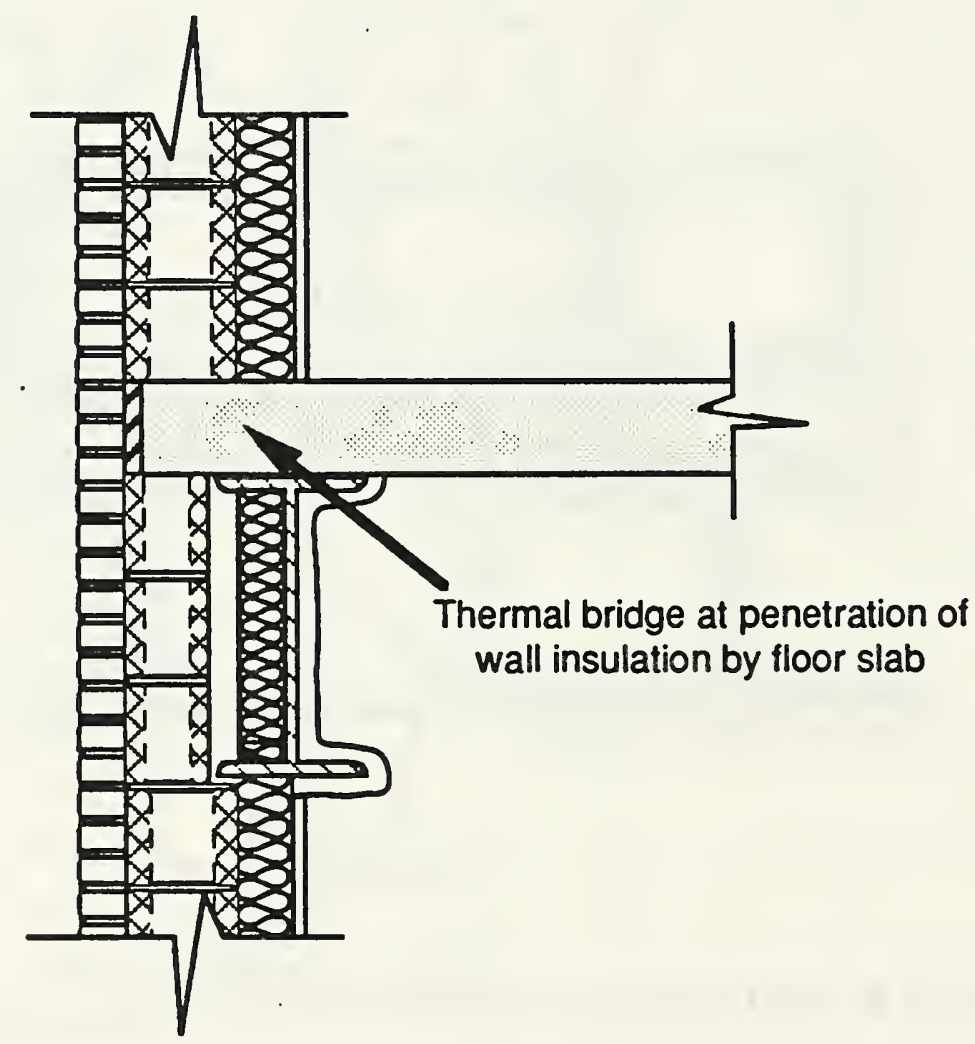

Figure 2.8 Thermal Bridge at Floor-Wall Connection (Grot 1985) 
Thermal bridge at penetration

of wall insulation by floor slab

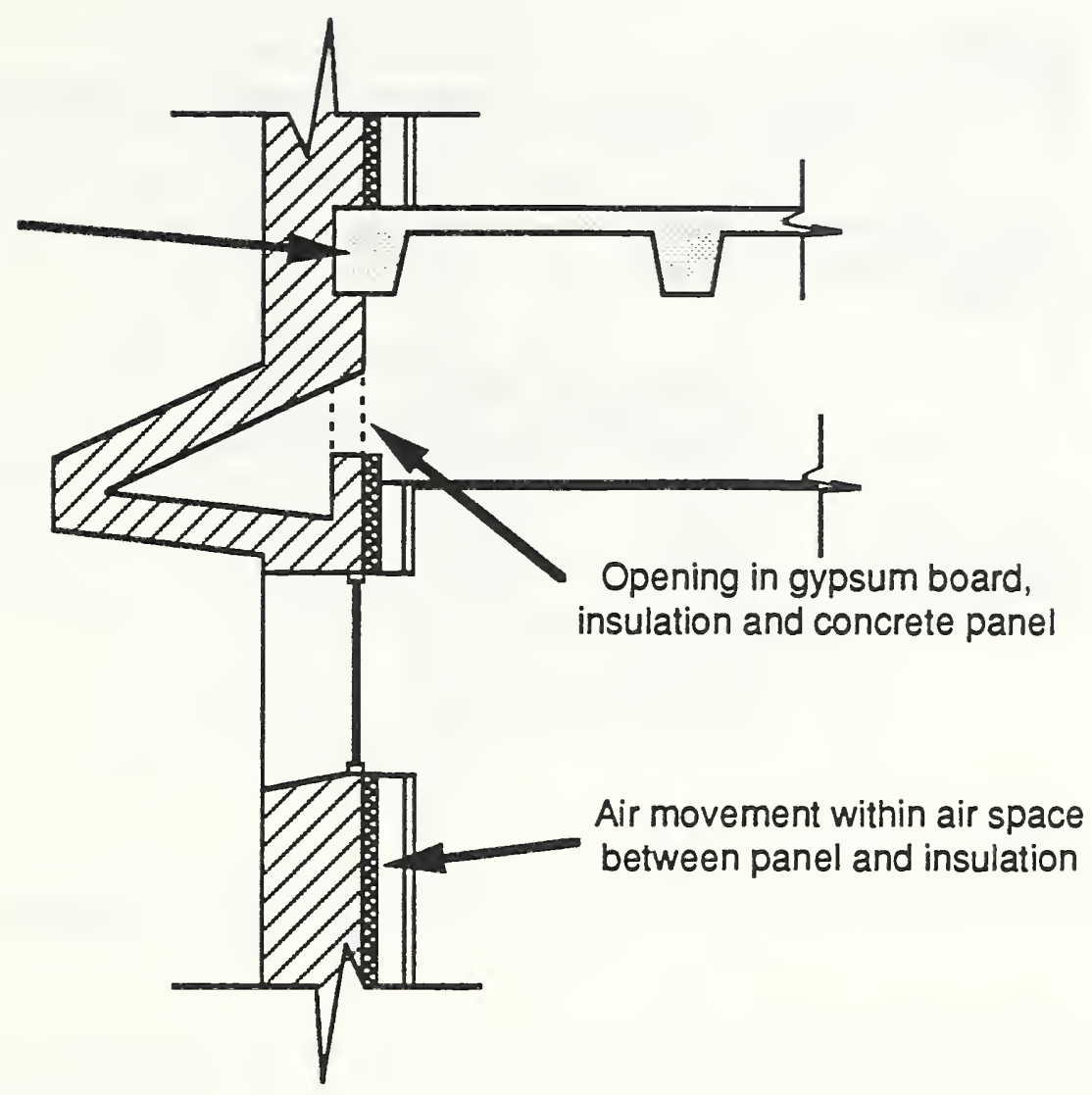

Figure 2.9 Thermal Bridge at Floor-Wall Connection \#2 (Grot 1985)

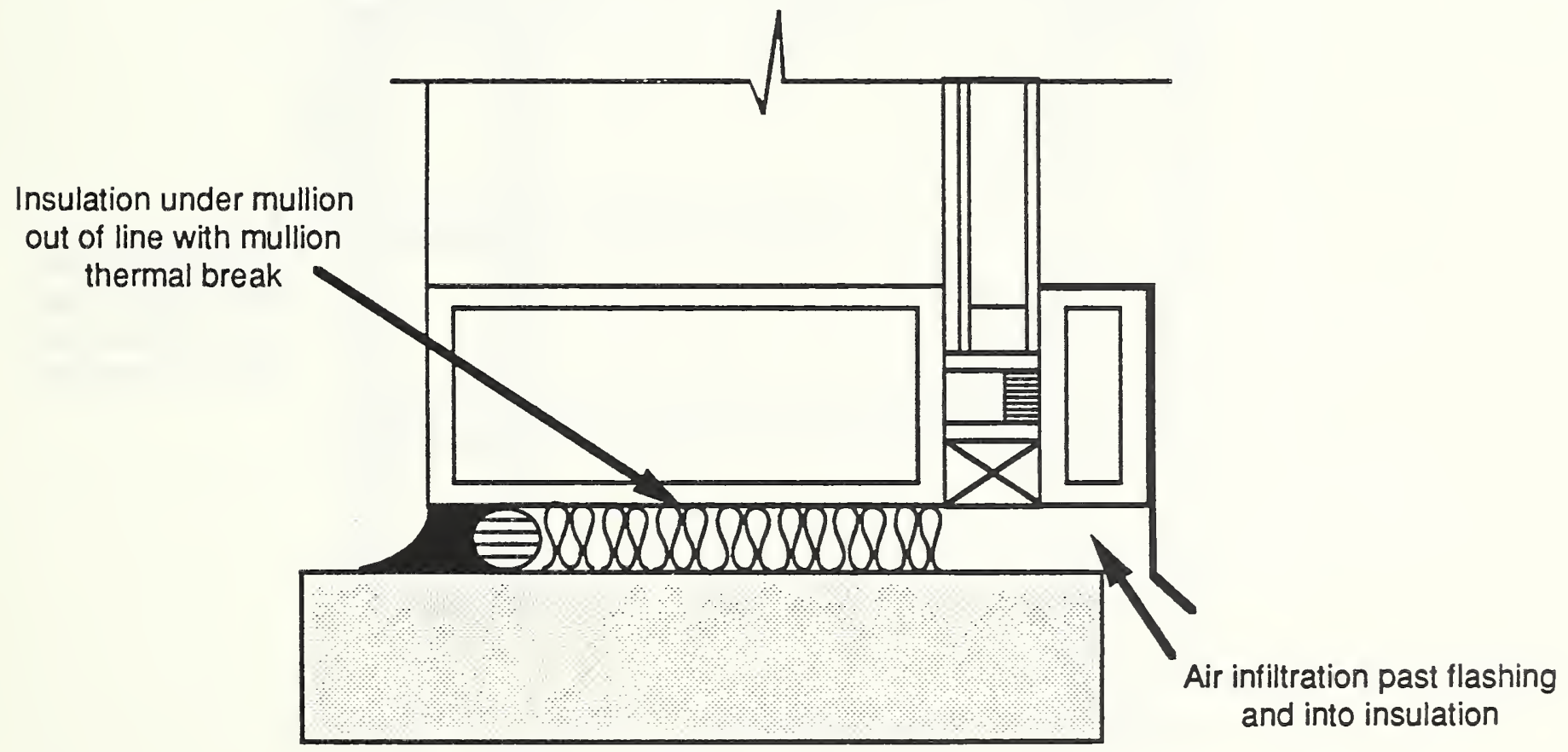

Figure 2.10 Connection of Curtain Wall and Grade (Quriouette 1983) 


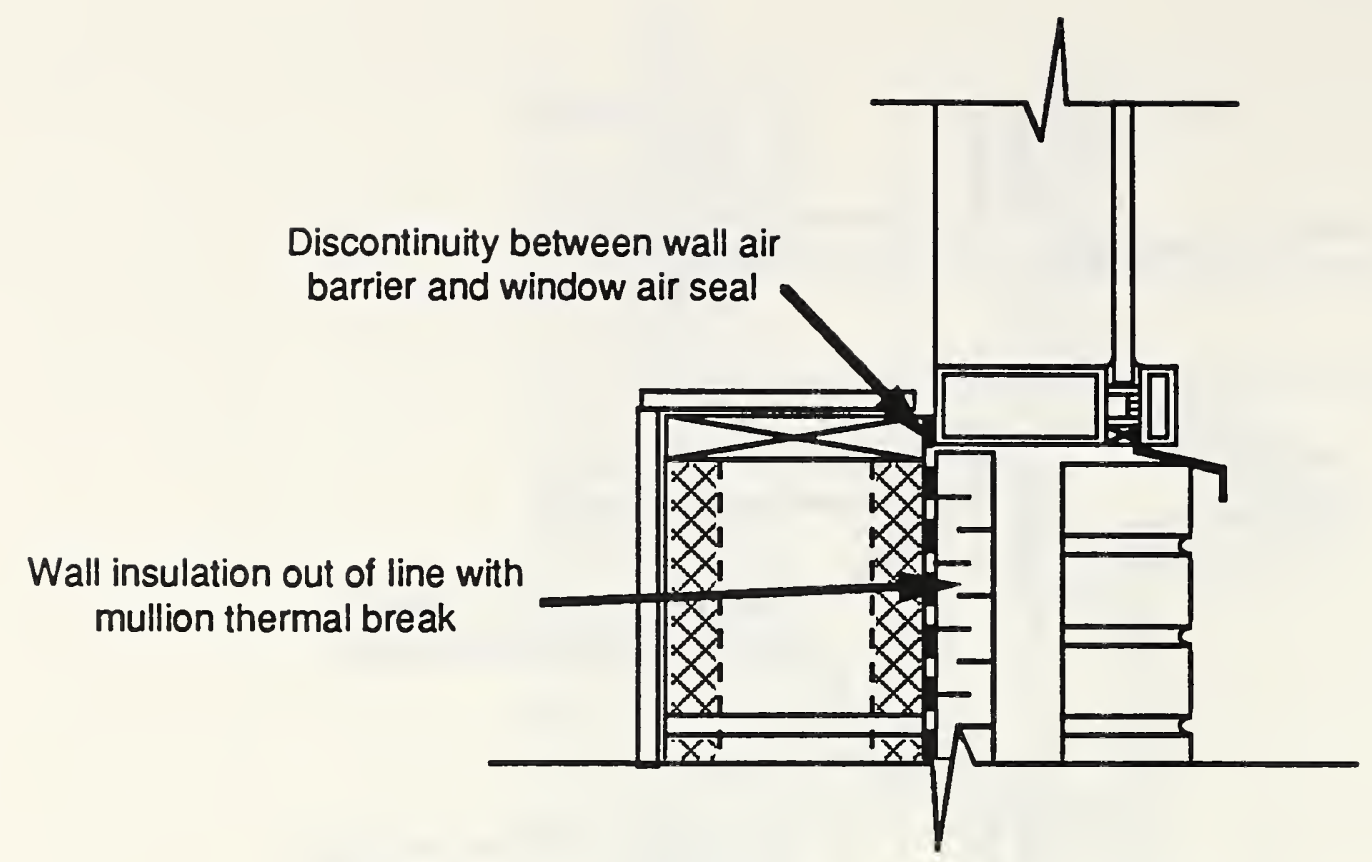

Figure 2.11 Connection of Curtain Wall and Masonry Wall (Quirouette 1983)

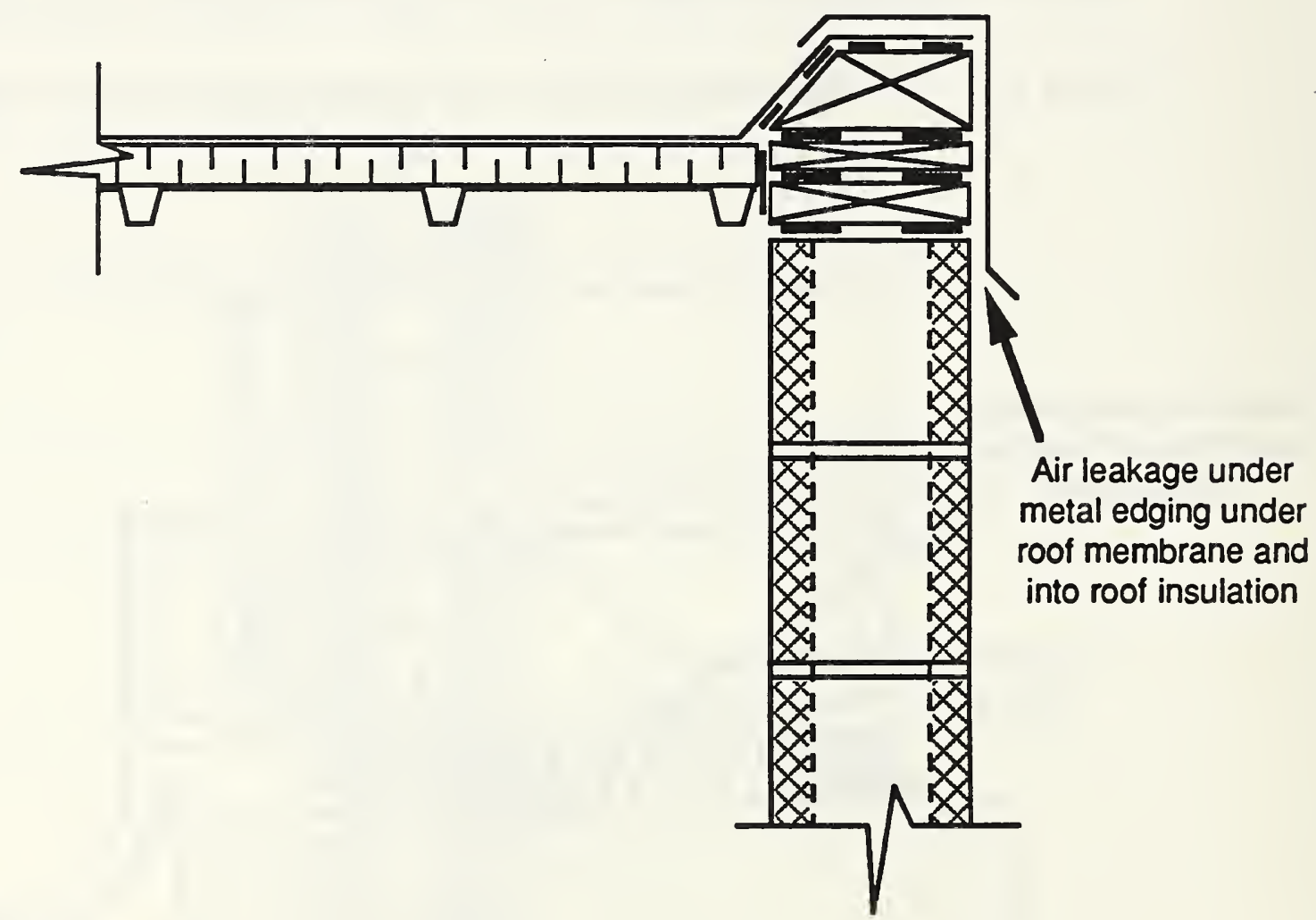

Figure 2.12 Wall-Roof Connection (Riedel 1982) 


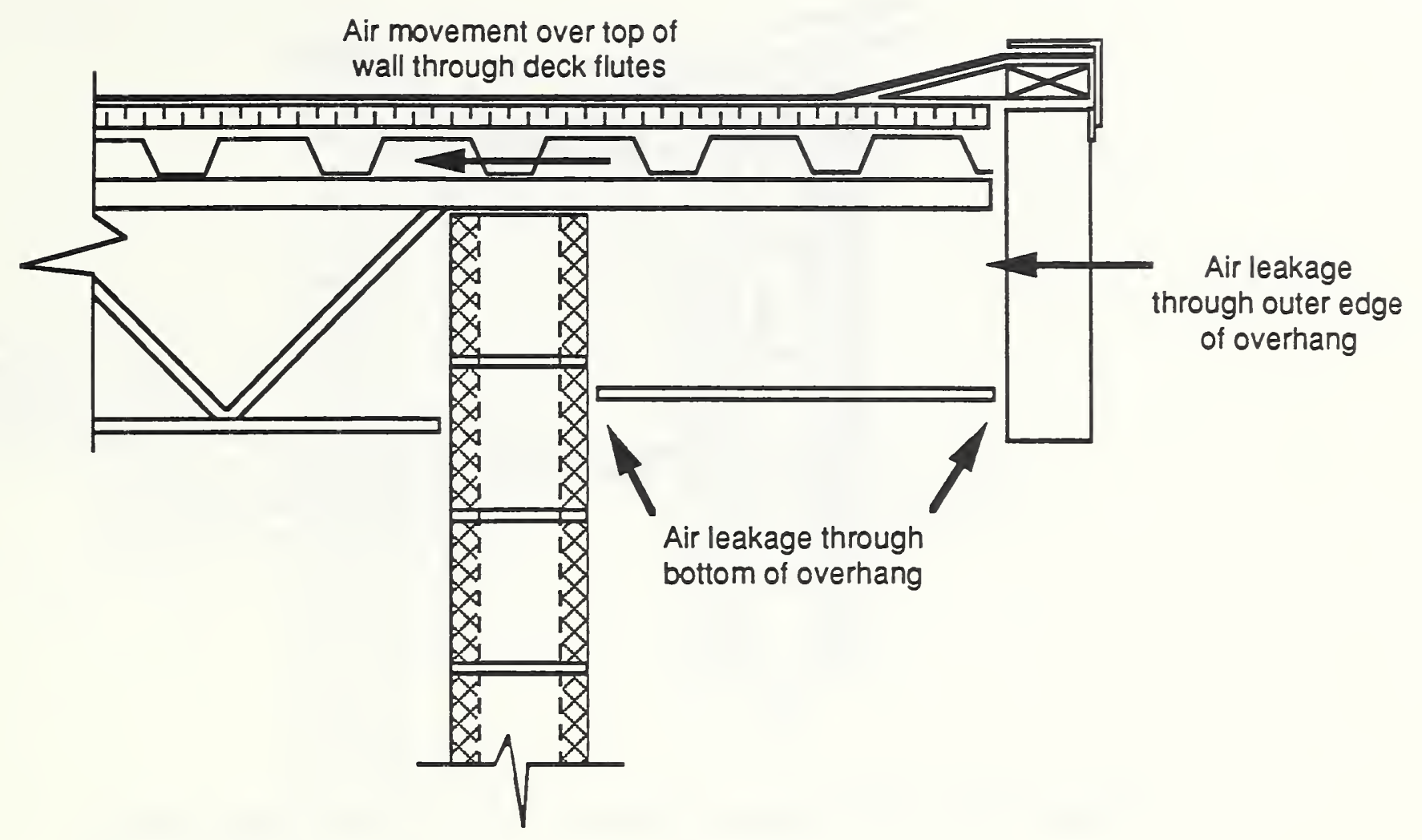

Figure 2.13 Connection of Wall and Roof Overhang (Riedel 1982)

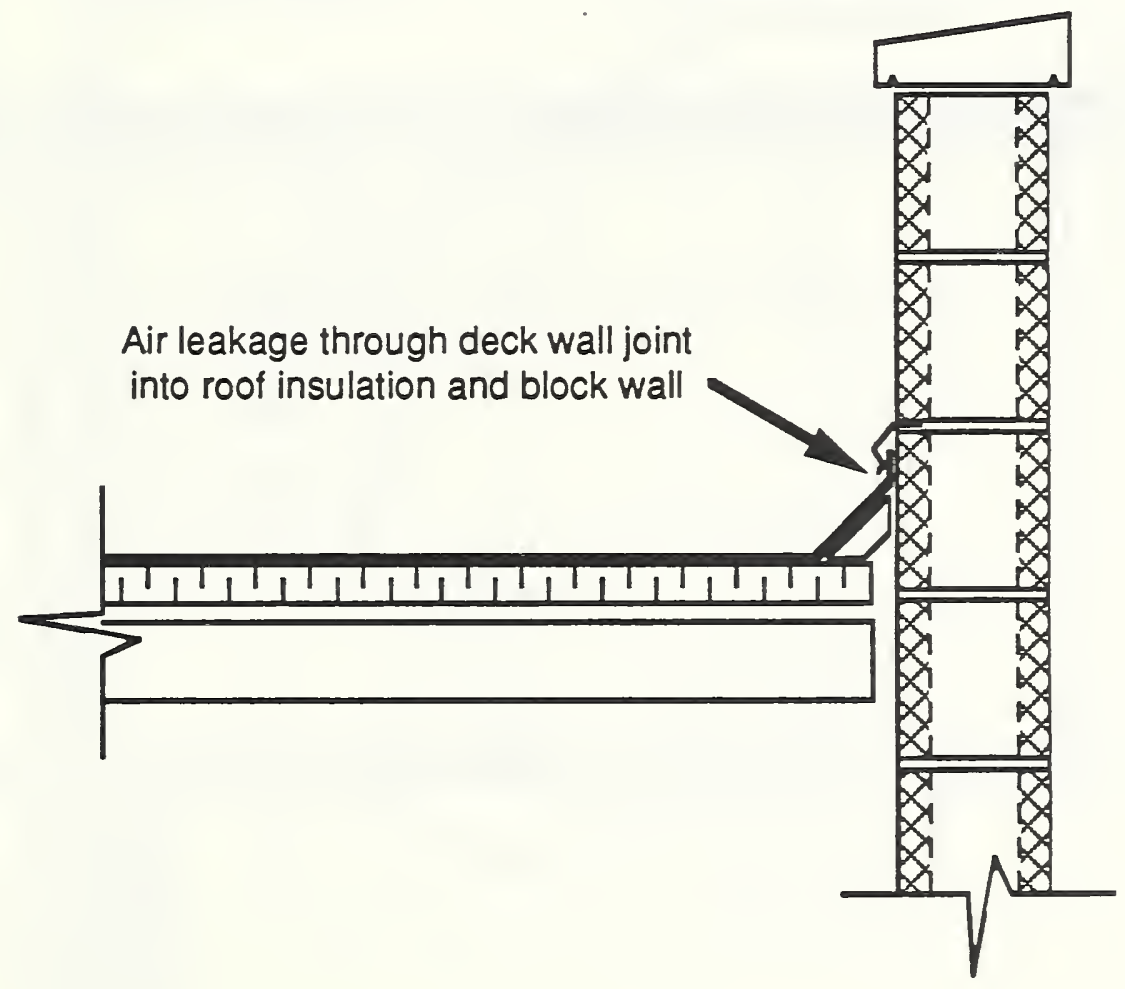

Figure 2.14 Connection of Wall and Parapet (Riedel 1982) 


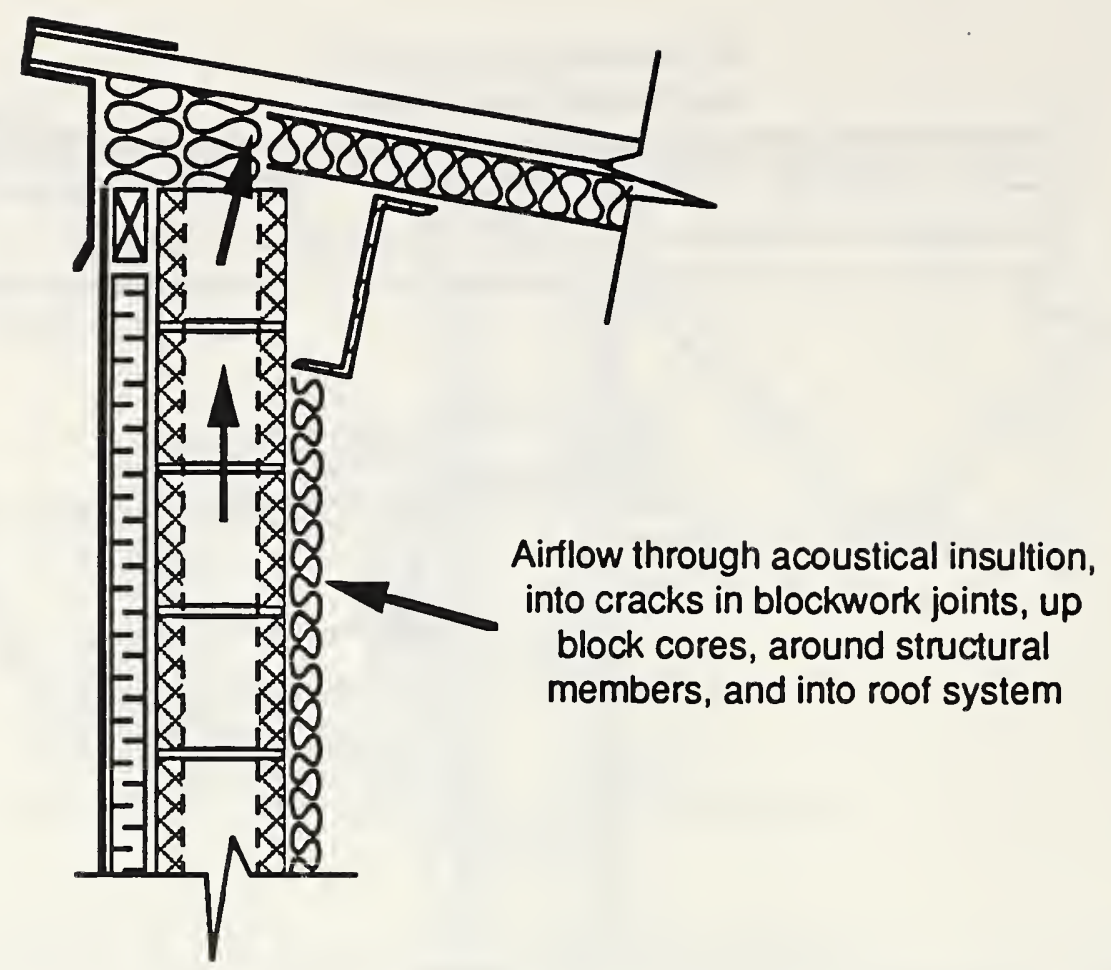

Figure 2.15 Connection of Masonry Wall and Roof (Burn 1983)

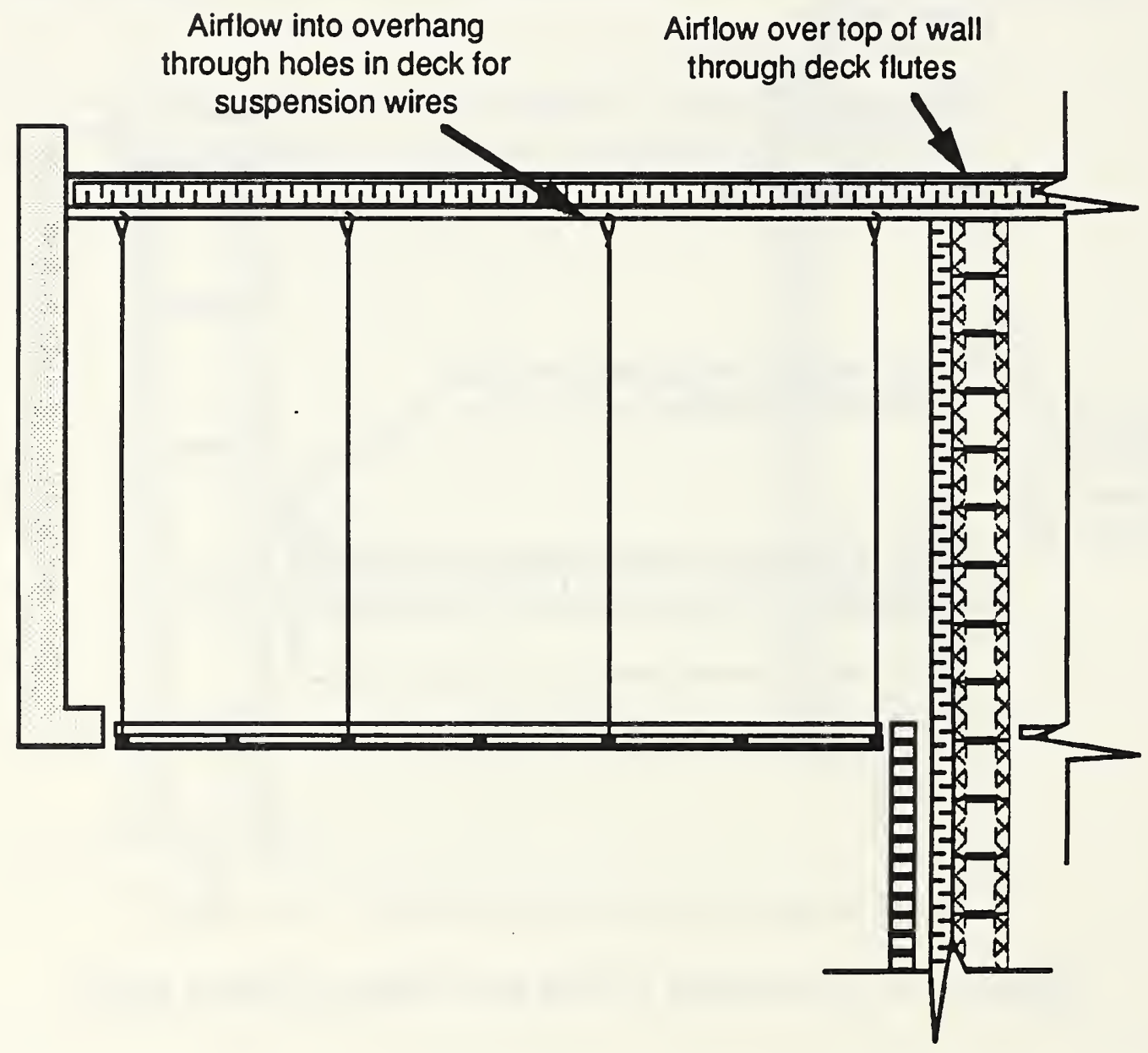

Figure 2.16 Connection of Wall and Soffit (Perreault 1980) 
Unsupported rigid insulation may not remain in place, breaking continuity of insulation layer and air barrier

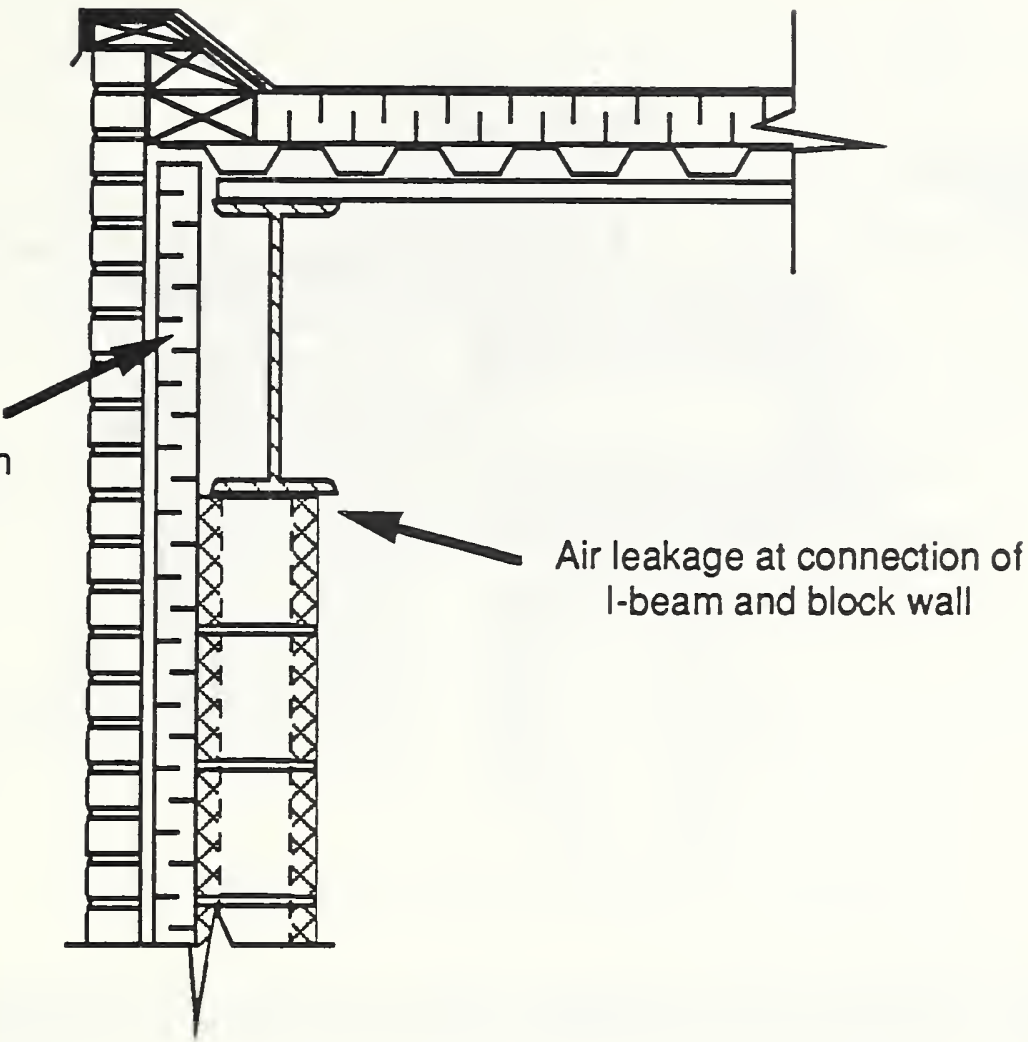

Figure 2.17 Connection of a Wall and Roof (Turenne 1980)

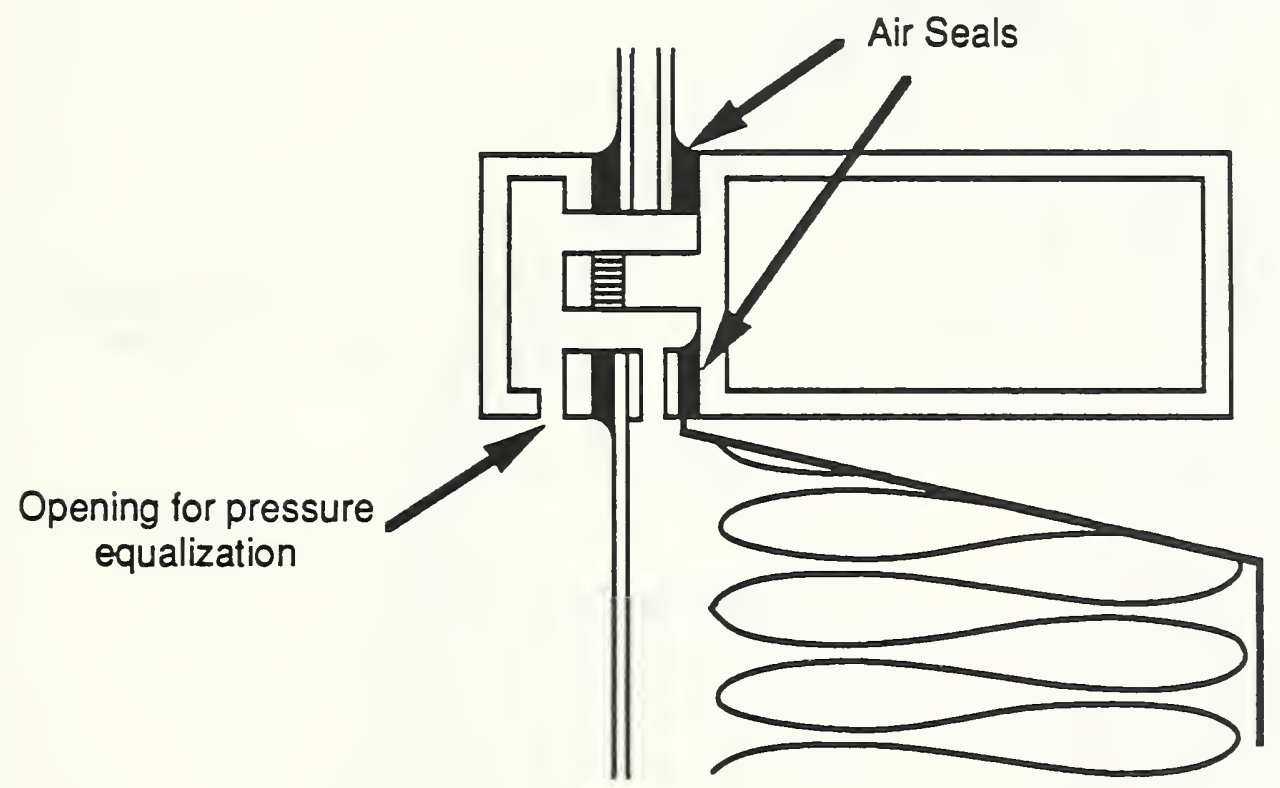

Figure 2.18 Window / Mullion Insulated Spandrel Panel Connection (Quirouette 1983) 


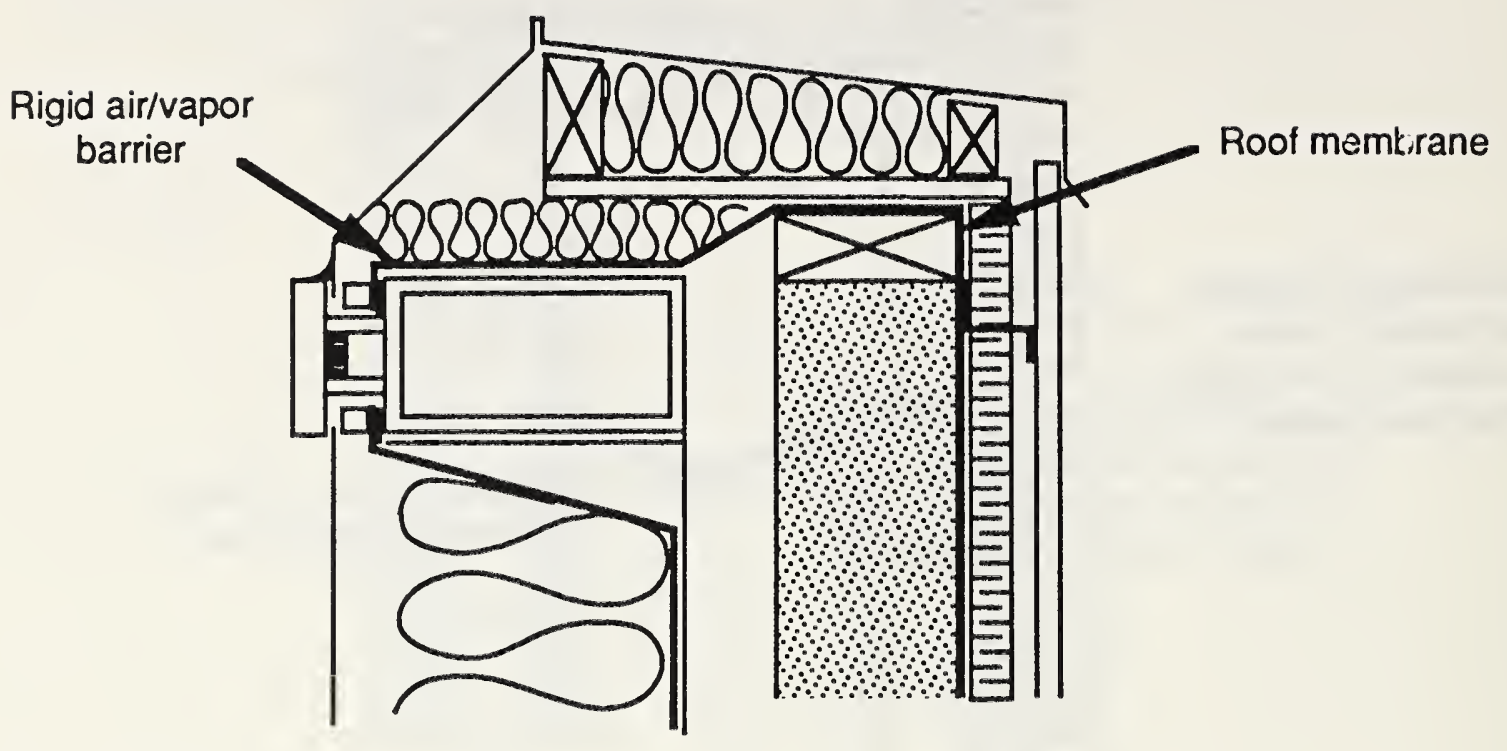

Figure 2.19 Parapet Wall / Curtain Wall Connection (Quirouette 1983)

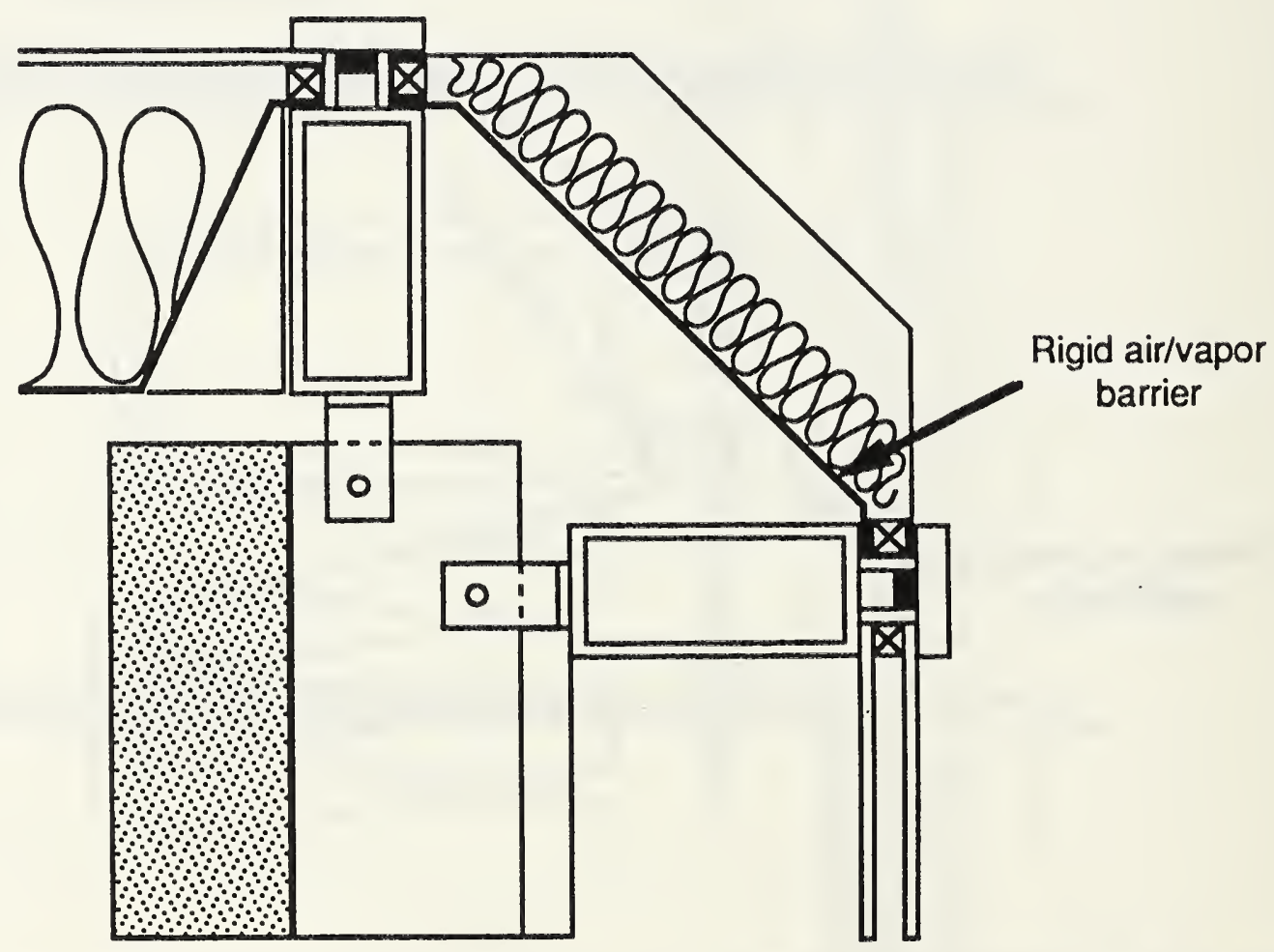

Figure 2.20 Outside Corner of Curtain Wall (Quirouette 1983) 


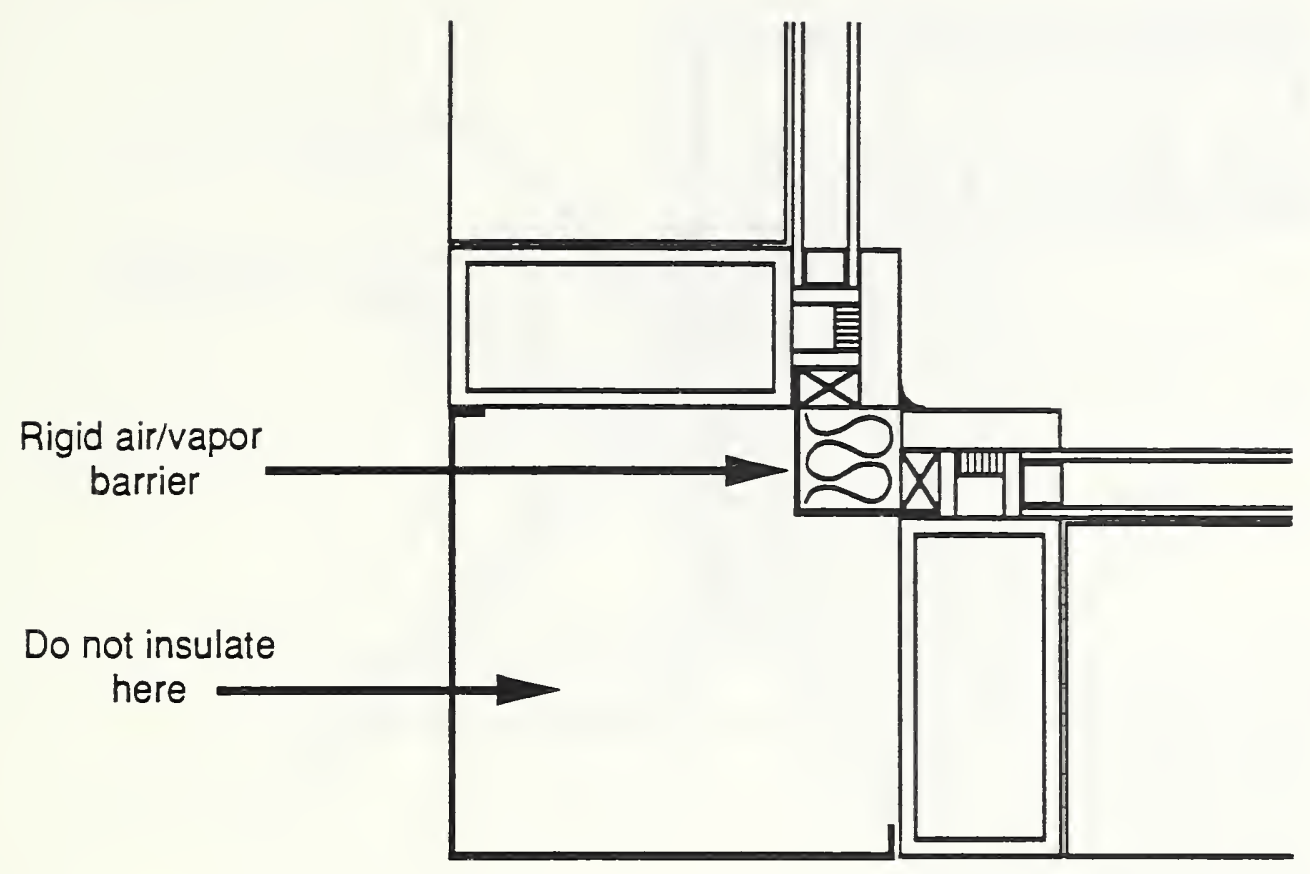

Figure 2.21 Inside Corner of Curtain Wall (Quirouette 1983)

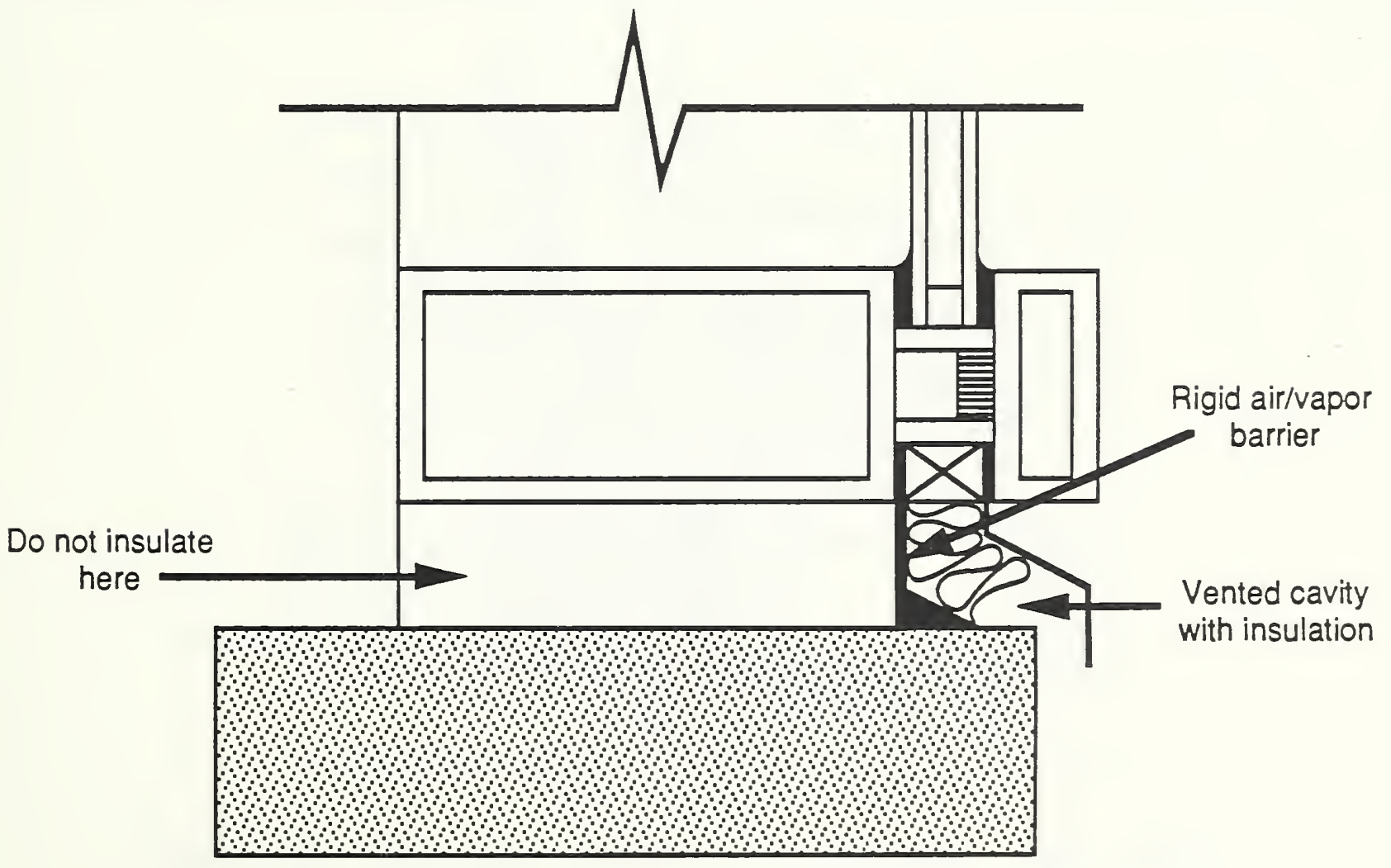

Figure 2.22 Grade Connection at Curtain Wall (Quirouette 1983) 


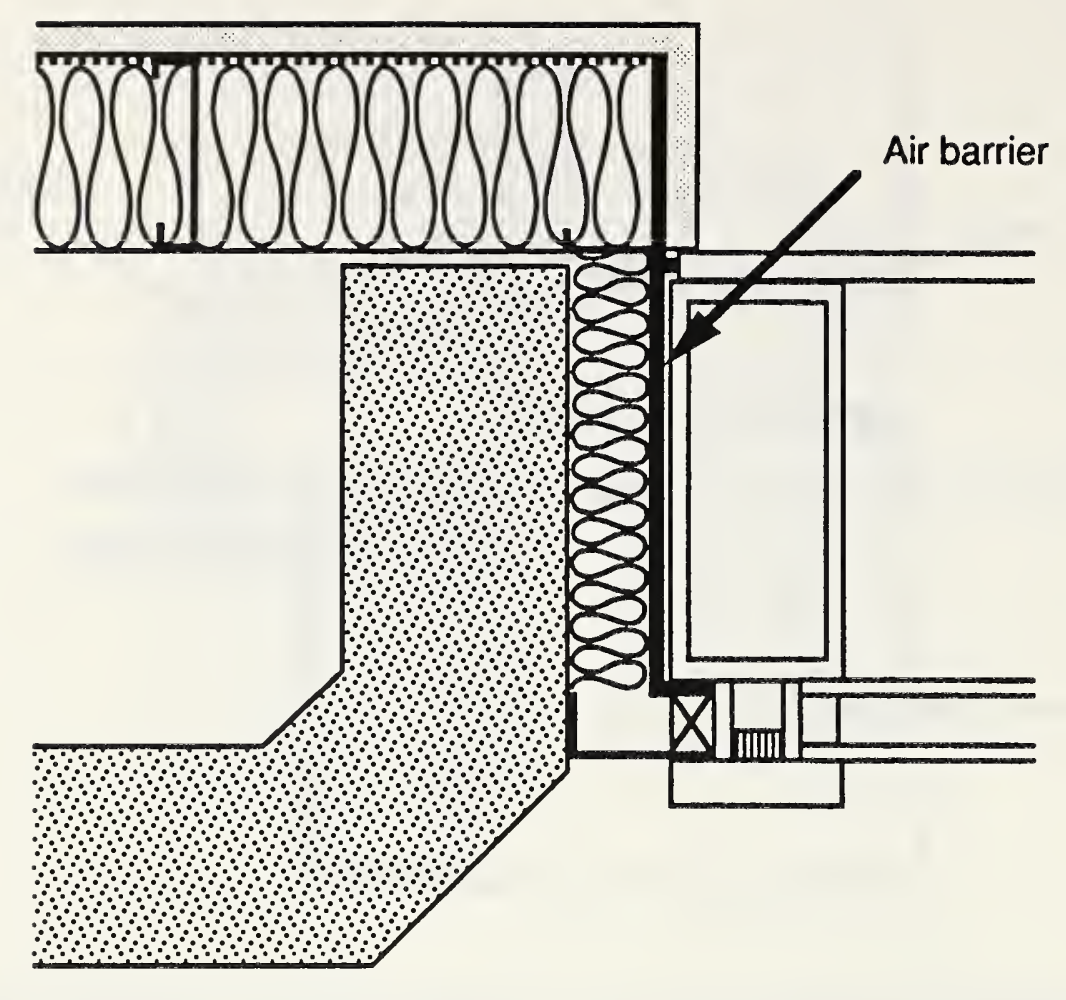

Figure 2.23 Precast Concrete / Curtain Wall Connection (Quirouette 1983)

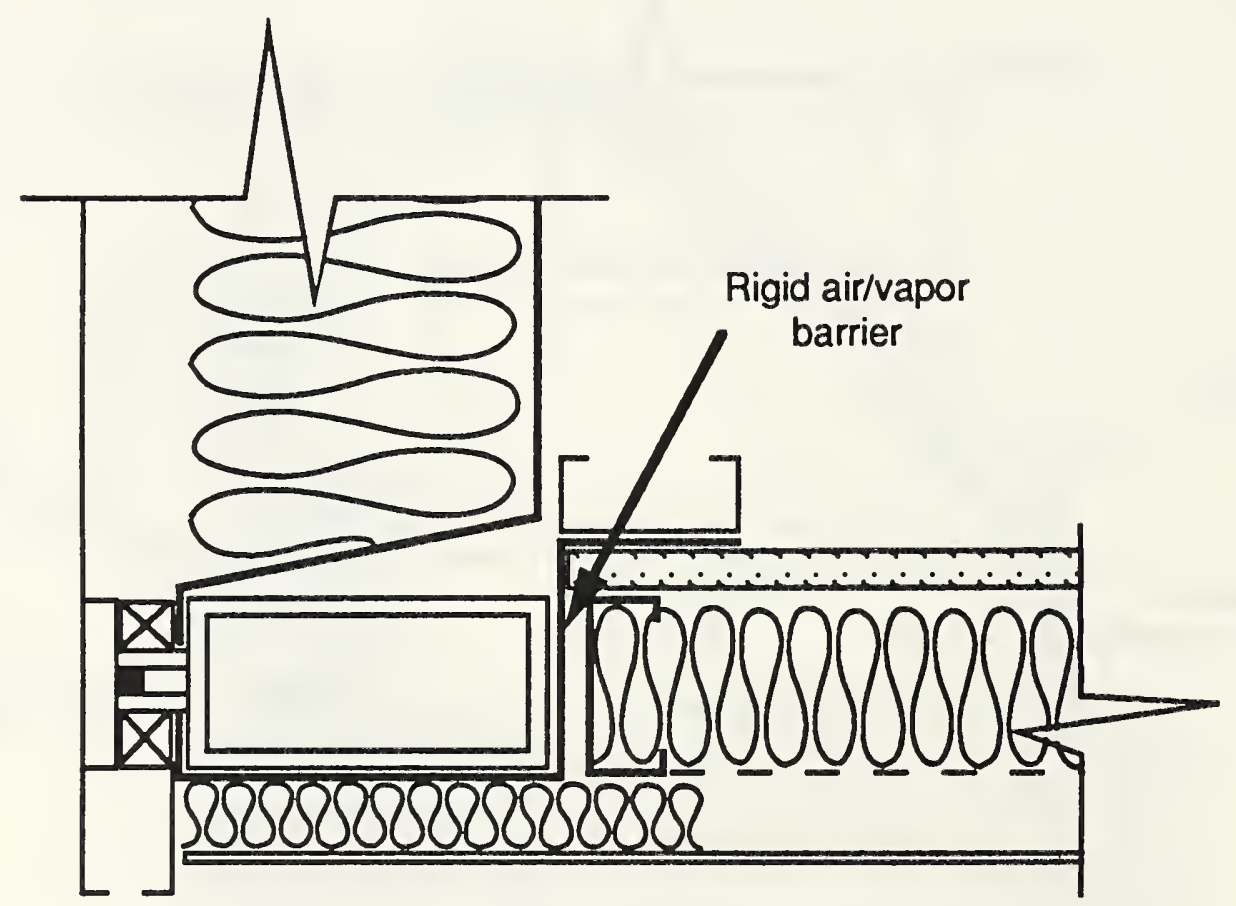

Figure 2.24 Heated Soffit / Curtain Wall Connection (Quirouette 1983) 


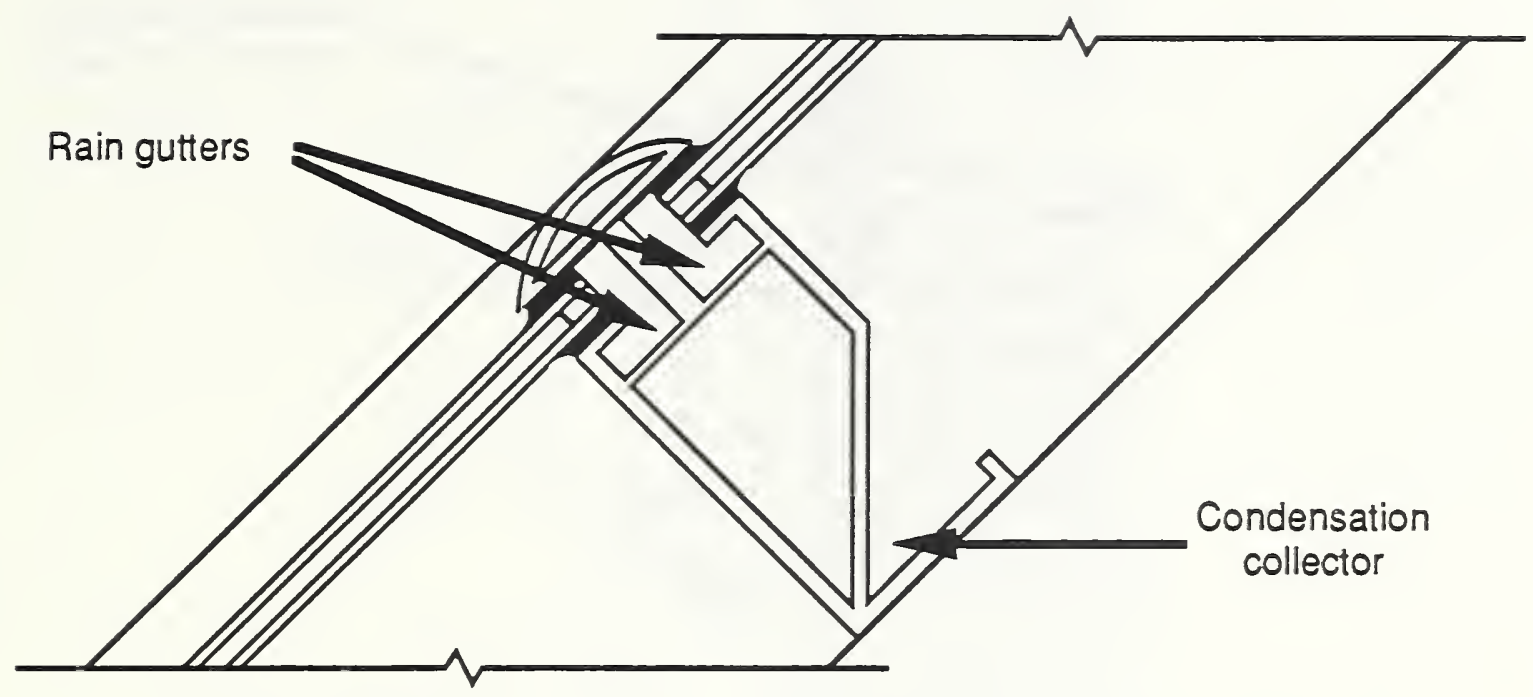

Figure 2.25 Sloped Glass Wall (Quirouette 1983)

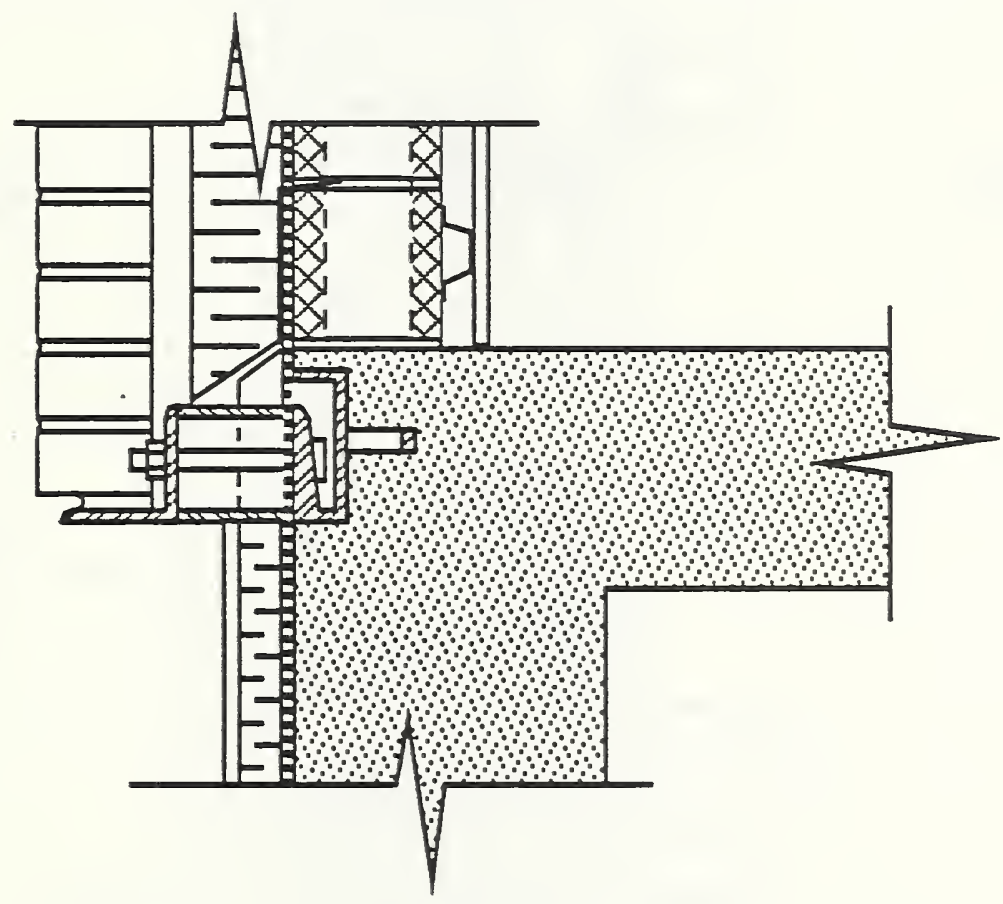

Figure 2.26 Foundation / Masonry Wall Connection (Burn 1980) 


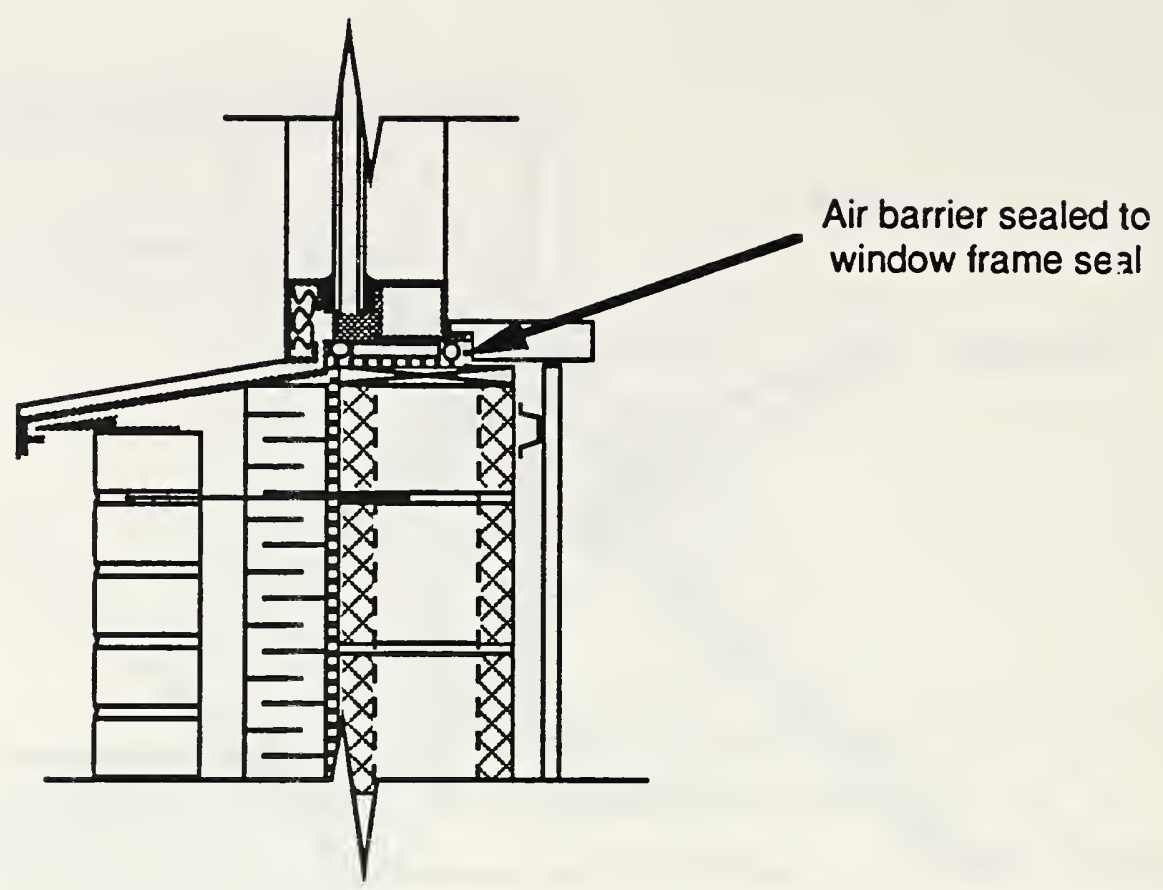

Figure 2.27 Window Sill / Masonry Wall Connection (Burn 1980)

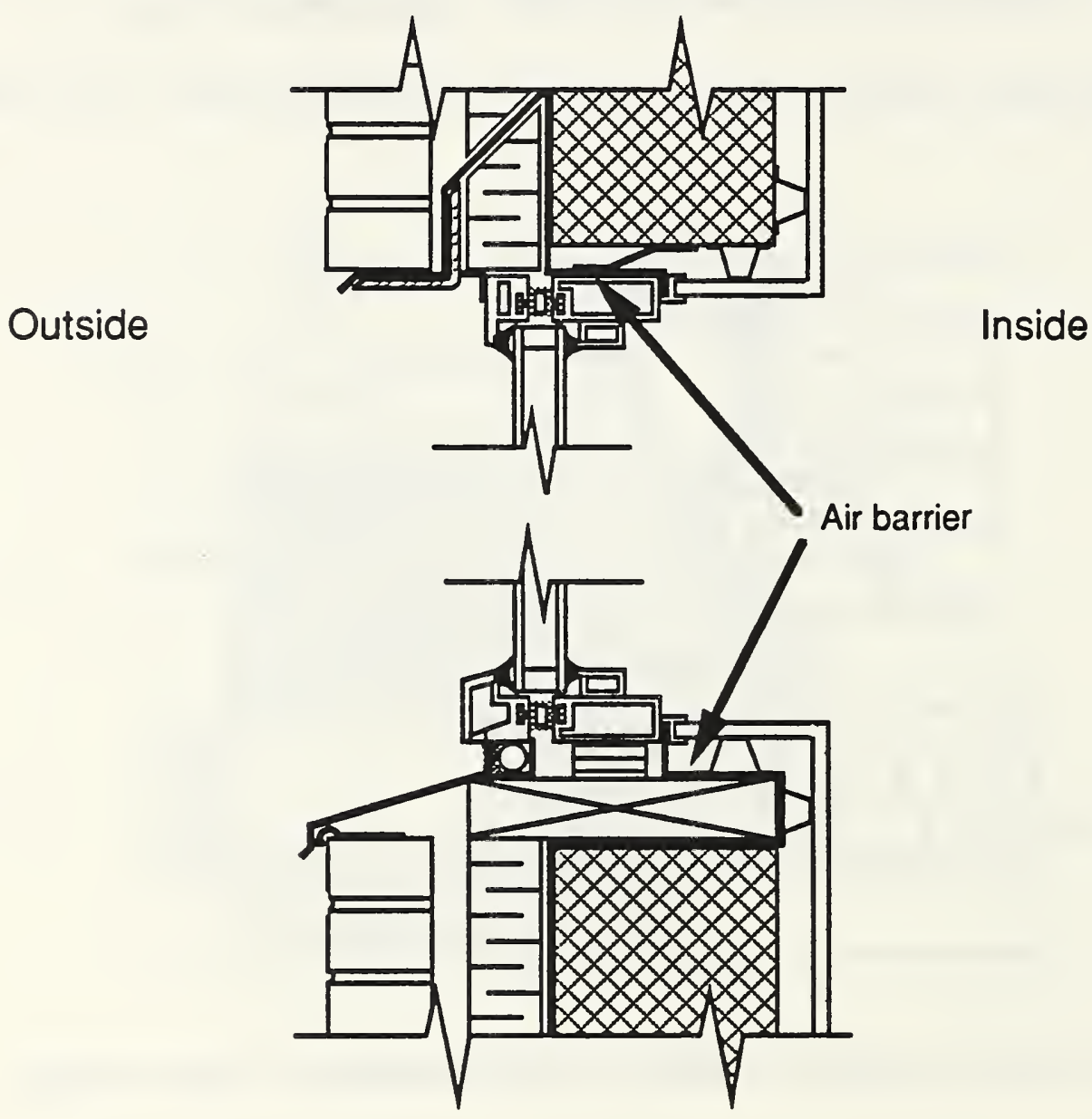

Figure 2.28 Window Sill / Masonry Wall Connection (Patenaude 1988) 


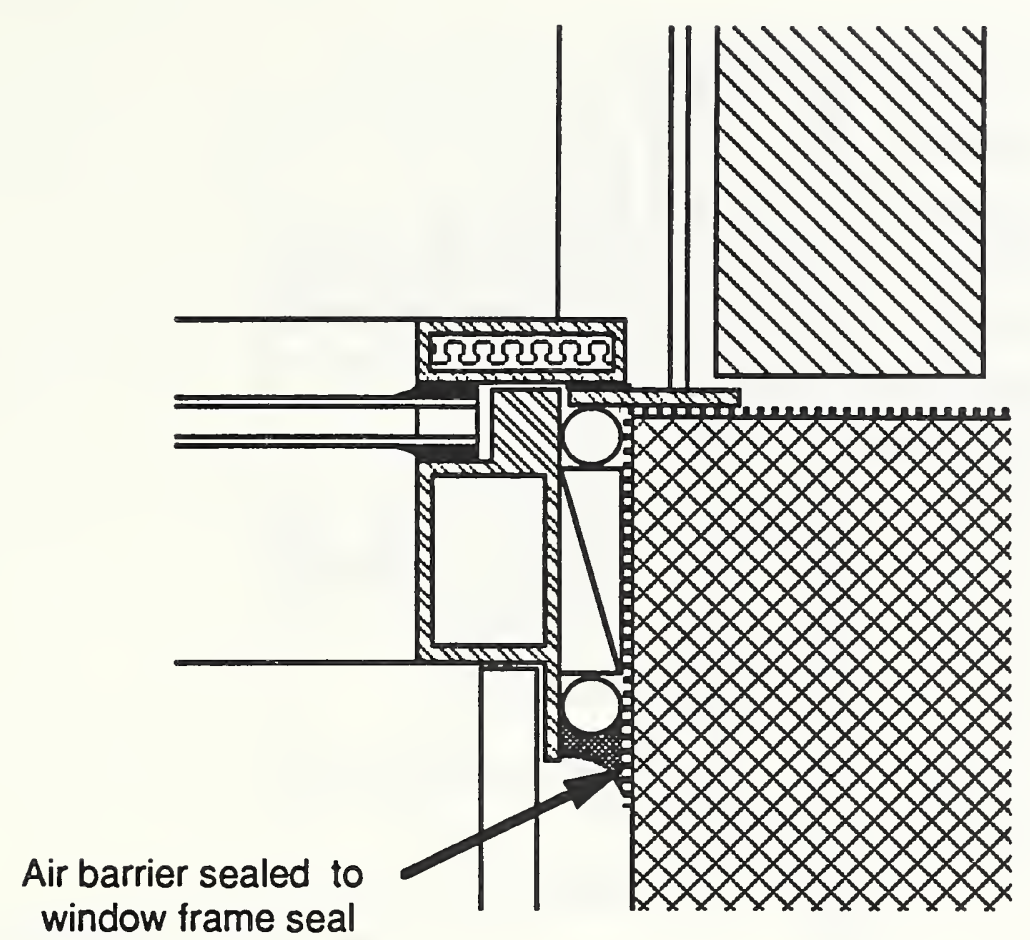

Figure 2.29 Window Jamb / Masonry Wall Connection (Burn 1980)

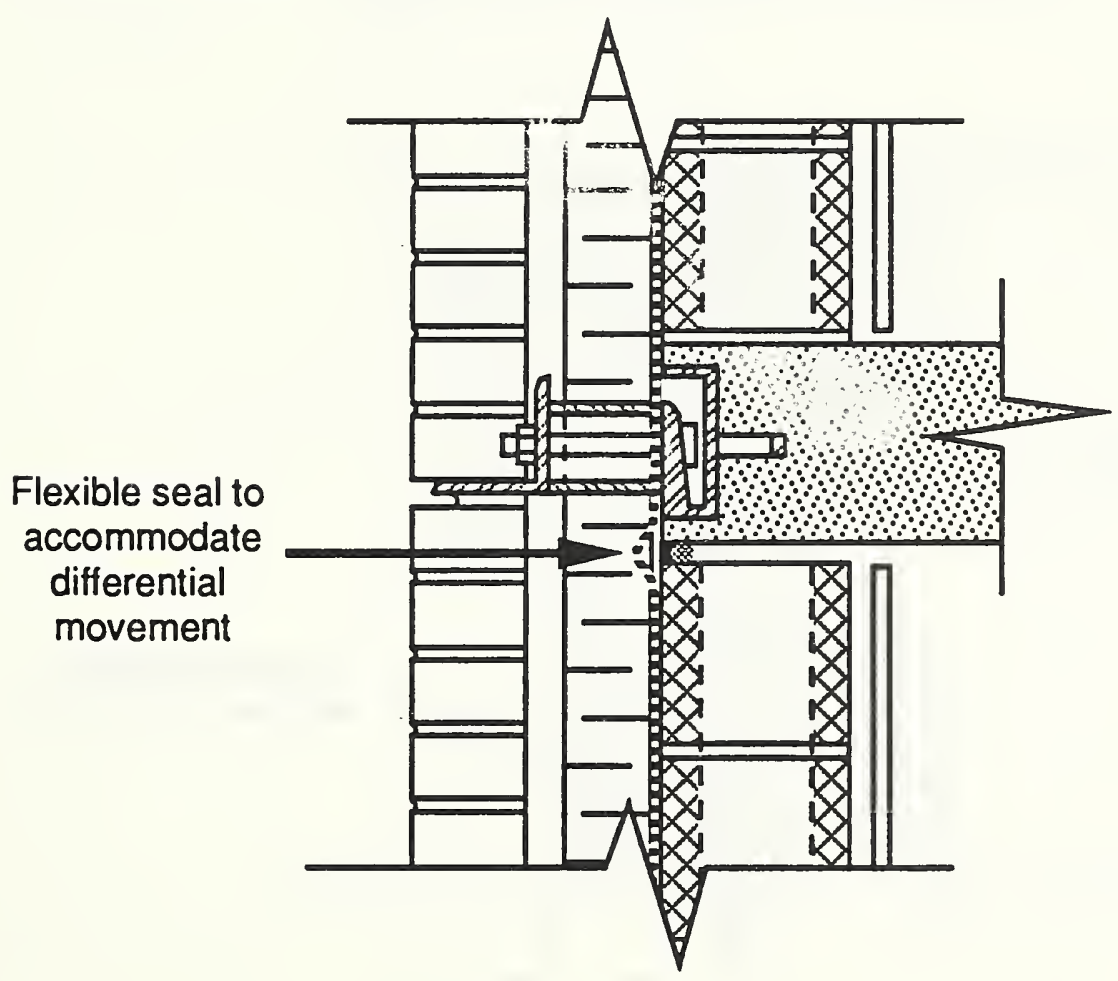

Figure 2.30 Floor / Masonry Wall Connection (Burn 1980) 


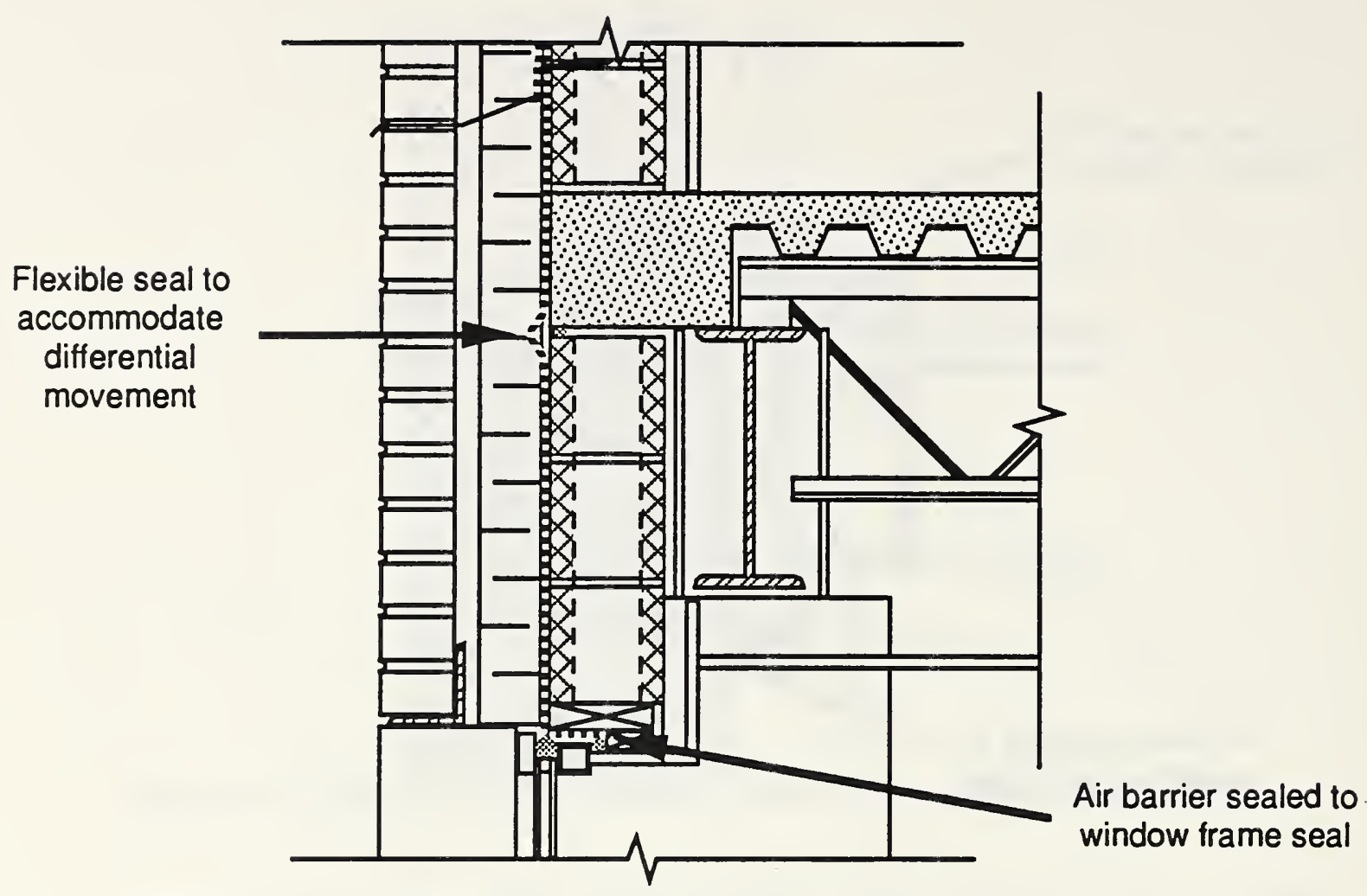

Figure 2.31 Masonry Wall / Floor Connection and Window Head in a Steel Frame Building (Burn 1980)

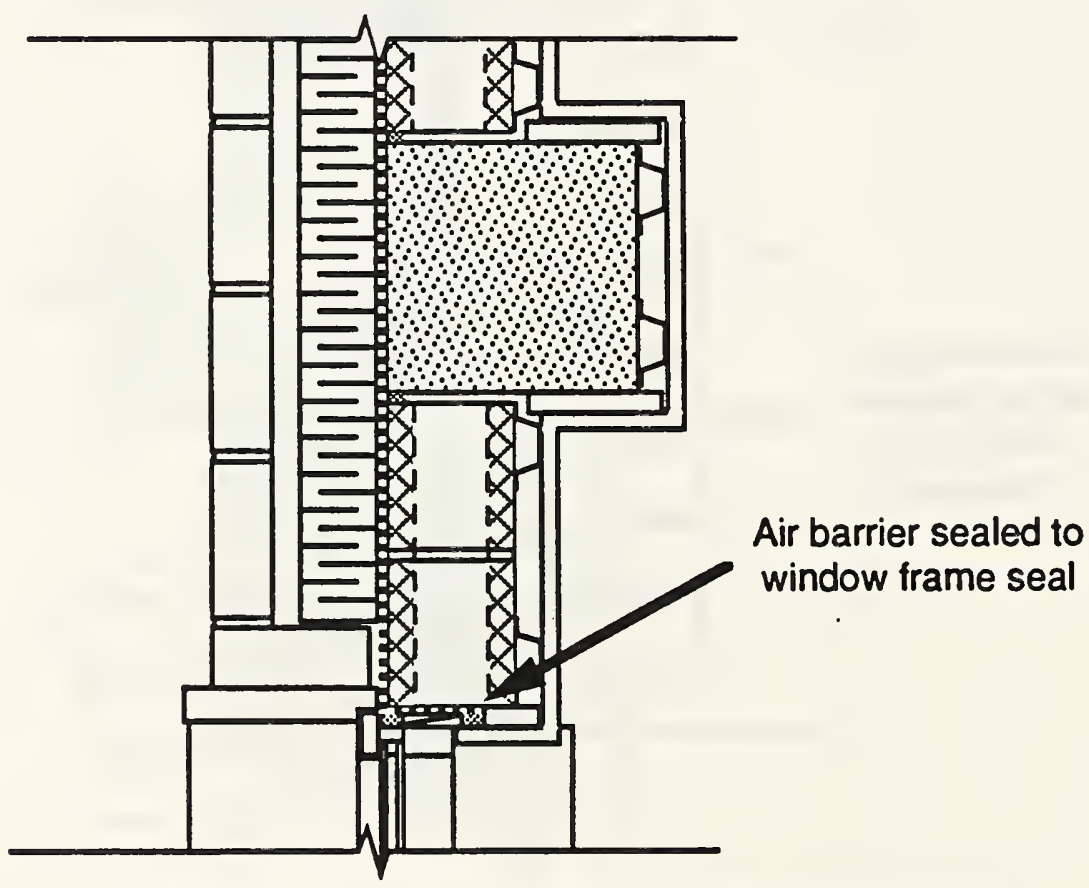

Figure 2.32 Masonry Wall / Column Connection and Window Jamb (Burn 1980) 


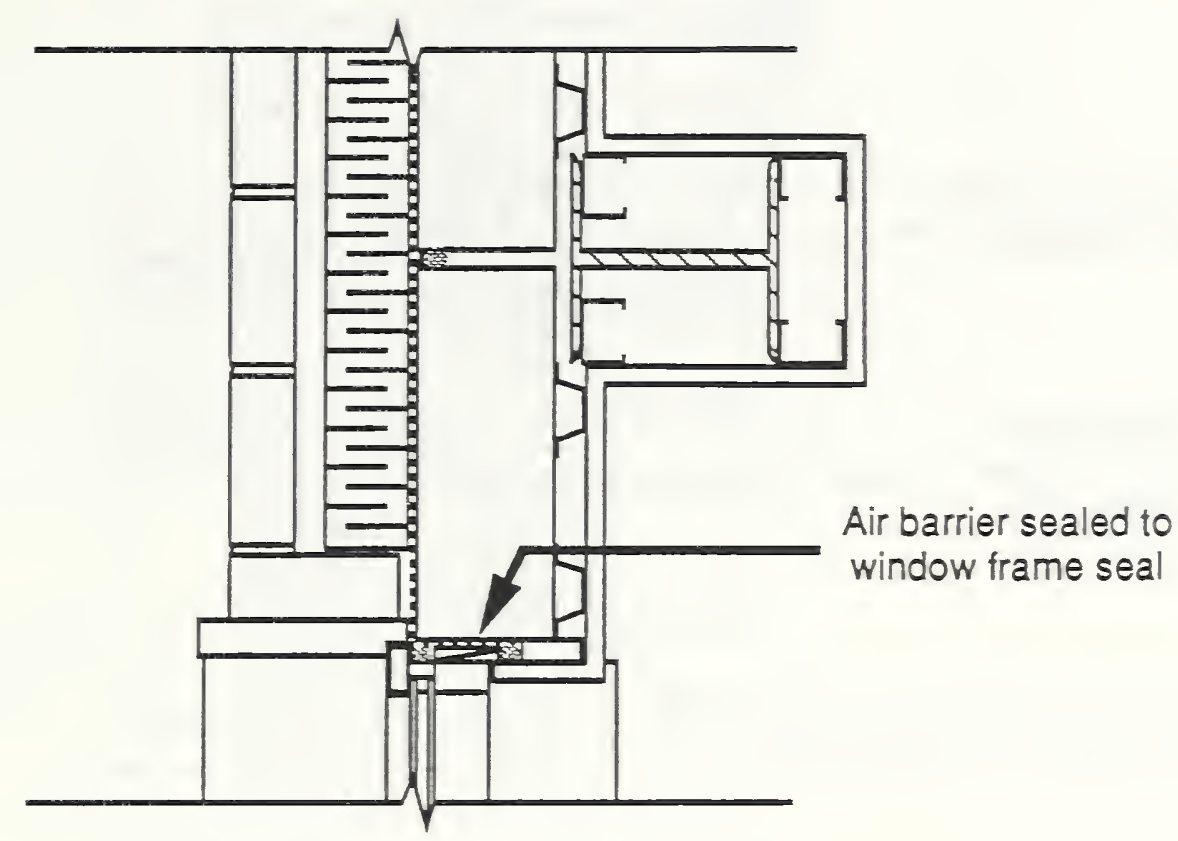

Figure 2.33 Masonry Wall / Steel Column Connection and Window Jamb (Burn 1980)

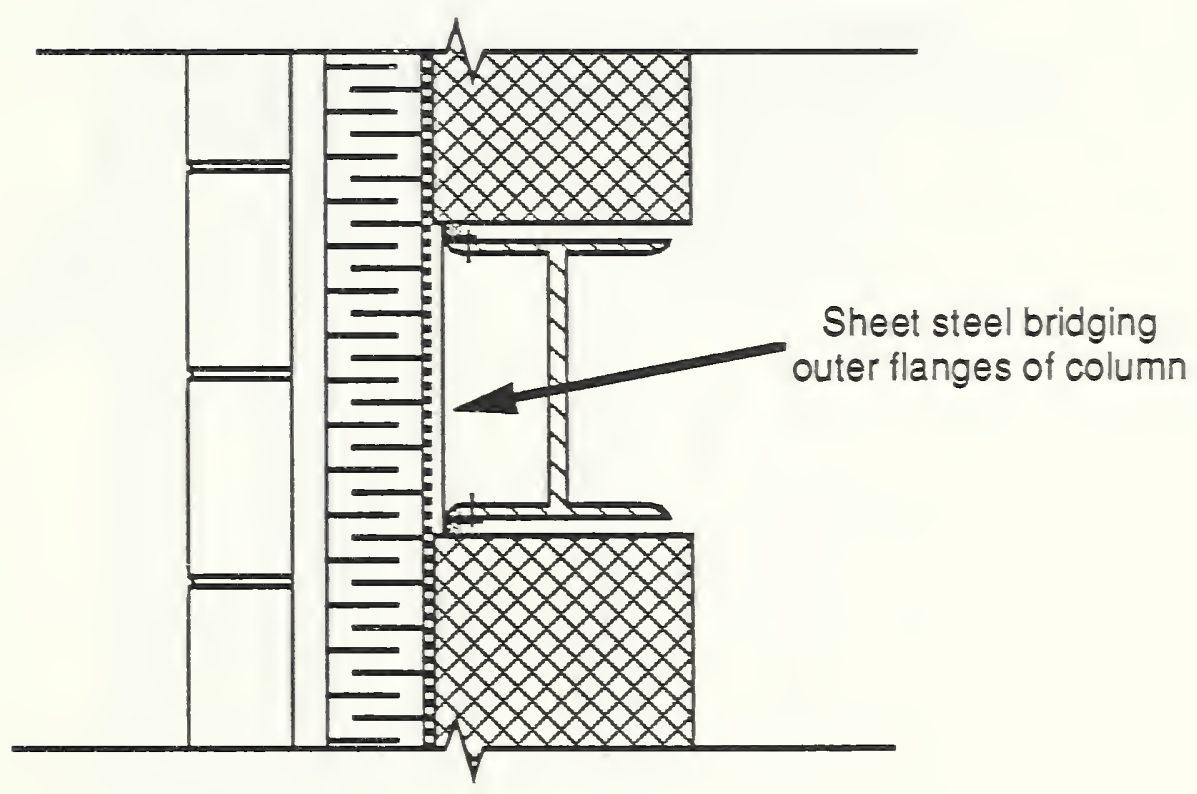

Figure 2.34 Masonry Wall / Steel Column Connection and Window Jamb (Burn 1980) 


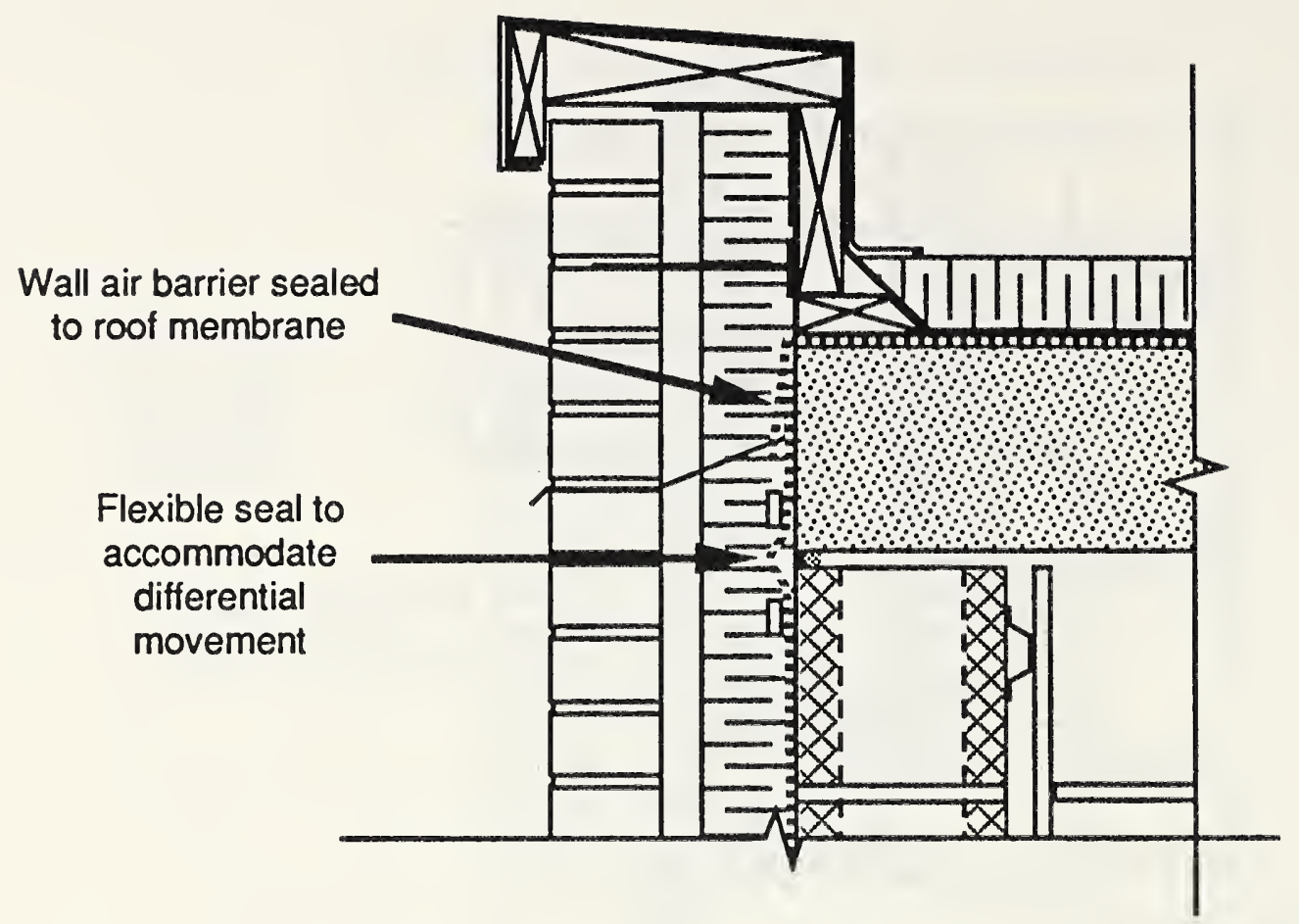

Figure 2.35 Masonry Wall / Flat Roof Edge (Burn 1980)

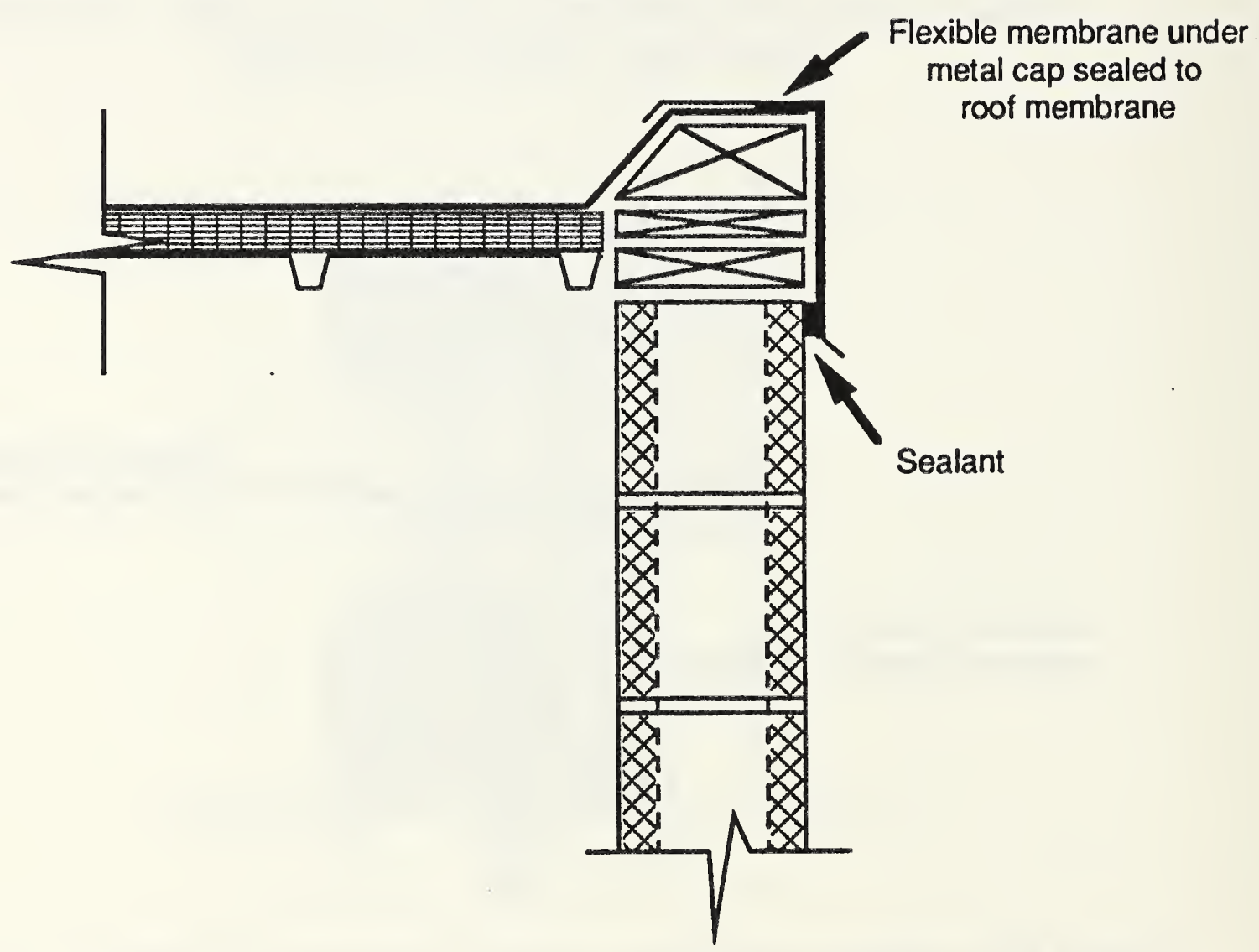

Figure 2.36 Masonry Wall / Flat Roof Edge (Riedel 1982) 


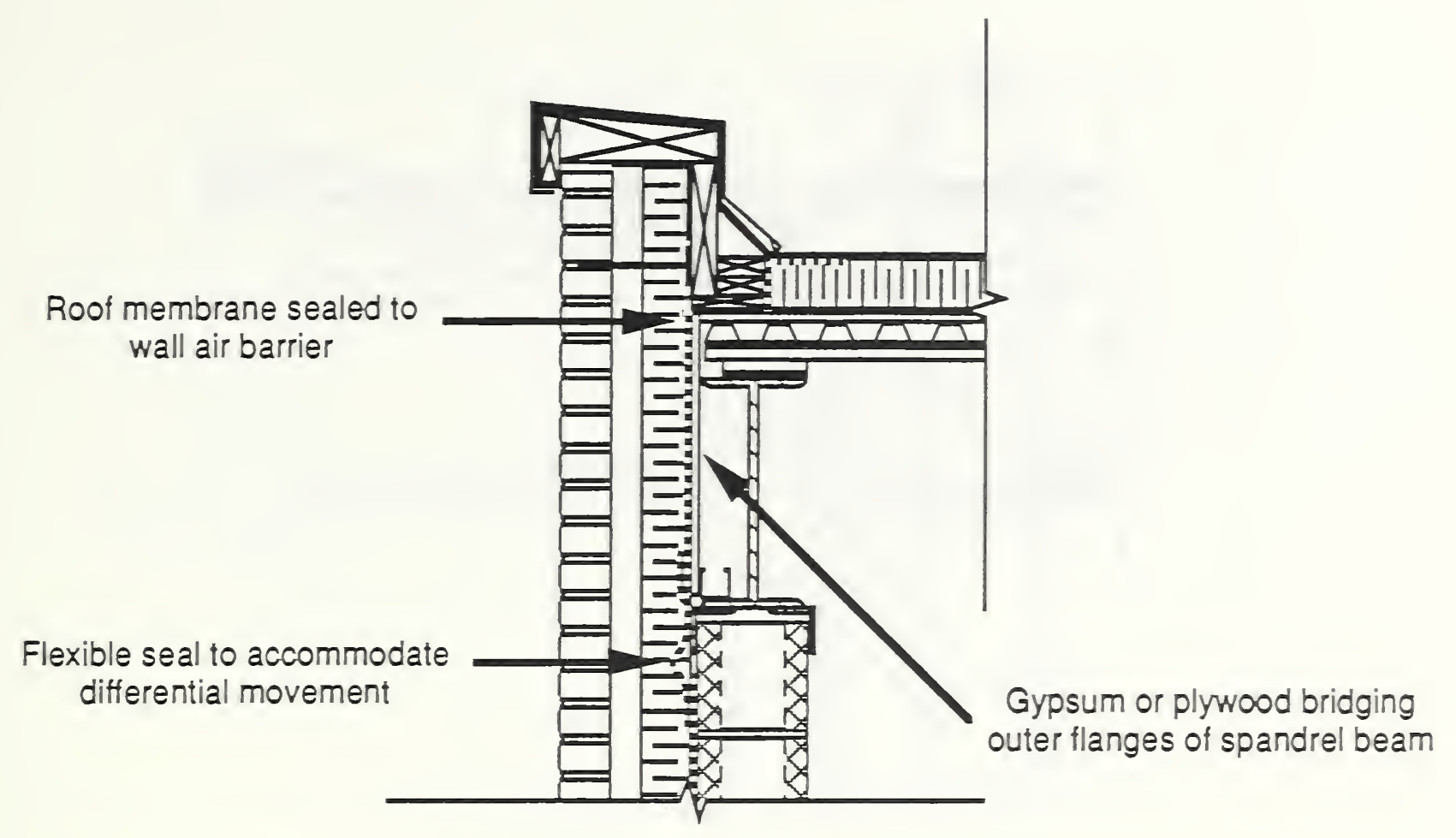

Figure 2.37 Masonry Wall / Flat Roof Edge in a Steel Frame Building (Burn 1980)

Flexible membrane, supported by sheet metal closure, connecting roof membrane to wall air barrier

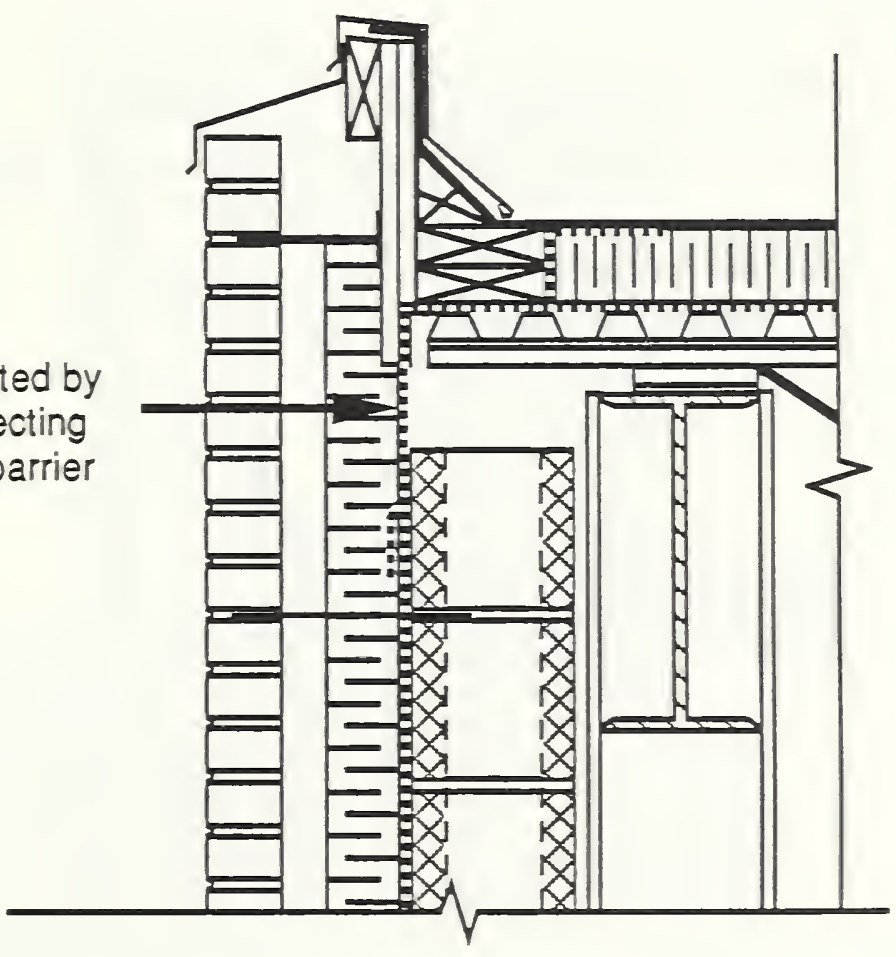

Figure 2.38 Masonry Wall / Flat Roof Edge in a Steel Frame Building (Turenne 1980) 


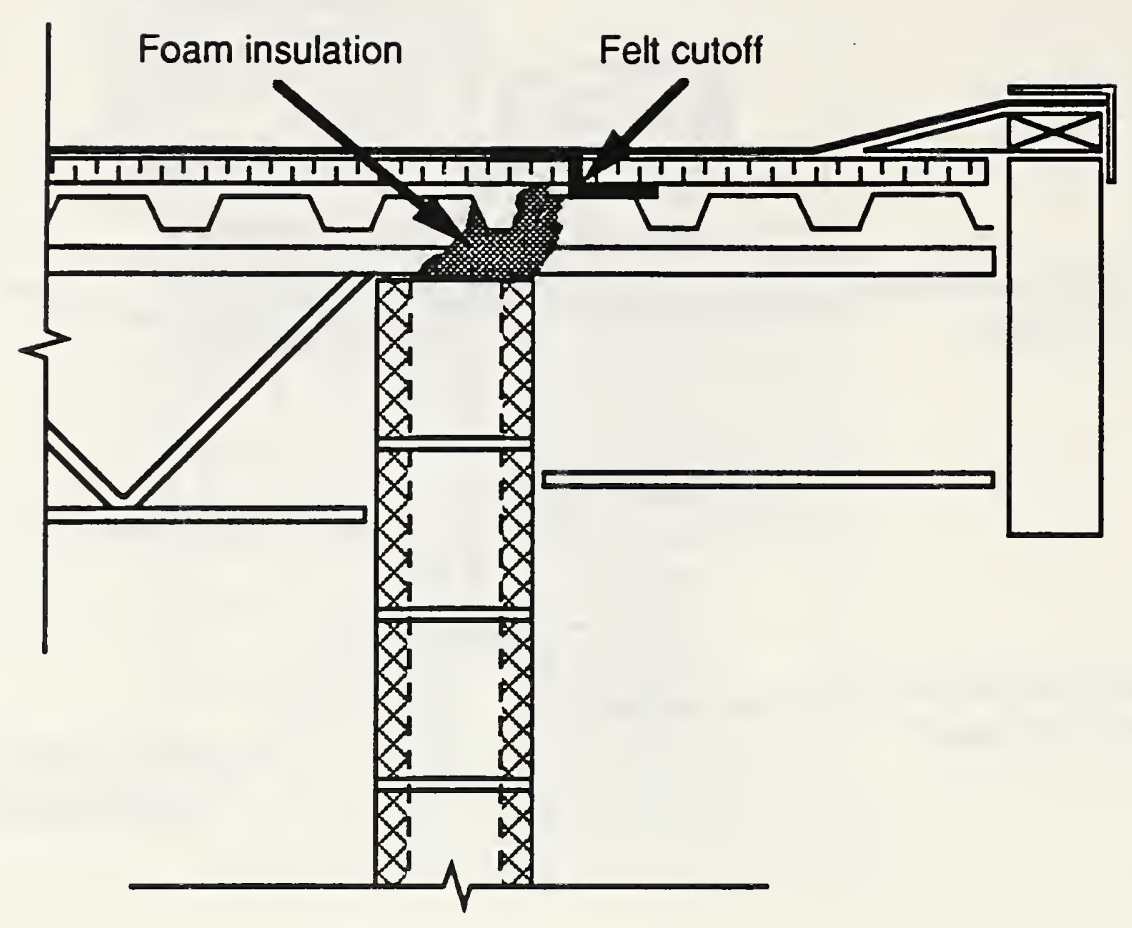

Figure 2.39 Masonry Wall / Overhang Roof (Riedel 1982)

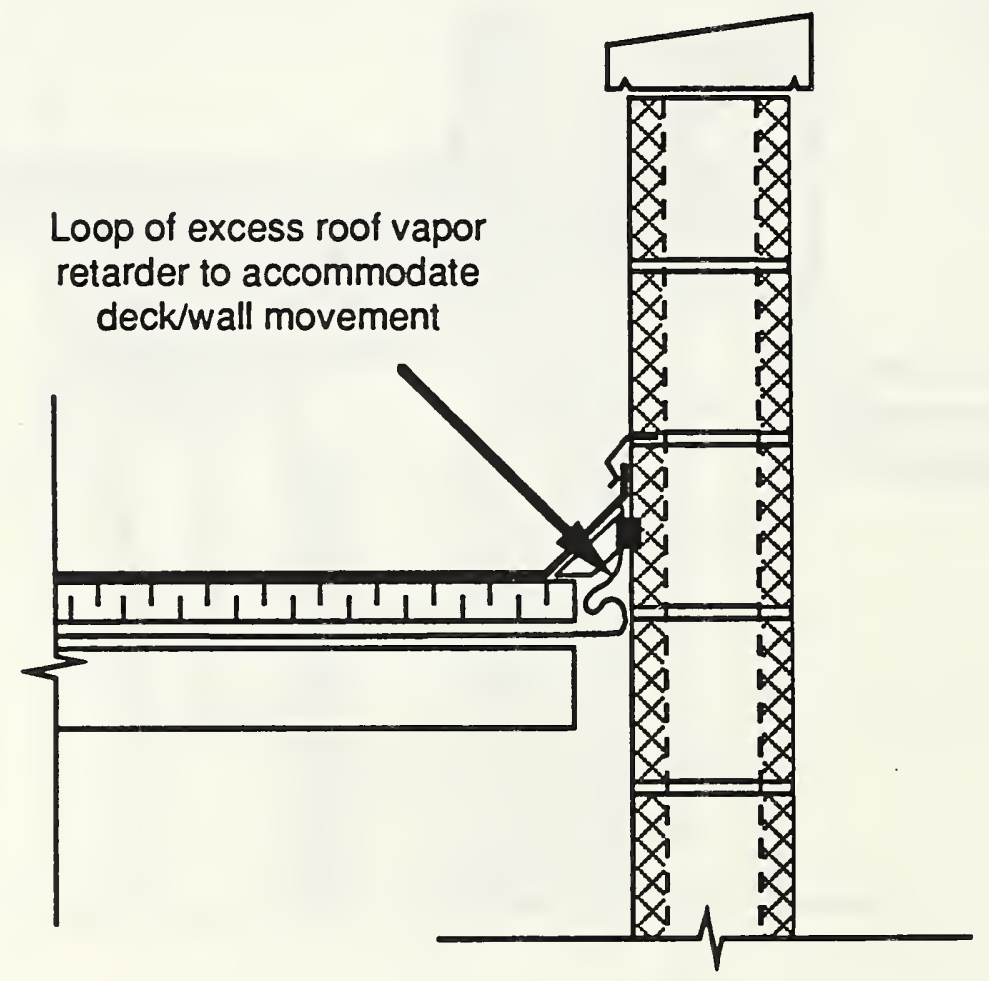

Figure 2.40 Masonry Parapet Wall / Roof Connection (Riedel 1982) 


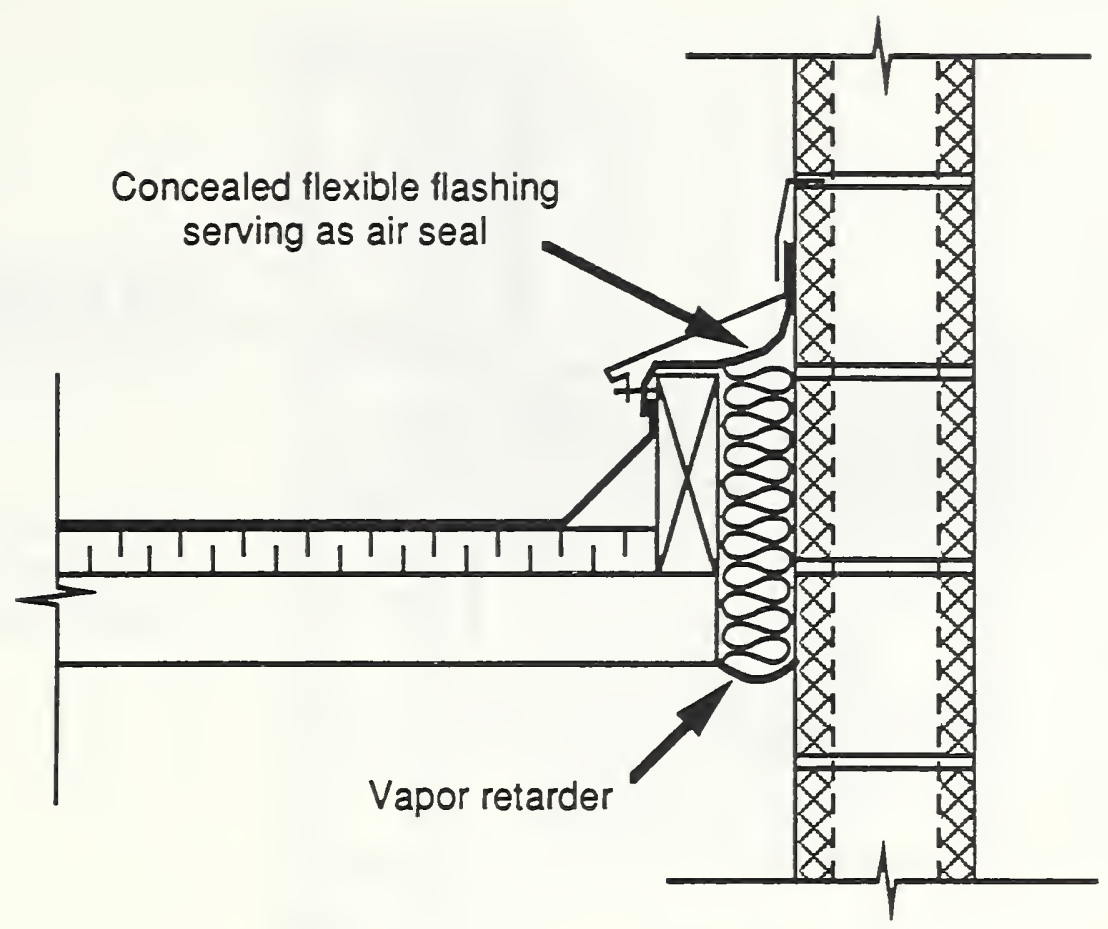

Figure 2.41 Masonry Parapet Wall / Roof Connection at Expansion Joint (Riedel 1982)

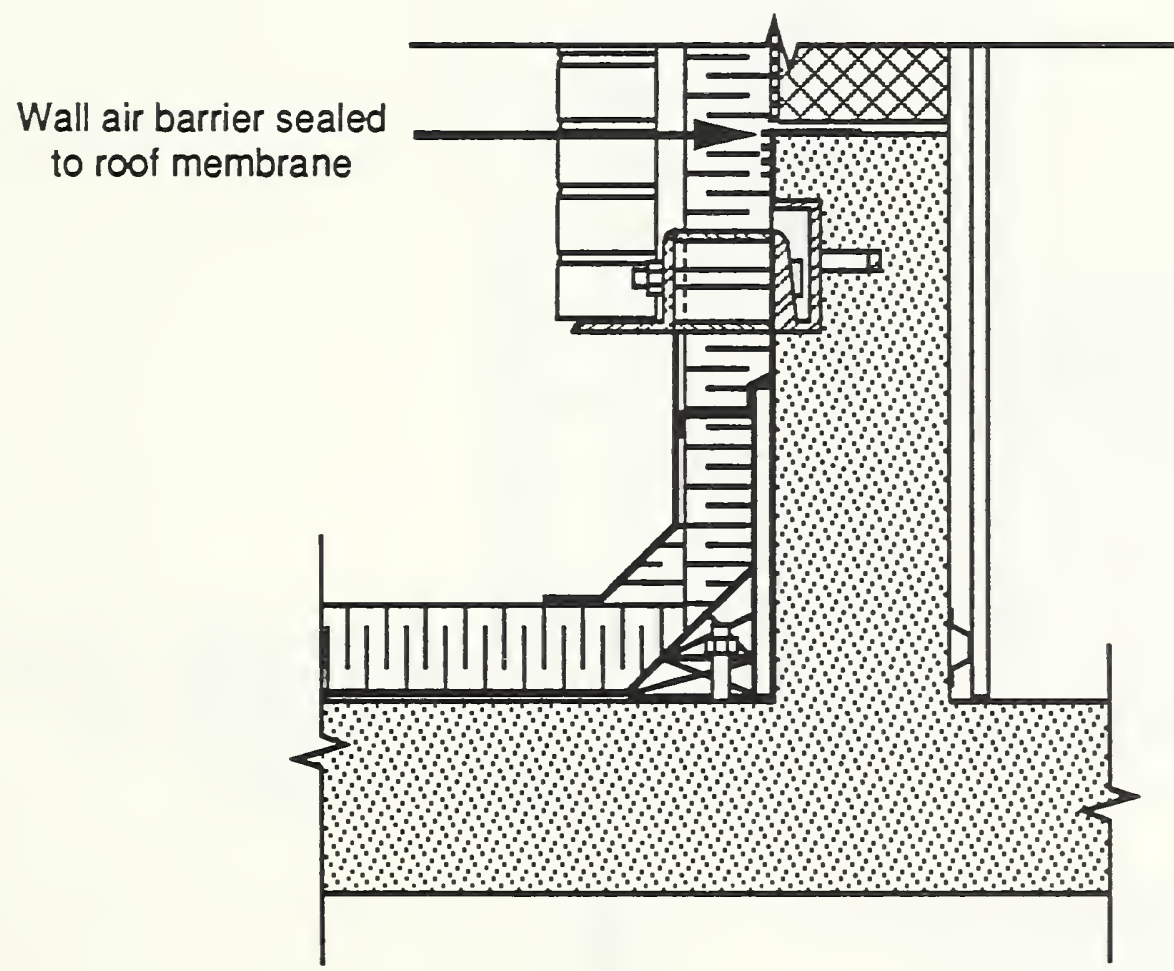

Figure 2.42 Masonry Setback Wall / Roof Connection (Turenne 1980) 


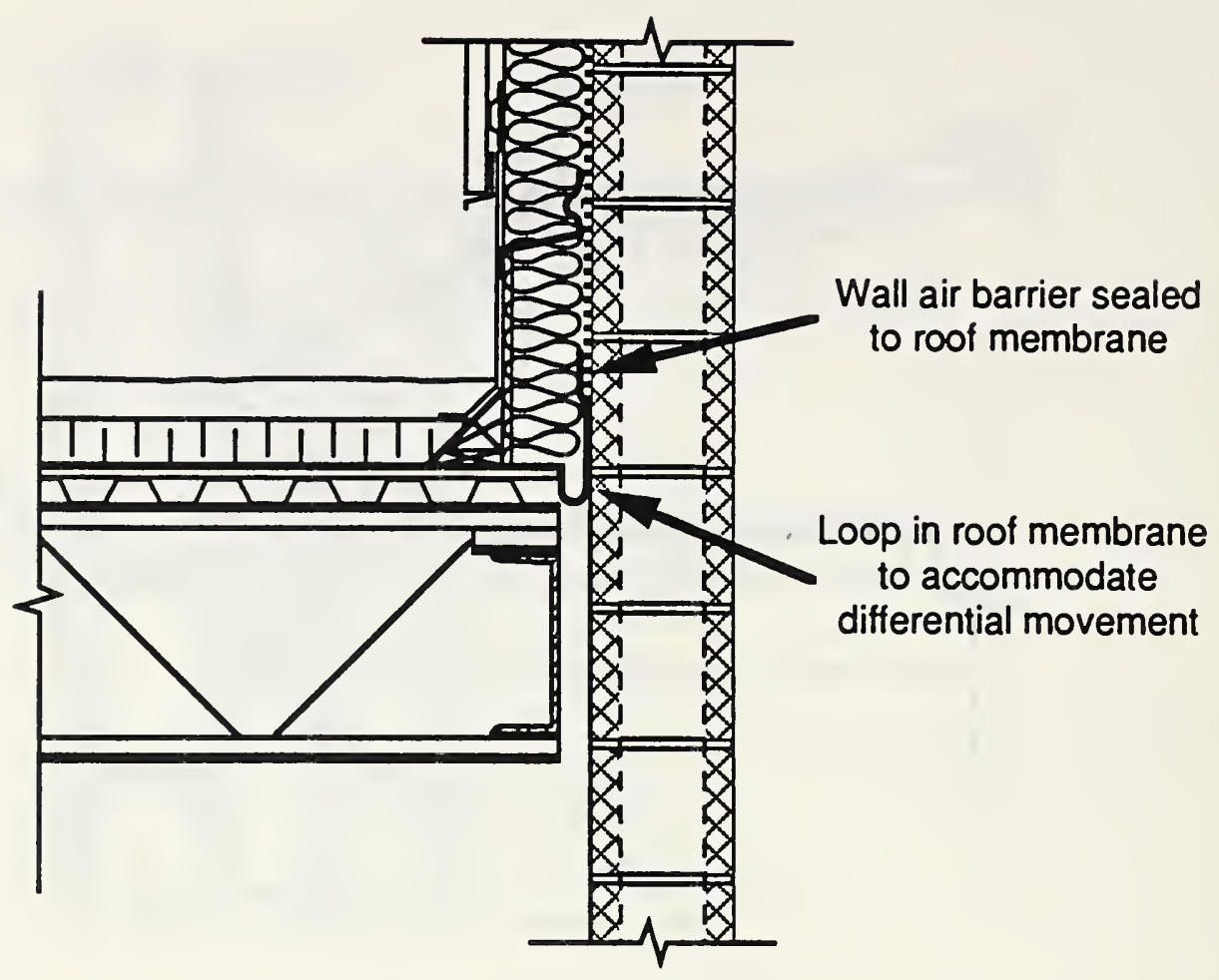

Figure 2.43 Masonry Setback Wall / Roof Connection (Turenne 1980)

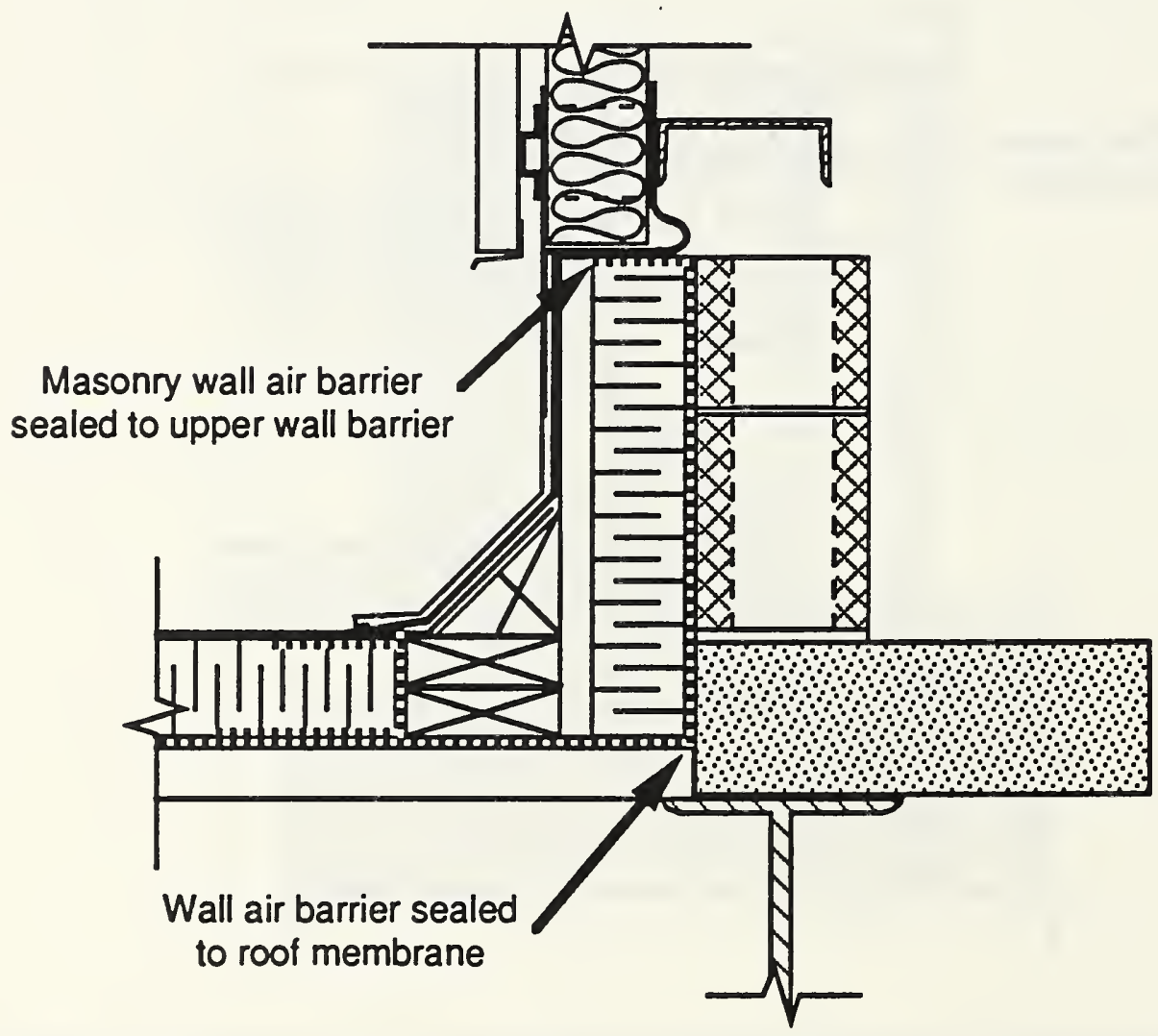

Figure 2.44 Masonry Setback Wall / Roof Connection (Turenne 1980) 
Flexible seal between wall air barrier and foundation barrier to accommodate differential movement

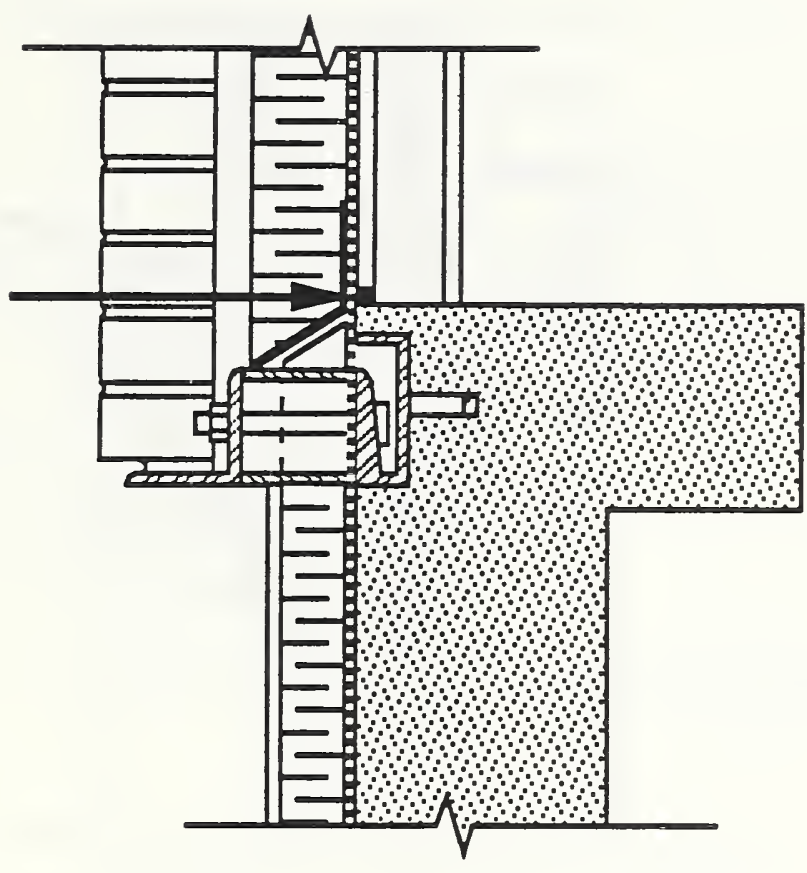

Figure 2.45 Metal Stud Wall / Foundation Connection (Quirouette 1980)

Flexible joint or sliding cover strip connecting top and bottom edges of gypsum board

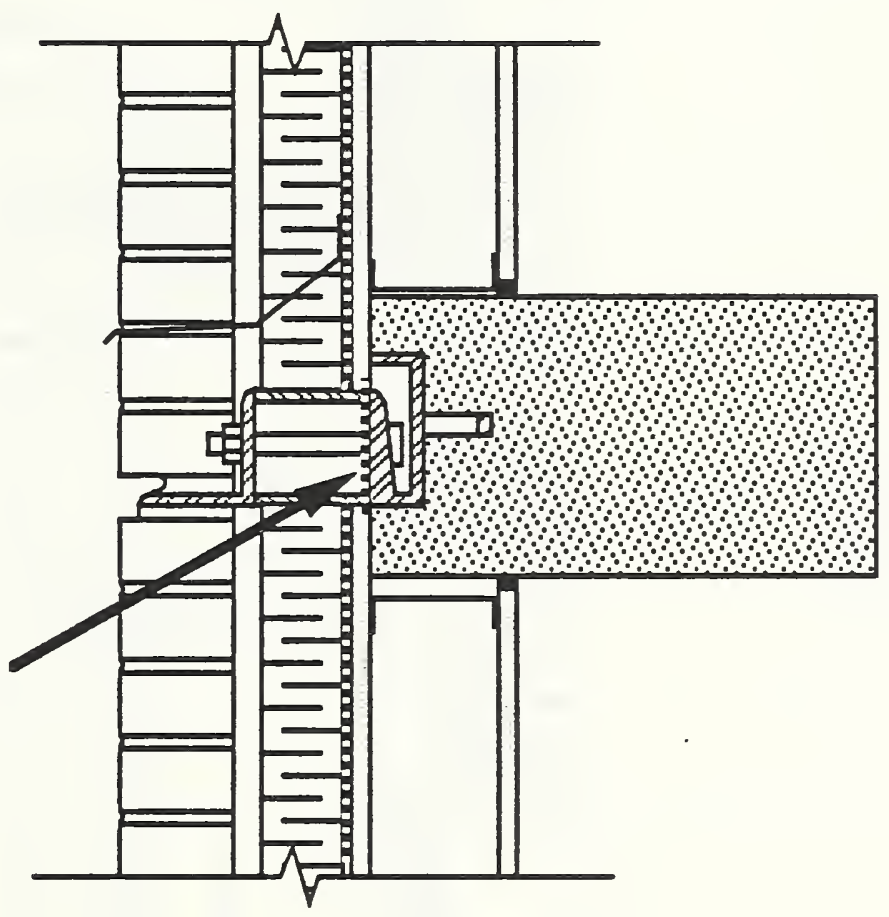

Figure 2.46 Metal Stud Wall / Floor Connection (Quirouette 1980) 


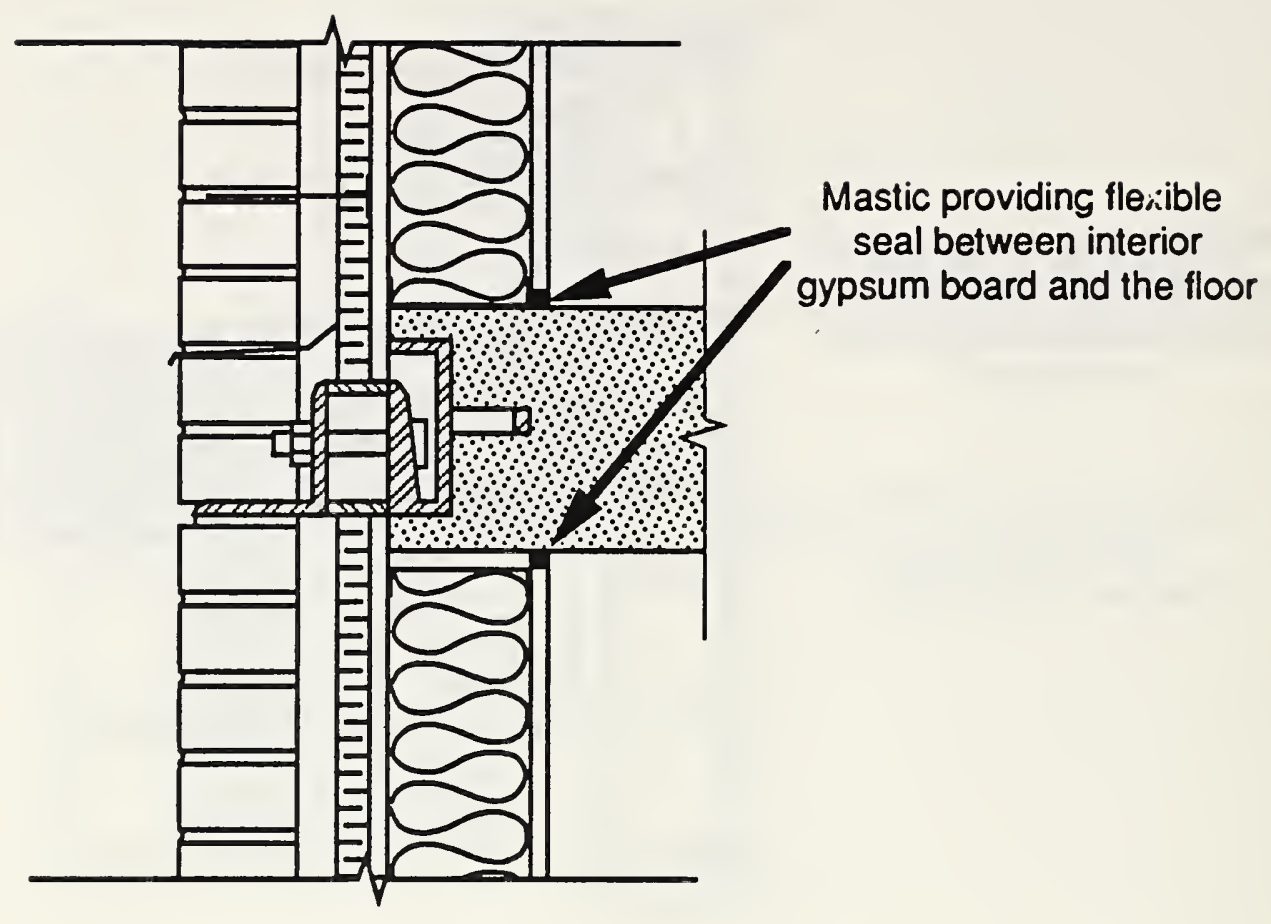

Figure 2.47 Metal Stud Wall / Floor Connection (Quirouette 1980)

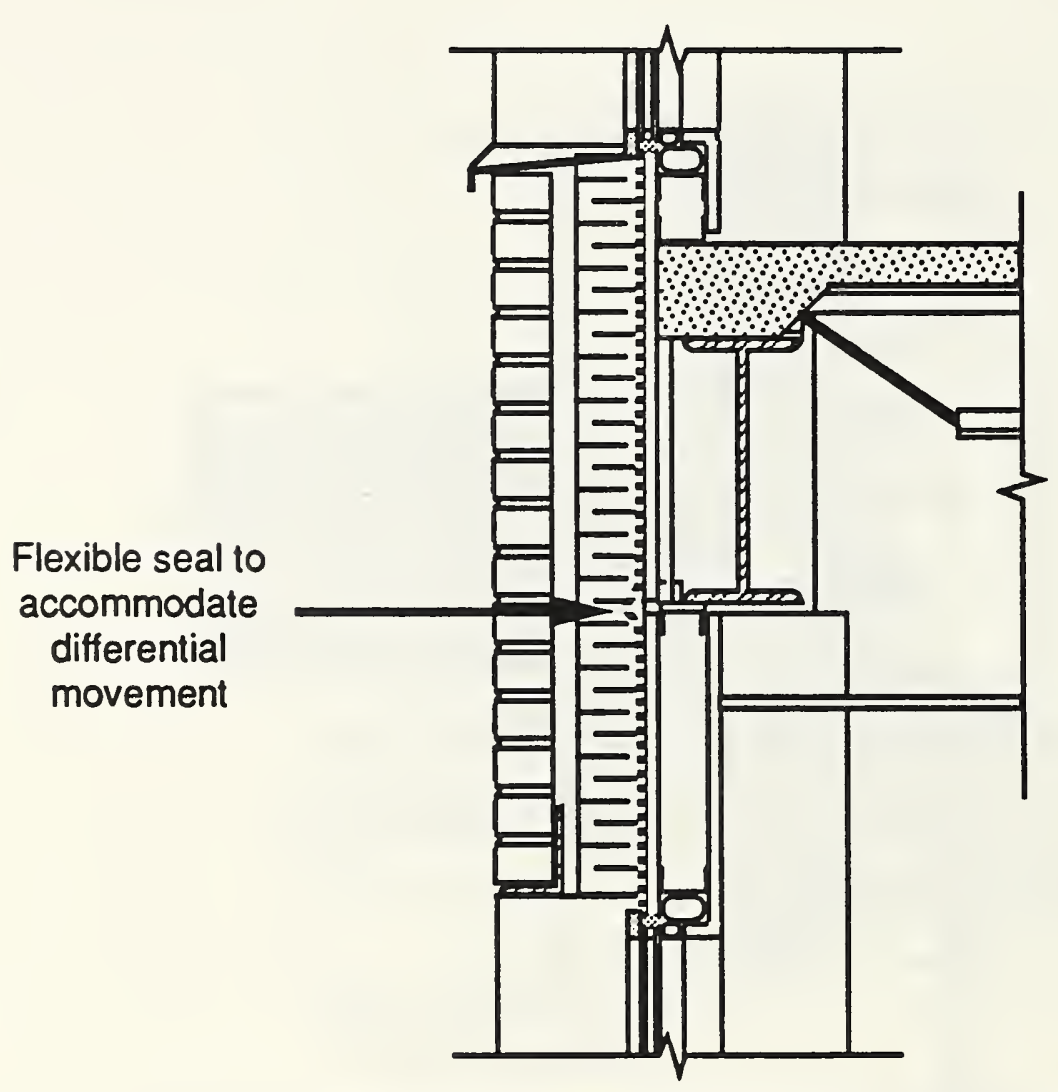

Figure 2.48 Metal Stud Wall / Floor Connection and Window Head and Sill (Quirouette 1980) 


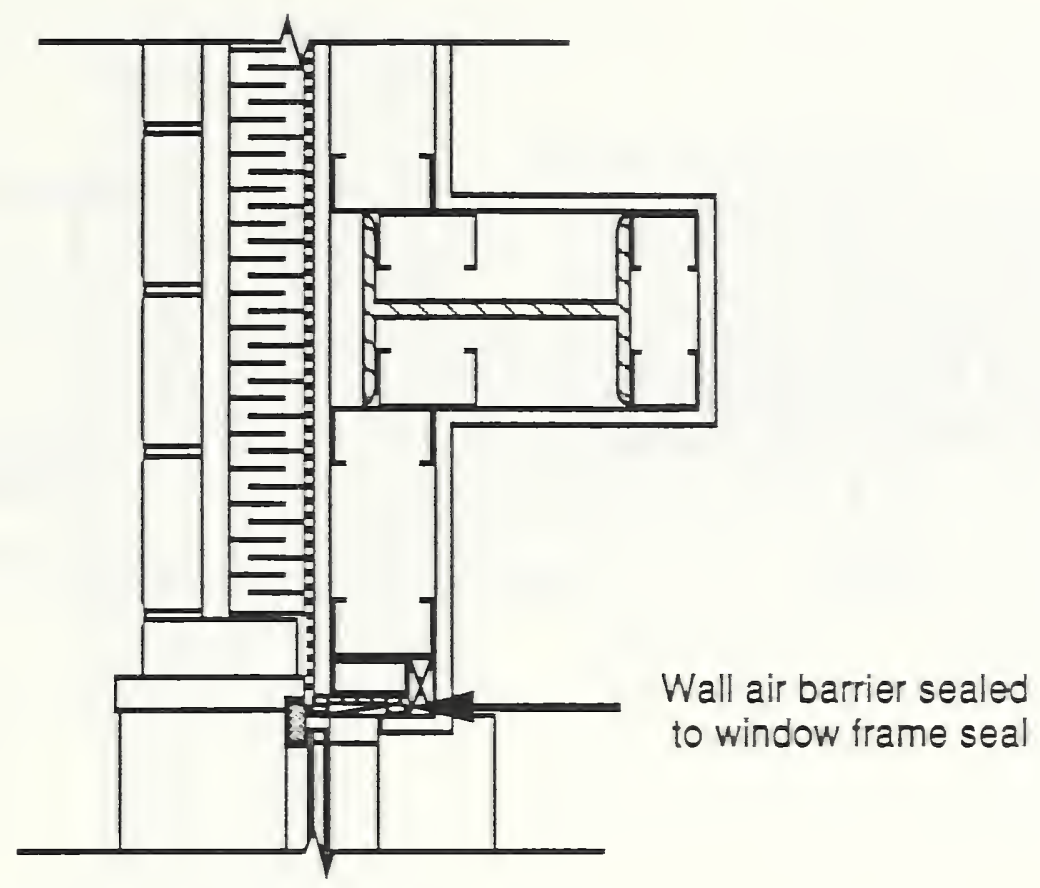

Figure 2.49 Metal Stud Wall / Steel Column Connection and Window Jamb (Quirouette 1980)

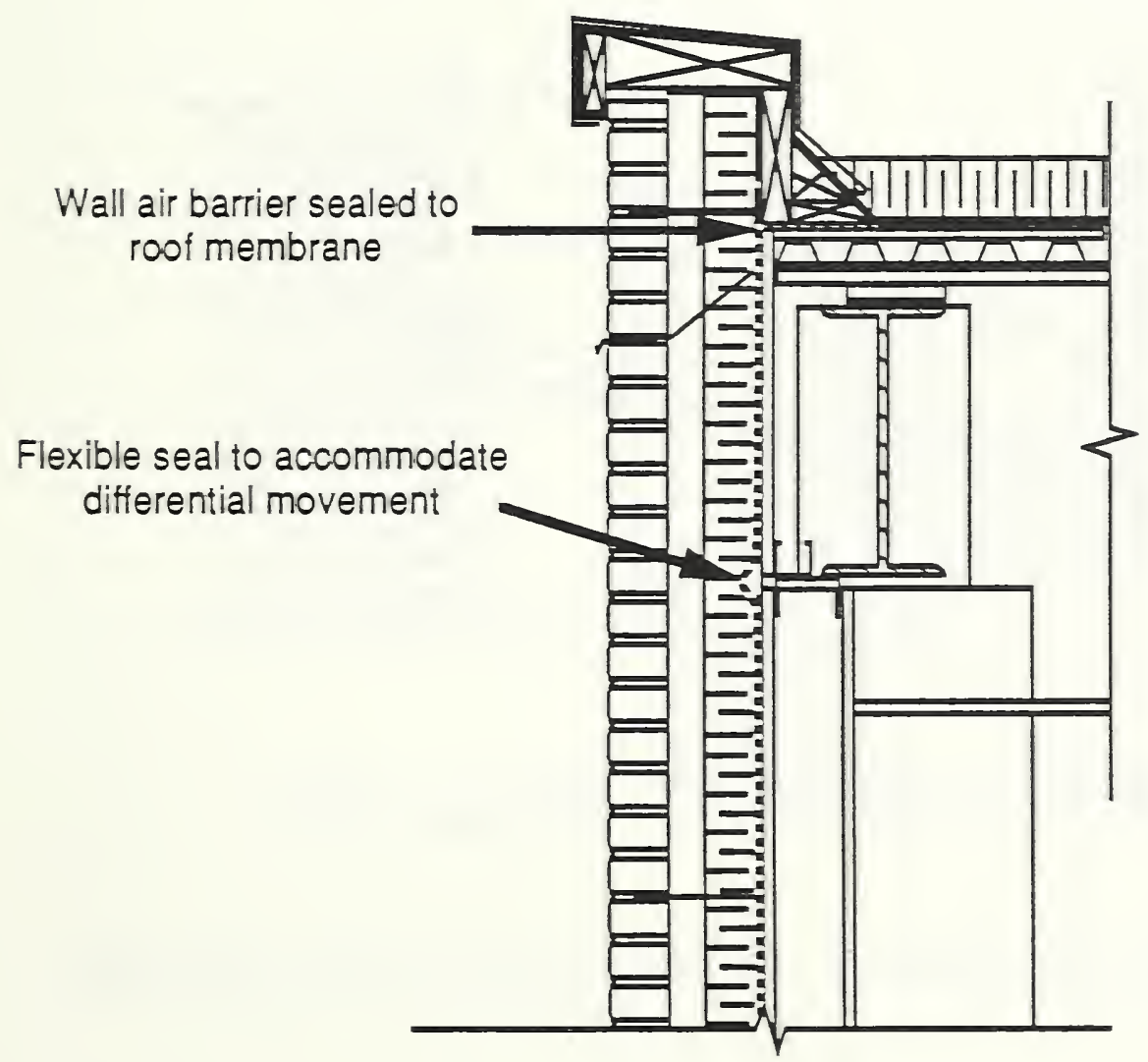

Figure 2.50 Metal Stud Wall / Flat Roof Edge (Quirouette 1980) 


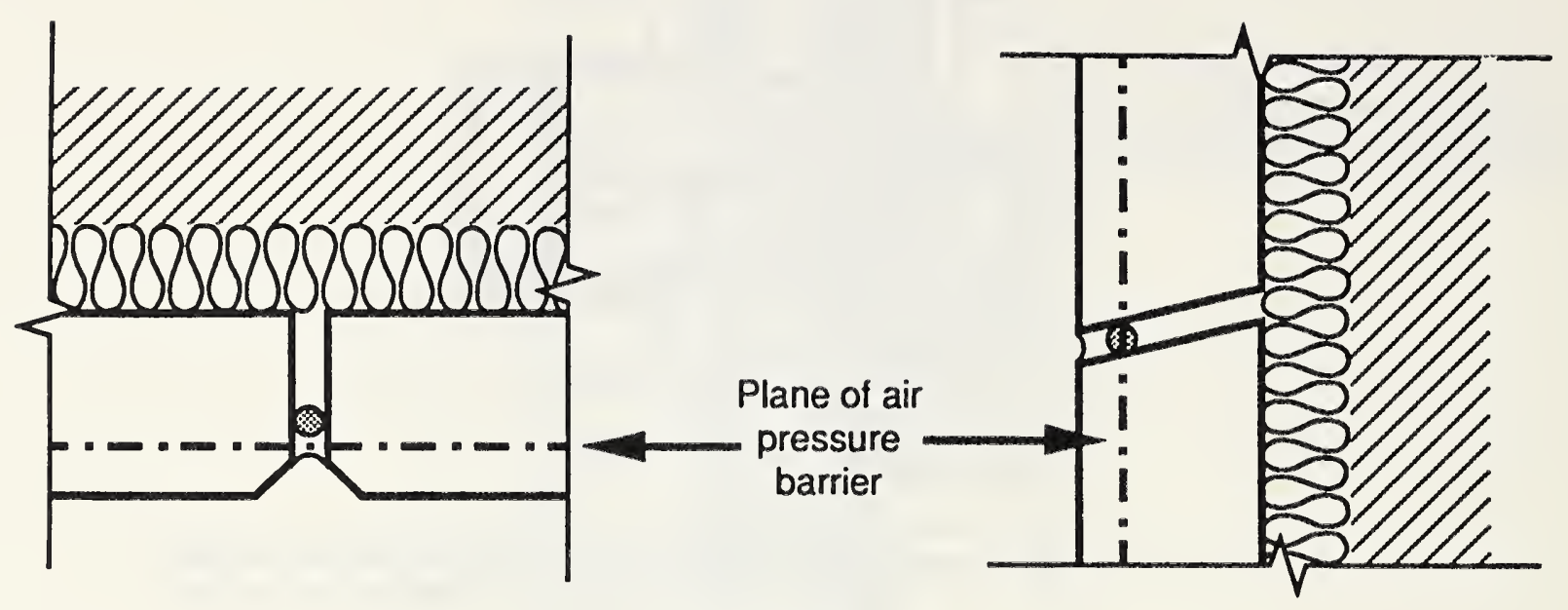

Figure 2.51 Precast Panel Face Seal Seams (Rousseau 1983)
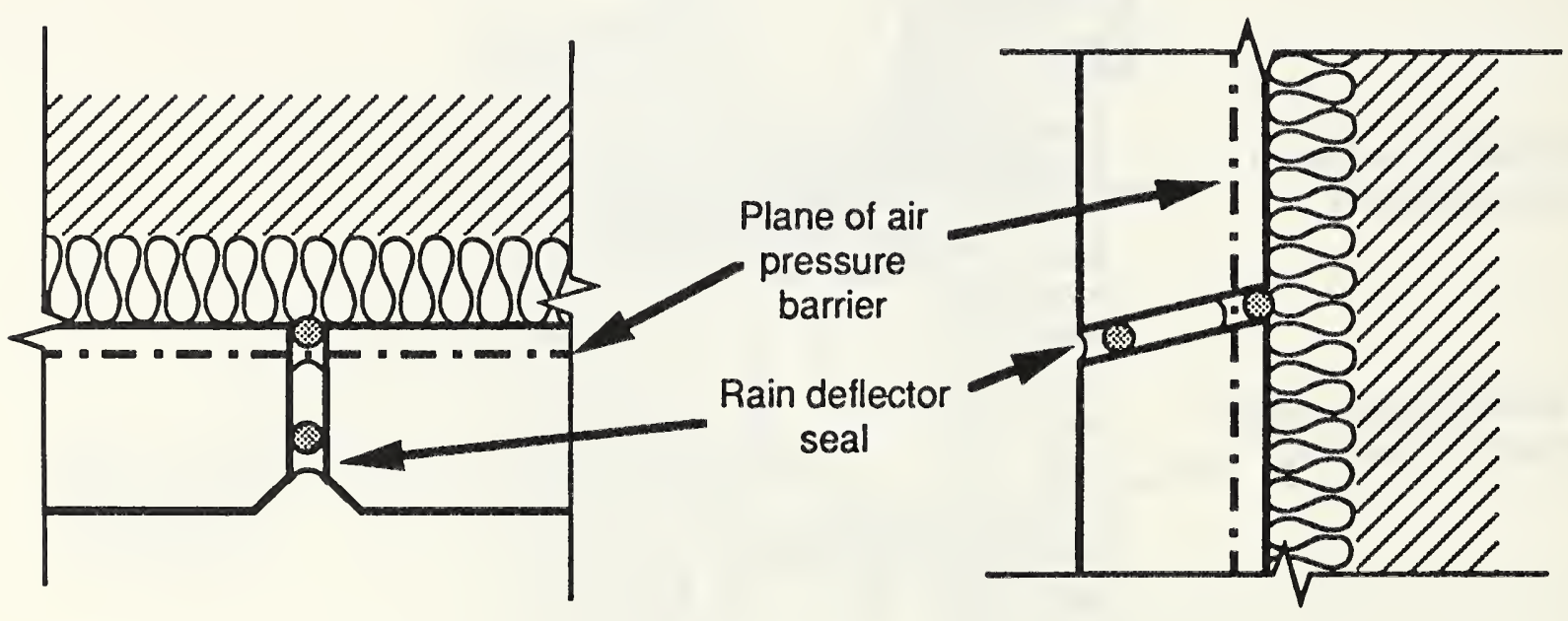

Figure 2.52 Precast Panel Two-Stage Seam (Rousseau 1983) 


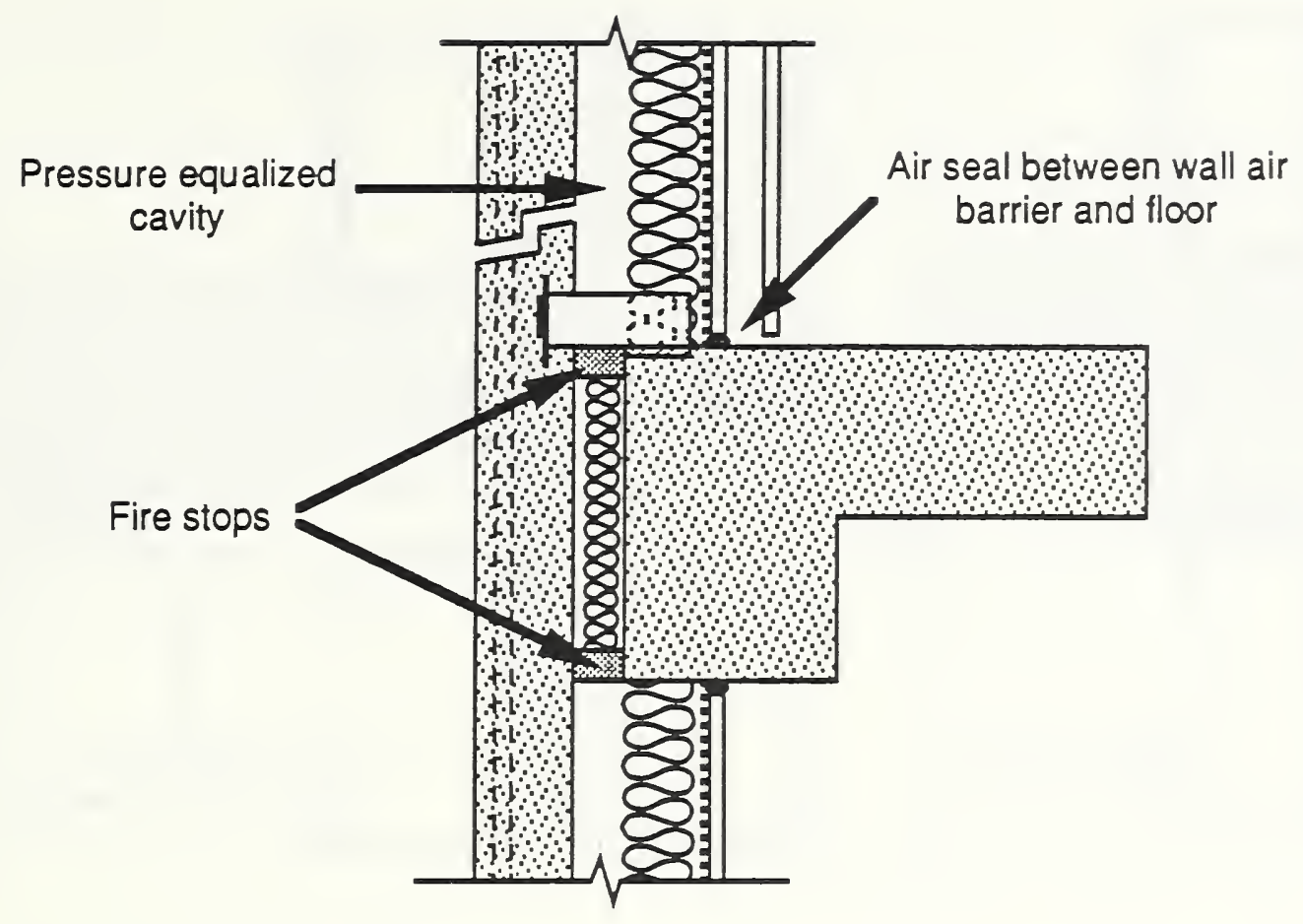

Figure 2.53 Precast Panel Pressure Equalized Rain Screen Floor / Wall Connection (Rousseau 1983)

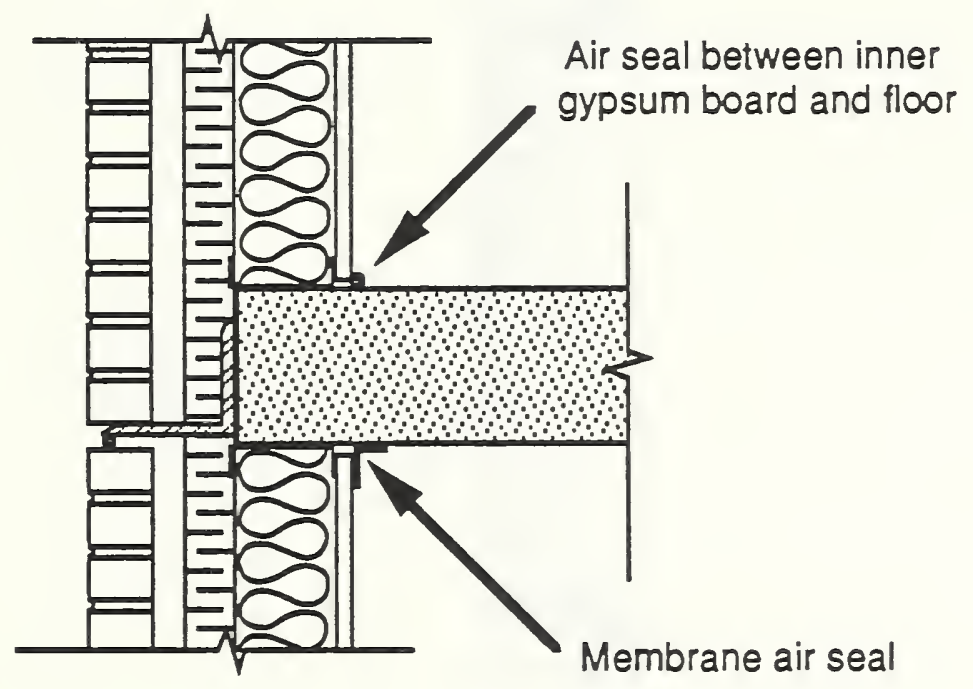

Figure 2.54 Wall / Floor Connection: Accessible Drywall Approach (Perreault 1989) 

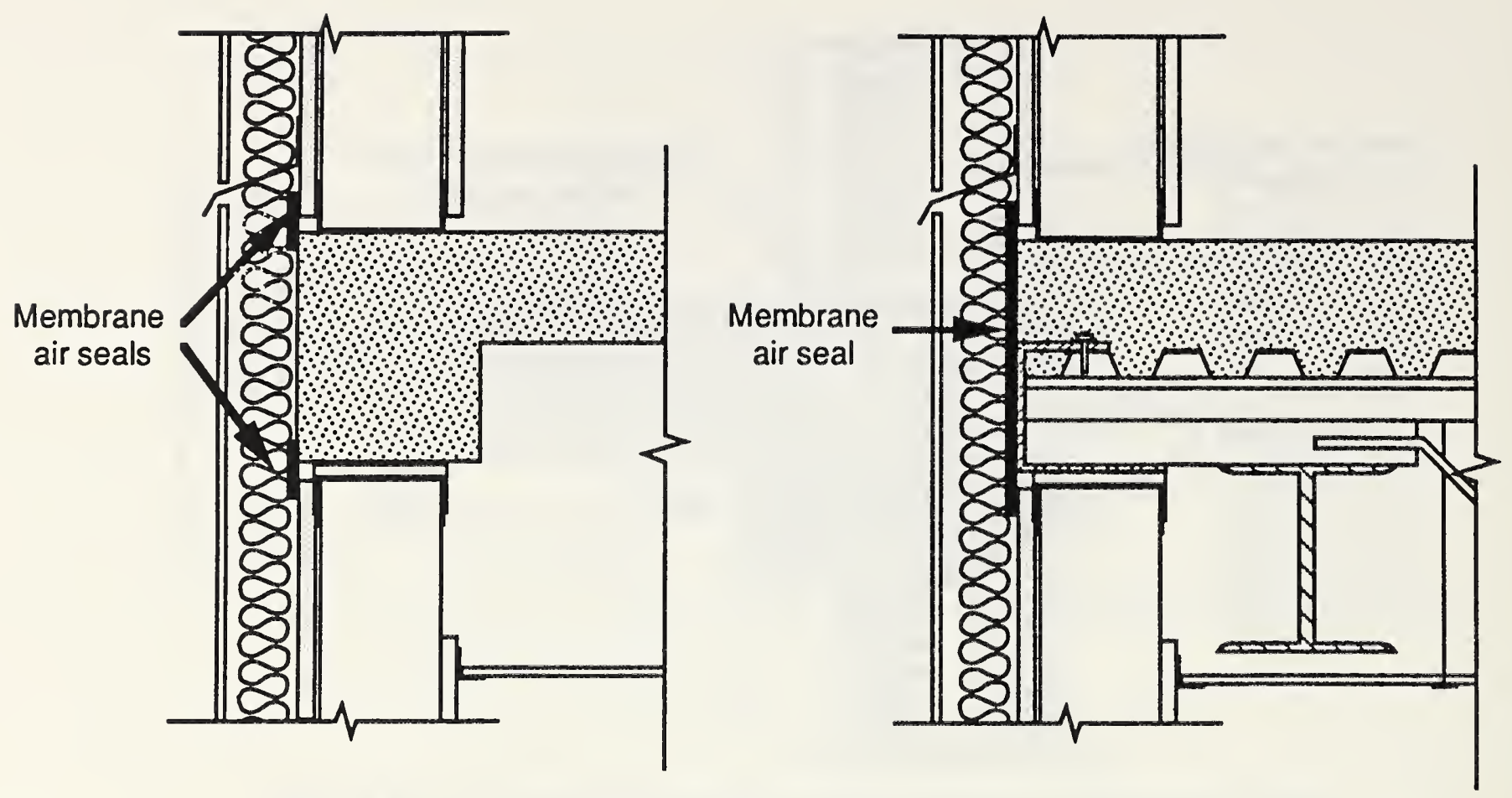

Figure 2.55 Wall / Floor Connection: Nonaccessible Drywall Approach (Perreault 1989)

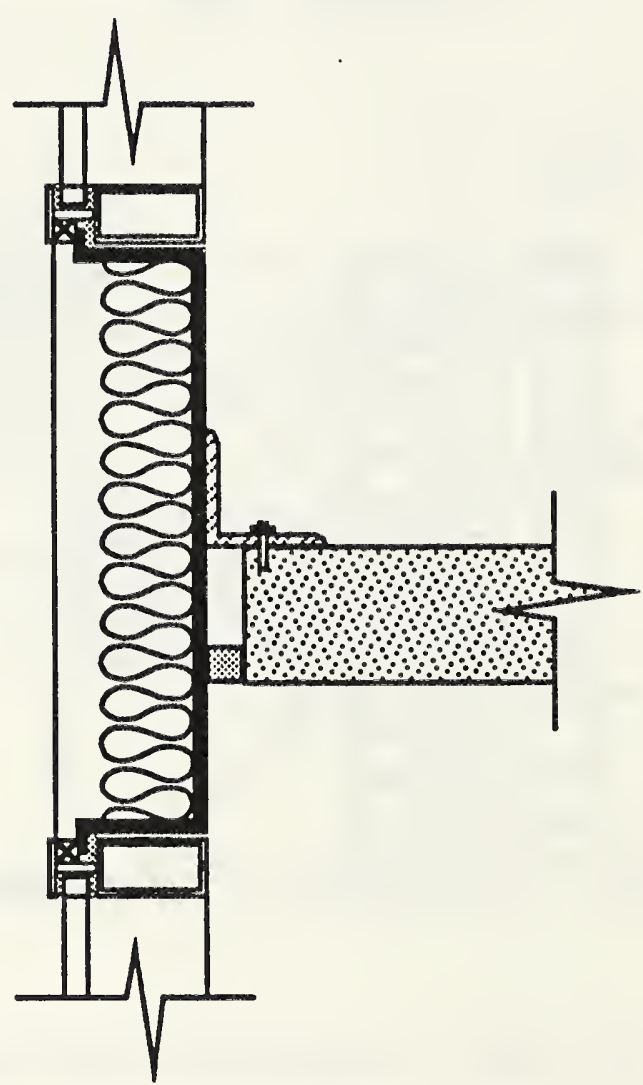

Figure 2.56 Wall / Floor Connection: Metal Air Barrier (Perreault 1989) 


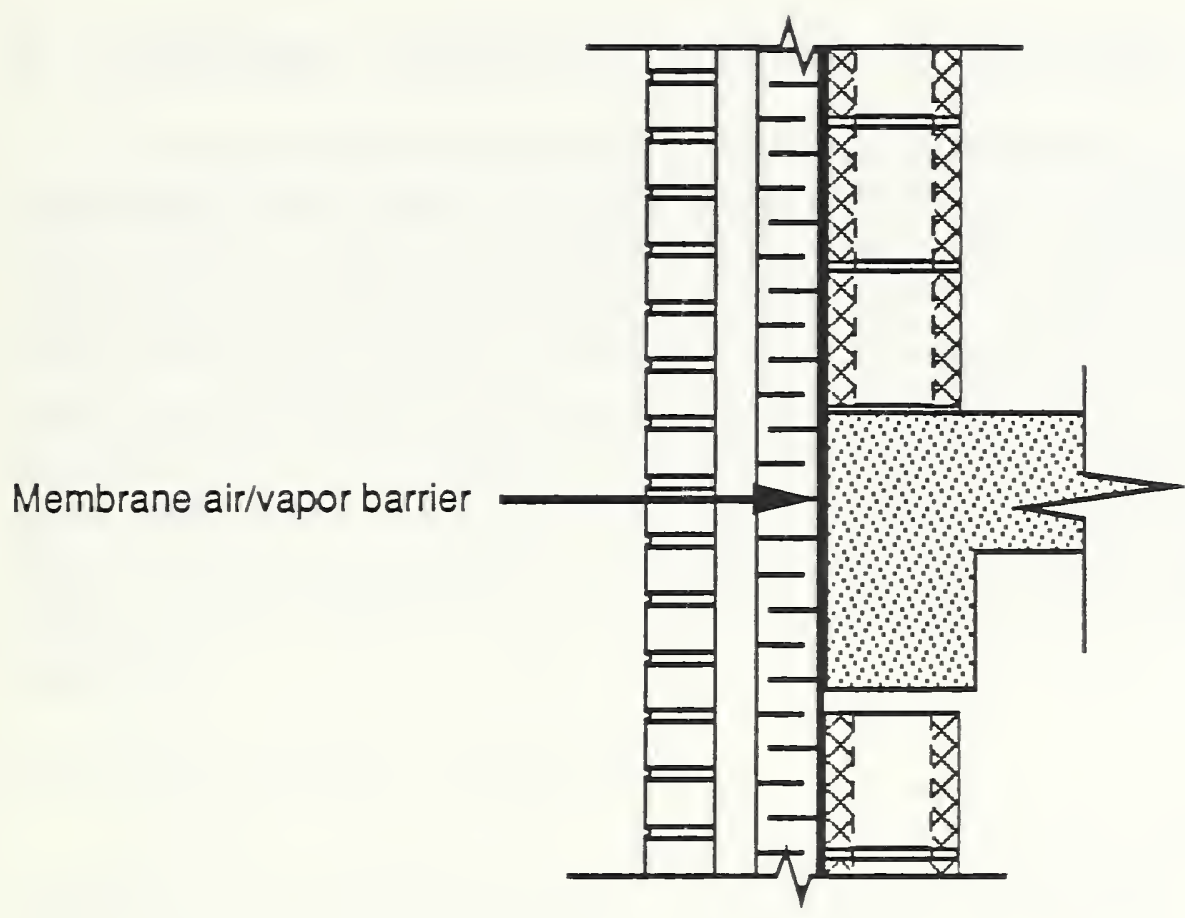

Figure 2.57 Elastomeric Membrane System (Perreault 1989) 



\section{EXISTING ENVELOPE DESIGN GUIDELINES}

There are several construction guides, architectural handbooks and standards that contain information relevant to thermal envelope design. Most of this is general information on design principles and construction techniques or guidance on the selection of U-values and glazing levels. While some of these documents recognize the importance of thermal envelope defects, they do not necessarily emphasize the importance of these problems or contain the information or design details necessary to construct building envelopes that avoid these defects. This section describes several such documents including construction handbooks, guides to energy conservation, the GSA Facility Standards for the Public Buildings Service, ASHRAE/IES Standard 90.11989 , and the DOE Energy Conservation Performance Standards for Commercial Buildings.

\subsection{Construction Handbooks}

Numerous construction handbooks exist containing information relevant to the design of the thermal envelopes of commercial buildings. These handbooks provide much information on envelope design but do not specifically address the issues of thermal defects and air leakage. Many of the design details that they do provide impact these thermal performance issues, but they are not presented in a manner that stresses the importance of good detailing for achieving good thermal envelope performance. These handbooks fall into two categories, general construction guides and guides to specific construction techniques. The construction guides describe several types of building construction (Ching 1975, Watson 1978), but they either do not address thermal envelope performance issues or they do not provide the details necessary to construct thermal envelopes that are free of thermal bridges, excessive air leakage, and other thermal defects. Sweet's Catalog File of Selection Data (McGraw Hill) describes various envelope constructions in some detail, presenting information on a variety of building envelope components and systems. It is a good source of information on these different systems, but it does not emphasize thermal issues or the design details necessary for achieving good thermal performance.

The second category of construction handbooks describe specific constructions such as steel (Newman 1988) or concrete masonry (Elminger 1976). These handbooks provide numerous details relevant to these construction types, but do not provide details directed specifically towards the avoidance of thermal defects. The National Roofing Contractors Association publishes a guide to roofing construction (NRCA 1989) that provides design guidance for roofing systems. This manual includes descriptions of roofing systems and materials and numerous constructions details includirig wall/roof connections and roofing system penetrations. It also includes design information that is relevant to thermal performance such as guidance on insulation systems, waterproofing, vapor retarders and roofing system venting. It does not address many important thermal performance issues such as thermal bridging, air leakage and other thermal defects. 


\subsection{Energy Conservation Guides}

In response to the "energy crisis" of the 1970s, several guides to energy conserving building design were published to serve as a resource to designers (AIA 1974 and 1982, Royal Architectural Institute of Canada 1979, Shaw 1986). These energy conservation guides address the thermal envelope in varying degrees of detail. They all contain some discussion of insulation, thermal mass, fenestration, and materials, but are more variable in their discussions of thermal defects. In some cases, they simply mention the importance of controlling infiltration through air sealing the envelope, the criticality of insulation at construction joints, and the need to avoid thermal bridges, but do not indicate how to design and construct an envelope that actually achieves these goals. The handbook published by the Royal Architectural Institute of Canada (1979) is more informative than most, with useful discussions of thermal bridges, airtightness and sealing, positioning the air barrier, and rain screen principles. It does provide some details in these discussions, but not enough to achieve the thermal performance objectives discussed in the handbook. A design guide of particular interest was developed by Owens Corning Fiberglas (1981) and contains design details for twenty-one walls and ten roofing systems. For each case it presents tables of calculated U-values, schematic diagrams, and discussions of properties, benefits and precautions associated with each system. The guide also contains one-hundred eight details representative of twelve common constructions including joints between roofs and walls, walls and floors, and walls and the ground, as well as joints between different wall systems and penetrations of walls and roofs. The guide is very good on insulation system considerations, i.e. the maintenance of continuity of the insulation layer, but it does not deal with air leakage and air barrier systems.

\subsection{Guidelines and Standards}

GSA, ASHRAE and DOE have published guidelines and standards on building design that contain material relevant to the thermal envelope. The GSA Facilities Standards for the Public Buildings Service (1990) contains limited information on the thermal envelope. It does require that the building design comply with the latest version of ASHRAE Standard 90. It also specifies airtightness limits on exterior glazing systems based on component pressurization testing. The only other requiremerii rels yant to the thermal envelope is the provision and installation of a vapor barier in timates with more than $\mathbf{4 0 0 0}$ heating degree days. There is no additional disit:sision of airtightness, thermal defects or how to achieve good thermal envelope perticrmance.

In 1989 two commercial building energy standards were published, ASHRAE Standard 90.1-1989 Energy Efficient Design of New Buildings Except New Low-Rise Residential Buildings, and the DOE Energy Conservation Voluntary Performance Standards for Commercial and Multi-Family High Rise Residential Buildings. The DOE energy performance standards for commercial and high rise residential buildings are mandatory for federal buildings and voluntary for non-federal buildings (1989). The requirements of both standards in the area of the thermal envelope are very similar and include minimum requirements, design principles, and two paths for compliance, prescriptive or system performance. The minimum requirements specify 
calculation procedures for envelope $U$-values, shading coefficients, wall heat capacity, and other parameters. These requirements also contain airtightness standards for windows, doors and entrances, and recommend the use of vestibules or revolving doors to control the stack effect in tall buildings. They also recommend sealing exterior joints and list several locations of concern. The prevention of moisture migration is discussed, and it is recommended that one consider vapor retarders. The section on design principles contains general recommendations on the control of heat transfer due to conduction and infiltration through the use of insulation, minimizing thermal bridging, and employing details that enhance the fit and integrity of joints. Both the minimum requirements and the design principles are fairly general in their discussion of the avoidance of thermal defects and do not provide the detailed design information that is necessary to avoid these defects. The two paths of compliance, prescriptive and system performance, provide maximum $U$-values and minimum $R$ values for walls, roofs and floors, but do not provide any additional information on thermal bridges, air leakage or other thermal defects.

\subsection{Summary}

While there are published guidelines and standards that provide guidance on thermal envelope design, they generally do not address design issues relevant to achieving good thermal performance or provide the necessary design details. The design standards and guidelines specify envelope U-values and the airtightness of some building components, but they do not address the many other important factors affecting thermal envelope performance, specifically the avoidance of thermal defects. One could design and construct a thermal envelope that is based on these design guidelines but still performs poorly due to inadequate attention to detail. Based on the review of existing design guidelines and standards, there are no existing documents that provide the practical, detailed design information that will be contained in the NIST/GSA envelope design guidelines. 


\subsection{References}

AIA, Eneray Conservation in Building Design, American Institute of Architects, Washington, DC, 1974.

AlA, Arctijtest's Handbook of Energy Practice. Volume 3 The Building Envelope, American instriute of Architects, Washington, DC, 1982.

ASHRAE, "Energy Efficient Design of New Buildings Except New Low-Rise Residential Buildings," ASHRAE Standard 90.1-1989, American Society of Heating, Refrigerating, and Air-Conditioning Engineers, Inc., 1989.

Ching, F.D.K., Building Construction Illustrated, Van Nostrand Reinhold Company, New York, 1975.

DOE, Energy Conservation Voluntary Performance Standards for Commercial and Multi-Family High Rise Residential Buildings, Federal Register 10 CFR 435, Office of Conservation and Renewable Energy, Department of Energy, 1989.

Elminger, A., Architectural \& Engineering Concrete Masonny Details for Building Construction, National Concrete Masonry Association, Herndon, VA, 1976.

GSA, Eacilities Standards for Public Buildinas Service, PBS P 3430.1A, General Services Administration, 1990.

Newman, M., Structural Details for Steel Construction, McGraw-Hill Book Company, New York, 1988.

NRCA, The NRCA Roofing and Waterproofing Manual, 3rd Edition, National Roofing Contractors Association, Rosemont, lllinois, 1989.

Owens/Corning Fiberglas, Design Guide for Insulated Buildings, Toledo, Ohio, 1981.

Royal Architectural Institute of Canada, Energy Conservation Desian Resource Handbook, Ottawa, 1979.

Shaw, A., Editor, Energy Desian for Architects, American Institute of Architects, Washington, DC, 1986.

Watson, D.A., Construction Materials and Processes, 2nd Edition, McGraw-Hill Book Company, New York, 1978. 


\section{THERMAL ENVELOPE DESIGN GUIDELINES}

The review of thermal envelope research results and existing design guidelines and standards have demonstrated the need for detailed information on how to design building envelopes with good thermal performance. The envelope design guidelines being developed by NIST will serve this need by providing design details that emphasize thermal integrity, airtightness and the avoidance of thermal defects. Since the presentation of the guidelines will determine their impact, careful consideration must be given to the organization and format of the guidelines. In order to address questions of presentation and format, NIST contracted with Steven Winter Associates to analyze these issues. This work included reviewing documents used by thermal envelope designers and making recommendations on the organization and format of the NIST guidelines. This section describes the proposed format and content of the envelope design guidelines based on the NIST literature review and the findings of Steven Winter Associates.

\subsection{Perspective of the Design Professional}

For the guidelines to impact thermal envelope design, they must be formatted in a manner that will be useful and appealing to the intended audience of design professionals. The contract with Steven Winter Associates was intended to obtain this important perspective. The Steven Winter findings were in part based on interviews with a select group of architects across the country to determine which design guidelines and/or reference documents they commonly use to design building envelopes. These interviews were also used to determine the level of interest in the NIST envelope design guidelines, what the content of these guidelines might effectively be, and how this information should be formatted.

There are currently no comprehensive source documents for designing office building envelopes. Architects synthesize information from a variety of sources including: trade magazines, newsletters, and other publications; Sweet's Catalog and other sources of product information; standards and specifications from ASTM, AAMA, ASHRAE and others; and the past experience of the architect. In essence, the architect develops idiosyncratic "guidelines" for each project, drawing on a wide range of sources and materials. Therefore, the proposed guidelines should conform to this process, acting more as a reference document that designers can access than as a guide that they must follow. The guidelines should not attempt to also incorporate existing inforrnarion readily available from other sources, but should focus on state-ofthe-art enveloos: design details directed towards achieving good thermal performance. In other worcs, the guidelines should not be an exhaustive compendium of information that also includes design details of critical areas in the building envelope; rather, they should focus exclusively on these details and their basis in sound design principles.

The format and organization of the guidelines should be based on the perspective of the designer, employing a predominantly graphical presentation and being organized according to building envelope materials and construction systems, as opposed to general concepts such as "moisture control" and "infiltration." Although there was not complete consensus on this latter point among the architects interviewed, the majority preferred a document that presents information on specific building systems (e.g. bearing walls) and subsystems (e.g. composite masonry 
bearing walls), because this is the way they approach building design. The guidelines need to get to the important points quickly; background and introductory information should be kept to a minimum. Less information presented clearly will be more useful, and more used, than more information presented in a dense and overly complicated manner. If appropriate, the research that has led to the recommendation of a specific detail or technique should not be included in the main body of the document, but rather in a series of appendices. The guidelines should emphasize basic principles, reinforced as much as possible by "real-world" examples where these principles have been effectively applied. Clearly depicted case studies of the actual use of a particular detail will be valuable in conveying information to the users and convincing them of its usefulness.

\subsection{Description of the Guidelines}

The design guidelines will serve as a resource to the design professional, providing information on how to design a thermal envelope that performs well in terms of heat, air and moisture transfer. This information will be directed towards improved performance through the use of envelope details that serve to maintain the integrity of the thermal insulation system and minimize air leakage. The guidelines will not contain recommendations on envelope design options such as U-values, glazing systems, daylighting strategies, and the use of thermal mass. Instead, they will provide the designer who has already made decisions on the basic design of the thermal envelope with practical information on how to ensure good thermal performance.

The literature review revealed that many thermal envelope performance problems are due to a lack of attention to detail in designing the thermal envelope or the development of details that either can not be constructed or can not accommodate the forces or movements to which they are subjected during or after construction. The locations at which these thermal defects occur generally involve the intersections of building components and are associated with inadequate attention being given to the continuity of the insulation system and the importance of envelope airtightness. Generally the difference between a thermal envelope with poor performance and an envelope with thermal integrity is a design that is based on the recognition of the importance of the attention to detail, envelope system performance, and the fundamentals of heat, air and moisture transfer. Designing a thermal envelope with good thermial integrity need not be based on advanced technology; the tools required for such a desigi, i.e. materials, design principles and systems, have been available for many years. While technical research has been useful in quantifying the effects of thermal defects and developing diagnostic techniques for identifying their occurrence, the information that is needed for the design guidelines is available primarily from experienced designers and builders who have been achieving success in thermal envelope performance and from building consultants who have been dealing with failures.

In order to present practical design information in an effective and useful manner, the material in the guidelines will be presented as a series of "Fact Sheets" containing information focused on a particular envelope system. The fact sheets will be selfcontained units, including all relevant data and drawings to explain the basic principles involved and containing design details that describe "how to do it right." 
Drawings will be generic in nature, but presented in enough detail so the designer understands how the basic principles involved can be practically applied in a real building. Highly articulated, "working drawing" level details will not be used, as they tend to be overly specific. The goal is to tell the designer what needs to be done, not exactly how to do it.

\subsection{Guidelines Format}

The information in the guidelines will be presented in the form of "Fact Sheets" that present concise, graphically-oriented information on a building envelope system. The fact sheets are divided into two major categories, envelope assemblies (e.g. a Brick/CMU Composite Bearing Wall) and the components which make up these assemblies (e.g. Face Brick or Concrete Masonry Units Used as Backup). This organizational approach is intended to conform to the way architects and other professionals approach the design of the building envelope. For example, an architect designing a three-story concrete frame building with brick infill walls will need to access design information on this particular configuration.

Each assembly fact sheet will present information to achieve good thermal, moisture and infiltration performance in that particular assembly through proper detailing, material and component selection, and component assembly. The fact sheets will employ a four page format, an example of which is shown in Figure 4.1 for a "CMU/Brick Composite Infill Wall." The cover page introduces the assembly and provides four key pieces of information. First, there is a generic drawing of the assembly executed in sufficient detail to illustrate all the important design issues that will be discussed in the fact sheet. A list of the specific issues to be discussed follows the drawing. In this example they include the connections between the wall and the ceiling, the wall and the columns, the brick and the CMU back-up wall, the window and the wall, and the wall and floor, as well as the design of the interior finish and insulation systems. A list of the major components of the assembly is then given, along with an index to the component fact sheets containing further information. In this example these components include brick as a facing material, CMU as a back-up material, windows as "punched openings," insulation, and interior finishes. The cover page ends with a discussion of the general principles affecting good thermal, moisture and infiltration performance for this assembly.

The next two pages of the Assembly Fact Sheets provide discussions, at varying levels of deta!l, of the specific design issues identified on the Cover Page. The nature and depth of these discussions will be determined by the particular performance issues. It is anticipated that most of the discussions will require a combination of text and graphics. The overall thrust will be to show how and where the assembly can be enhanced to improve its overall thermal, moisture and infiltration performance. The final page of the Fact Sheet will be used as necessary for additional discussions and the presentation of informative case study presentations where a particular issue is dramatically depicted for this assembly. This final page will also provide space for any additional technical notes that might be appropriate and for references to further information.

The emphasis throughout each Assembly Fact Sheet in on the connections between components of the assembly and how these connections should be detailed for good thermal performance. Discussions of the components themselves, 
particularly with respect to their constituent materials, appear in the Component Fact Sheets. Separating assembly and component discussions will avoid the necessity of repeating the same materials-oriented discussions on a number of closely related Assembly Fact Sheets, and will allow the Assembly Fact Sheets to concentrate: on issues of direct relevance to the assembly. For example, information on concrete masonry as a back-up material in a variety of wall assemblies will be presented on one "CMU as a Back-up Material" Component Fact Sheet, rather that being discussed on every Assembly Fact Sheet in which CMU is used as a backup.

The Component Fact Sheets are intended to follow the same basic four page format as the Assembly Fact Sheets. The Cover Page of each Component Fact Sheet will provide three basic pieces of information, a schematic drawing of the component to be discussed, an index to all the Assembly Fact Sheets where this component is used, and a general discussion of the thermal, moisture and infiltration performance issues and considerations relevant to this particular component. The next two pages will contain more specific discussions on performance characteristics of the component. In the case of face brick these might include discussions of advances in lightweight insulating units, mortars, sealants and coatings, and brick laying techniques. The last page of a Component Fact Sheet will contain any additional technical notes and/or case study information deemed appropriate. In addition, relevant references for further, more detailed information will also be supplied here.

\subsection{Guidelines Organization}

This section presents the proposed organization of the design guidelines, including an outline of the Assembly and Component Fact Sheets. As currently envisioned, the guidelines will be organized into the following six sections:

$\begin{array}{ll}1 & \text { Introduction } \\ 2 & \text { Assembly Fact Sheets } \\ 3 & \text { Component Fact Sheets } \\ 4 & \text { Special Discussion Section } \\ 5 & \text { Bibliography/References } \\ 6 & \text { Appendices }\end{array}$

The Introduction will discuss the purpose and organization of the guidelines and review the basic principles of good thermal envelope design and performance. The discussion on organization will inform the reader on where to find information on a particular enve! or fes system, how this information will be formatted, and where additional data re!evant their design needs are located. The Fact Sheet format will be introduced and explained, informing the reader on how to access the Fact Sheets and the information they contain. The emphasis of this section will be to provide the reader with a context within which the information in the guidelines can be placed. It will present the relevance of the information in the guidelines as they relate to the following questions: Why is proper detailing so valuable to minimizing conductive heat transfer and air leakage? What are the implications of air infiltration on overall building performance? Why does condensation occur and how does it affect thermal envelope performance?

The next section of the guidelines will contain the Assembly Fact Sheets 
discussed earlier, organized into a series of major wall and roof categories presented in Tables 4.1 and 4.2 respectively. The lists presented in these tables are preliminary.

Table 4.1 ASSEMBLY FACT SHEETS FOR WALL SYSTEMS

Bearlng Wall Assemblles

Composite

CMU/Stucco

CMU/Brick

CMU/CMU

CMU/Tile

CMU/Stone

CMU/EIFS

Tile/Brick

Tile/Tile

Cavity

CMU/Brick

CMU/CMU

CMU/Stone

Poured-in-Place

Concrete/Brick

Concrete/Tile

Concrete/Stone

Pre-Cast

Concrete

Concrete/Brick

Concrete/Tile

Concrete/Stone

Steel Frame

Steel/Brick

Steel/CMU

SteeVTile

SteelMetal panel

Steel/EIFS
Inflll Wall Assemblles

Composite

CMU/Stucco

CMU/Brick

CMU/CMU

CMU/Tile

CMU/Stone

CMU/EIFS

Tile/Brick

Tile/Tile

Cavity

CMU/Brick

CMU/CMU

CMU/Stone

Steel Frame

Steel/brick

Steel/CMU

Steel/Tile

Steel/Metal panel

Steel/EIFS
Curtaln Wall Assemblles

\author{
Stick \\ Aluminum/Glass \\ Aluminum/Metal panel \\ Aluminum/Stone \\ Aluminum/Other \\ Unit \\ Metal frame/Brick \\ Metal frame/CMU \\ Metal frame/EIFS \\ Metal frame/Tile \\ Metal frame/Stone \\ Spandrel \& Column Cap \\ Light metal/Brick \\ Light metal/ Metal \\ Light metaVEIFS \\ Steel truss/Stone \\ Steel truss/Brick \\ Pre-cast concrete/Finished \\ Pre-cast concrete/Stone \\ Pre-cast concrete/Tile
Panel
Pre-cast concrete/Finished
Pre-cast concrete/Stone
Pre-cast concrete/Tile


Table 4.2 ASSEMBLY FACT SHEETS FOR ROOF SYSTEMS

\author{
Membrane Low-Slope \\ Metal deck/insulation board/built-up roof membrane \\ Metal deck/insulation board/modified bitumen \\ Metal deck/insulation board/single-ply membrane \\ Metal deck/board/irma-modified bitumen \\ Metal deck/board/irma-single ply membrane
}

Metal deck with concrete/insulation board/built-up roof membrane Metal deck with concrete/insulation board/modified bitumen

Metal deck with concrete/insulation board/single-ply membrane

Metal deck with concrete/irma-modified bitumen

Metal deck with concrete/irma-single ply membrane

Metal deck with concrete/irma-liquid applied membrane

Cast-in-place concrete deck/insulation board/built-up roof membrane

Cast-in-place concrete deck/insulation board/modified bitumen

Cast-in-place concrete deck/insulation board/single-ply membrane

Cast-in-place concrete deck/irma-modified bitumen

Cast-in-place concrete deck/irma-single-ply membrane

Cast-in-place concrete deck/irma-liquid applied membrane

Precast concrete deck/insulation board/built-up roof membrane

Precast concrete deck/insulation board/modified bitumen

Precast concrete deck/insulation board/single-ply membrane

Precast concrete deck/irma-modified bitumen

Precast concrete deck/irma-single-ply membrane

Precast concrete deck/irma-liquid applied membrane

Wood deck/insulation board/built-up roof membrane

Wood deck/insulation board/modified bitumen

Wood deck/insulation board/single-ply membrane

Wood deck/irma-modified bitumen

Wood deck/irma-single-ply membrane

Membrane HIgh-Slope

Metal deck/insulation board/modified bitumen

Metal deck/insulation board/single-ply membrane

Wood deck/insulation board/modified bitumen

Wood deck/insulation board/single-ply membrane

Nonmembrane Low-slope

Metal deck/board/sprayed-in-place-foam insulation/coating

Metal deck with concrete/sprayed-in-place-foam insulation/coating

Cast-in-place deck/sprayed-in-place-foam insulation/coating

Precast concrete deck/sprayed-in-place-foam insulation/coating

Iviood deck/board/sprayed-in-place-foam insulation/coating

\author{
Nonmembrane High-slope \\ Metal deck/insulation board/standing-seam metal \\ Metal deck/insulation board/shingles \\ Metal deck/insulation board/tiles \\ Metal deck/insulation board/slate \\ Wood deck/insulation board/standing-seam metal \\ Wood deck/insulation board/shingles \\ Wood deck/insulation board/tiles \\ Wood deck/insulation board/slate \\ Preformed Metal Panel \\ Glass
}


The section containing Component Fact Sheets will follow the section of Assembly Fact Sheets within the guidelines and will describe constituent materials/ components used in the envelope assemblies. The preliminary organization of the Component Fact Sheets is shown in Table 4.3.

Table 4.3 COMPONENT FACT SHEETS

Bearing Wall Components

\begin{tabular}{cc}
$\begin{array}{cc}\text { Backup } \\
\text { CMU }\end{array}$ & $\begin{array}{c}\text { Facings } \\
\text { Tile }\end{array}$ \\
Stucco \\
Steel frame & Brick \\
& CMU \\
Tinsulation & Stone \\
\hline Fibrous & EIFS \\
Rigid & Metal panel \\
Foamed-in-place & Windows \\
Inflil Wail & Components \\
& \\
Backup & Facings \\
CMU & Stucco \\
Tile & Brick \\
Steel frame & CMU \\
& Tile \\
Insulation & Stone \\
Fibrous & EIFS \\
Rigid & Metal panel \\
&
\end{tabular}

Curtain Wail Components

$\begin{array}{cc}\text { Backup } & \text { Facinas } \\ \text { Aluminum mullions } & \begin{array}{c}\text { Glass } \\ \text { Steel frame }\end{array} \\ \text { Metal panel } \\ \text { Aluminum frame } & \text { Stone } \\ \text { Light metal frame } & \text { Brick } \\ \text { Steel truss } & \text { CMU } \\ \text { Pre-cast concrete } & \text { Tile } \\ & \text { EIFS } \\ \text { Insulation } & \text { Windows } \\ \text { Fibrous } & \\ \text { Rigid } & \\ \text { Foamed-in-plice } & \end{array}$

Roof Components

\author{
Deck \\ Metal \\ Metal with concrete \\ Cast-in-place concrete \\ Pre-cast concrete \\ Wood \\ Insulation \\ Fibrous board \\ Rigid board \\ Sprayed-in-place foam
}

$$
\begin{gathered}
\text { Membrane } \\
\text { Built-up } \\
\text { Single ply } \\
\text { Modified bitumen } \\
\text { Liquid applied } \\
\text { Surfacing } \\
\text { Stone aggregate } \\
\text { Concrete pavers } \\
\text { Fluid-applied coatings } \\
\text { Shingles } \\
\text { Tiles } \\
\text { Slate } \\
\text { Standing-seam metal } \\
\text { Skylights }
\end{gathered}
$$

The Special Discussion Section of the Guidelines will include those issues or topic areas that do not fit readily into the Assembly or Component sections. These may include Fact Sheets on constructions that do not fit into the assembly organizational scheme, Fact Sheets that overlap a number of subjects, and discussions of thermal envelope performance issues that are not assembly or component oriented. Examples of assemblies that might be discussed in this section include wall/roof connections such as parapets and overhangs. Topics that overlap many different Fact Sheet subjects might include coatings, sealants and expansion 
joints. Fact Sheets might also be developed on thermal performance issues that are not related to specific envelope constructions, such as a discussion of the stack effect in buildings.

The Bibliography/Reference section of the guidelines will contain references to further information on the topics covered in the body of the guidelines. The Appendices will cover those topic areas in which it is deemed useful to provide background technical information that is not necessary for individual Fact Sheets but may be of interest to some readers. Examples of potential topics for the Appendices include discussions of gaps in available knowledge, controversies regarding thermal envelope design, detailed presentations of selected case studies that dramatically demonstrate important thermal performance issues, expanded technical discussions of the physical principles relevant to thermal envelope performance, and a resource list of organizations involved in thermal envelope research, construction and regulation. 


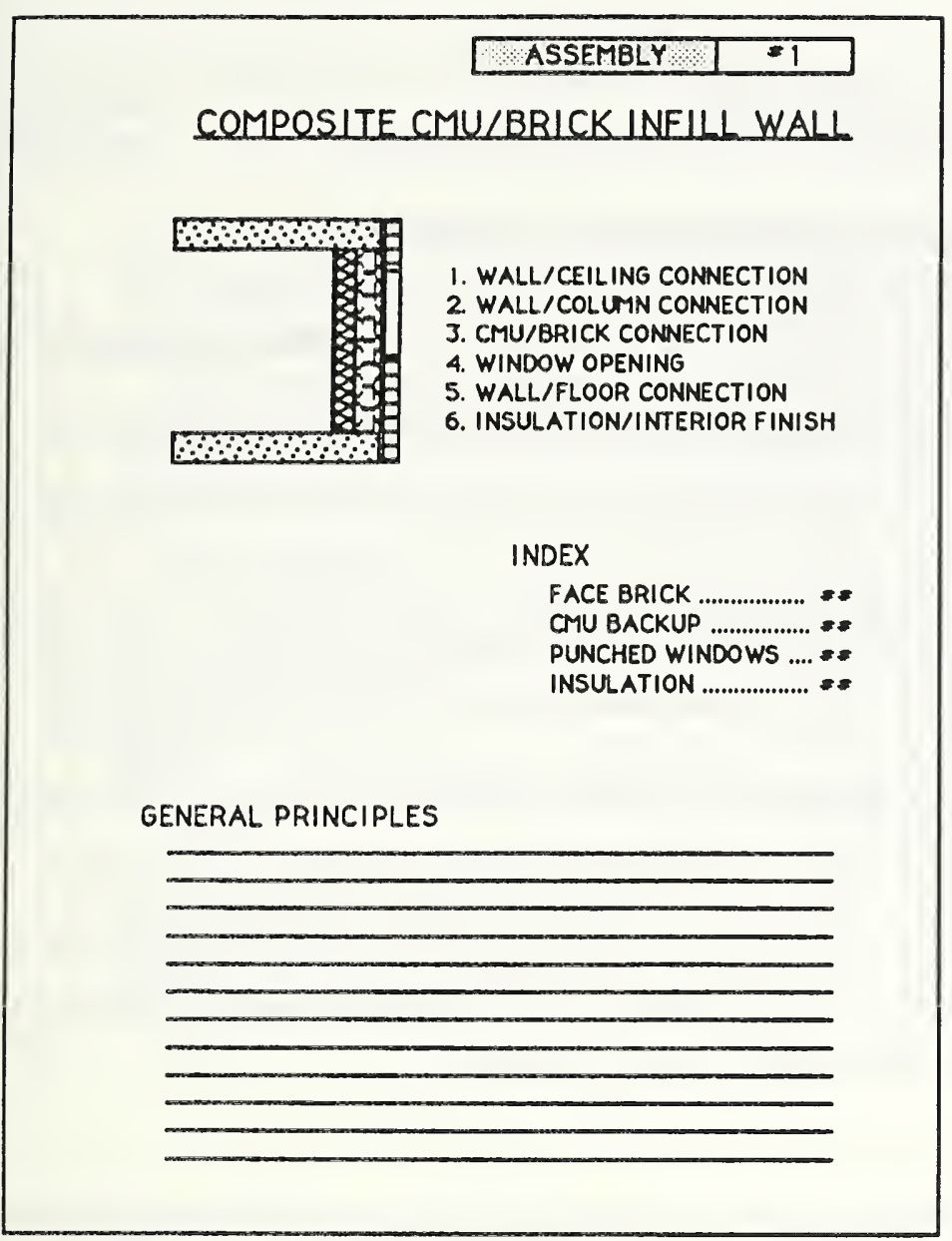

COMPOSITE CMU/BRICK WALL

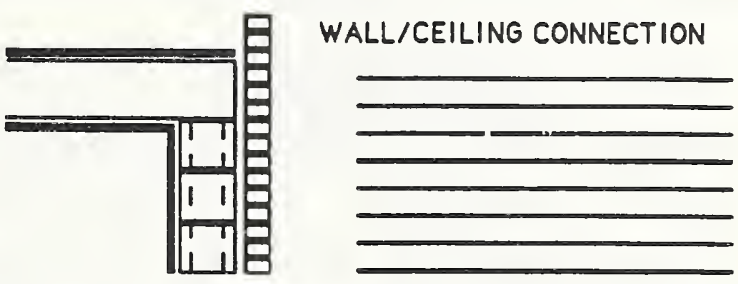

WALL/COLUMN CONNECTION
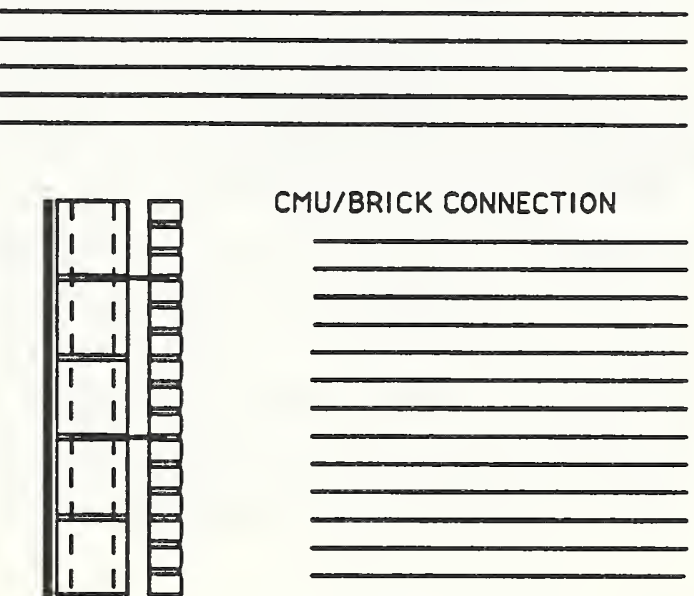

CMU/BRICK CONNECTION

\begin{tabular}{|l|l|}
\hline ASSEMBLY & $=1$ \\
\hline
\end{tabular}

COMPOSIIE CMU/BRICK WALL

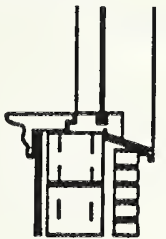

WINDOW OPENING

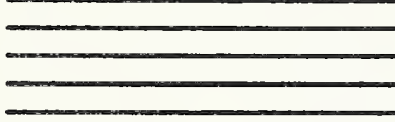

WALL/FLOOR CONNECITON
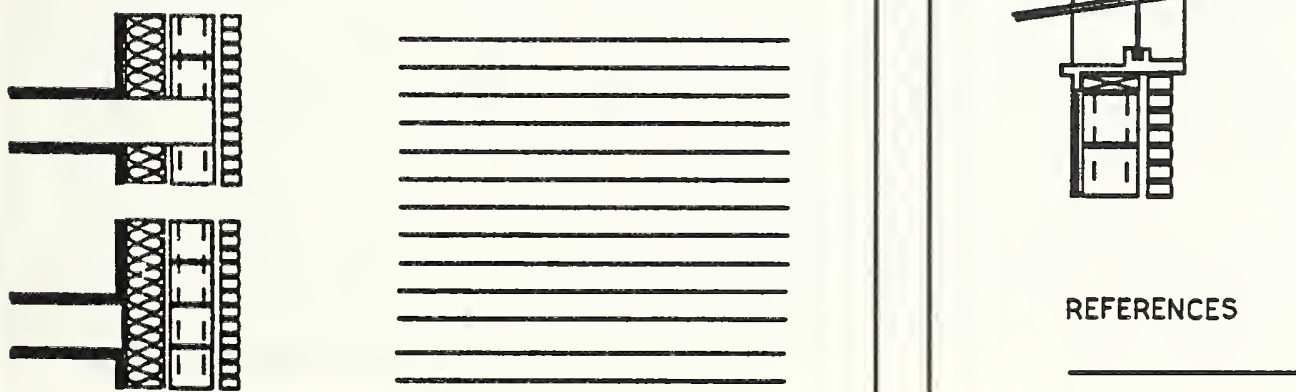

CASE STUDY

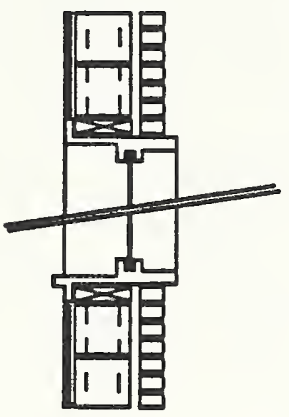

XYZ BUILDING

REFERENCES
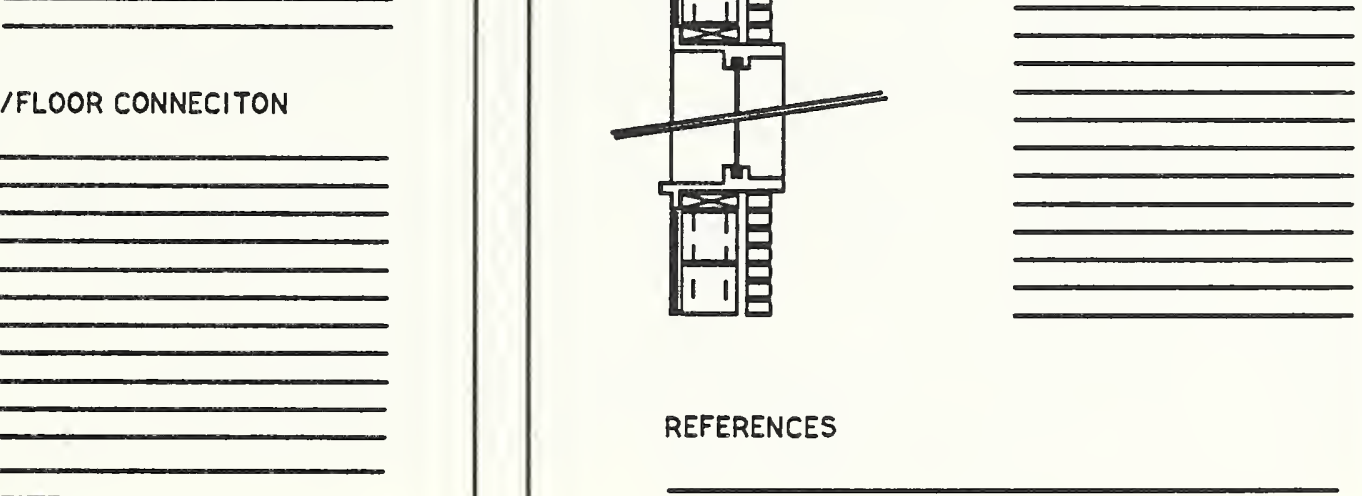

INSULATION/INTERIOR FINISH

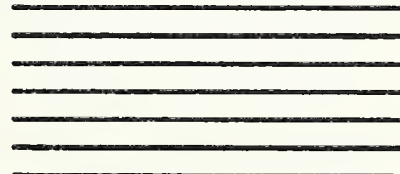

Figure 4.1 Sample Assembly Fact Sheet 


\section{CONCLUSIONS}

The thermal envelope design guidelines being developed by NIST will provide a practical tool for GSA design professionals to assist in the design and construction of federal buildings with good thermal envelope performance through the avoidance of the thermal defects. The guidelines will be organized by envelope system type and will emphasize those details that have been associated with thermal problems and for which proven design solutions are available. The guidelines will not tell the designer how to design the thermal envelope for a particular building project, but will provide specific and practical information to make their design perform well in the field.

The literature review has shown that only a limited amount of the information required for the guidelines' development has been published, and that the bulk of the input to these guidelines needs to come from practicing design professionals. In order to acquire information from this resource, NIST will contract with a small number of envelope design professionals to provide material for inclusion in the guidelines. In order to provide the opportunity for others who may have material to contribute to the guidelines, NIST has contracted with the National Institute of Building Sciences (NIBS) to solicit voluntary contributions. NIBS will acquire and assess these contributions, and they will then be considered by NIST for inclusion in the guidelines.

\section{ACKNOWLEDGEMENTS}

This effort was sponsored by the Public Buildings Service of the General Services Administration under an interagency agreement with the Center for Building Technology at NIST. The author wishes to express his appreciation to David Eakin of GSA for his assistance in this effort and to Erv Bales of the New Jersey Institute of Technology for his review of this document. 


\begin{tabular}{|c|c|c|}
\hline \multirow[t]{3}{*}{$\begin{array}{l}\text { NIST.1144 } \\
\text { (REV. 3-0) }\end{array}$} & \multirow[t]{3}{*}{$\begin{array}{l}\text { U.S. DEPARTMENT OF COMMERCE } \\
\text { NATIONAL INSTITUTE OF STANDARDS AND TECHNOLOGY }\end{array}$} & $\begin{array}{l}\text { 1. PUEUCATION OR REPOAT MUMDER } \\
\text { NISTIR } 4416\end{array}$ \\
\hline & & 2 PERFORMINO ORGANIZATION REPORT NUMLEA \\
\hline & & $\begin{array}{l}\text { 3. PULUCATION DATE } \\
\text { October } 1990\end{array}$ \\
\hline
\end{tabular}

4. TITLAND SUBTTLE

Development of Thermal Envelope Design Guidelines for Federal Office Buildings

5. AUTHOA(S)

Andrew K. Persily

6. PERFORMINO ORQAMIRATION (IF JOINT OR OTHER THAM MIST, SEE INSTRUCTIONS) U.S. DEPARTMENT OF COMMERCE

MATIONAL INSTITUTE OF STANDARDS AND TECHMOLOOY

CATHERSBURQ, MD 20890

7. CONTMCT/ORWT NUMLER

IAG 90-T001 GSA/PBS 87-03

2. TYPE OF REPORT AND PERIOD COVERED

9. SPONSOAJQ ORQAMIZATION MANE AND COMPLETE ADDRESS (STREET, CTY, STATE, ZP)

General Services Administration

Public Buildings Service

Washington, DC 20405

10. SUPPLEMENTANY MOTES

11. ABSTRACT (A 200-WORD OR LESS FACTUAL SUMMARY OF MOST SIOMIFICANT IMFOAMATION. IF DOCUMENT IMCLUDES A SIOMIFICANT EBUOCRAPHY OR UTERATURE SUAVEY, MEMTIOH IT HERE)

Office building envelopes are generally successful in meeting a range of structural, aesthetic and thermal requirements. However, poor thermal envelope performance will occur when there are discontinuities in the envelope insulation and air barrier systems, such as thermal bridges and air leakage sites. These discontinuities result from designs that do not adequately account for heat, air and moisture transmission, with many thermal defects being associated with inappropriate or inadequate detailing of the connections of envelope components. Despite the existence of these thermal envelope performance problems, information is available to design and construct envelopes that do perform well. In order to close the gap between available knowledge and current practice, the Public Buildings Service of the General Services Administration has entered into an interagency agreement with the Center for Building Technology of the National Institute of Standards and Technology to develop thermal envelope design guidelines for federal office buildings. The goal of this project is to transfer the knowledge on thermal envelope design and performance from the building research, design and construction communities into a form that will be used by building design professionals.

This report describes the NIST/GSA envelope design guidelines development at the end of the first year of effort on the project. The effort to this point has consisted of a literature review of research results and technical information on thermal envelope performance and design, an assessment of existing design guidelines as they relate to the thermal envelope, and the development of a format and outline for the design guidelines.

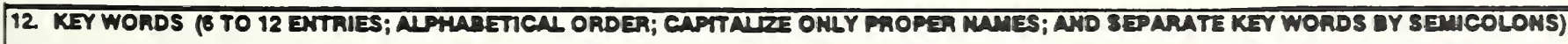

airtightness, building envelope, building performance, design, office building,

thermal bridges, thermal envelope

\begin{tabular}{|c|c|c|}
\hline \multicolumn{2}{|c|}{ 13. AVNLLAUTY } & 14. NUMLER OF PAIMTED PAQES \\
\hline $\mathrm{X}$ & UMuมmזอ & 85 \\
\hline $\mathrm{X}$ & 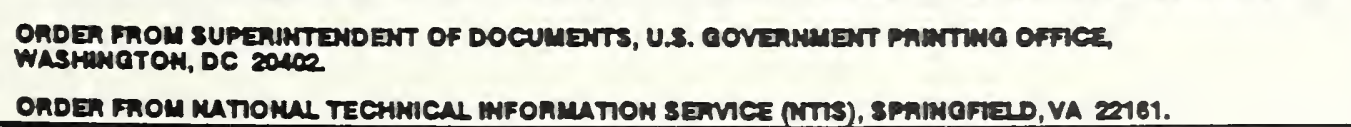 & 15. PAICE \\
\hline
\end{tabular}



